Illinois State University

ISU ReD: Research and eData

Theses and Dissertations

$4-12-2018$

\title{
You Have Seventy-Two Hours: How the City Complaint System Enables Criminalization of the Unsheltered Population
}

Lindsey Grace Earl

Illinois State University, Igearl@ilstu.edu

Follow this and additional works at: https://ir.library.illinoisstate.edu/etd

Part of the Criminology Commons, Criminology and Criminal Justice Commons, and the Social and Cultural Anthropology Commons

\section{Recommended Citation}

Earl, Lindsey Grace, "You Have Seventy-Two Hours: How the City Complaint System Enables Criminalization of the Unsheltered Population" (2018). Theses and Dissertations. 937.

https://ir.library.illinoisstate.edu/etd/937

This Thesis is brought to you for free and open access by ISU ReD: Research and eData. It has been accepted for inclusion in Theses and Dissertations by an authorized administrator of ISU ReD: Research and eData. For more information, please contact ISUReD@ilstu.edu. 


\section{YOU HAVE SEVENTY-TWO HOURS: HOW THE CITY COMPLAINT SYSTEM ENABLES CRIMINALIZATION OF THE UNSHELTERED POPULATION}

\section{LINDSEY GRACE EARL}

180 Pages

The unsheltered population has been denigrated since the formation of the United States. This is true in a city I call Marinville, Illinois where the privatization paradigm, social stratification, and anti-homeless ordinances have contributed to the shutdown of at least five homeless encampments. Multiple times per week, law enforcement officials interact with the chronically unsheltered population and incarcerate individuals for petty ordinance violations. In our current regulatory system, city officials, police officers, and homeless service organizations (HSOs) all influence the unsheltered population's lives, including options for social and spatial mobility. This thesis is based on multi-method research from 2016-2017: engaging in participant observation, conducting interviews, analyzing commentary on local news articles, surveys, and jail data. Stigmatization of the unsheltered population is evident in policing, city, and HSO cultures (although displayed differently), but the occupational structure and constraints of "public servanthood" for police officers and city officials enables criminalization of the unsheltered population. Moreover, the data reveals that "frequent flyers," or those who interact with the police once per week or have been incarcerated twenty-four of more times over seven years, cost taxpayers $\$ 12,908$ per year. Based on my evidence, providing housing for the 
frequent flyers is a more cost-effective and humane option than repetitive arrest and incarceration. Ultimately, I recommend greater public education, a switch to the "Housing First" model, implementation of mandatory homeless-specific trainings, utilization of the policeunsheltered population "best practices" flow-chart, increased access to social workers, city use of civil rights lawyers, sabbaticals, and inclusive shelter and day center expansion. These changes would be more effective in an ideological environment that is less oriented toward neoliberalism and more compassionate toward the unsheltered population.

KEYWORDS: Unsheltered Population, Homelessness, Encampment, Criminalization, Police, Social Services, City Government, Public Servant, Complaint System 
YOU HAVE SEVENTY-TWO HOURS: HOW THE CITY COMPLAINT SYSTEM

ENABLES CRIMINALIZATION OF THE UNSHELTERED POPULATION

LINDSEY GRACE EARL

A Thesis Submitted in Partial Fulfillment of the Requirements for the Degree of:

MASTER OF SCIENCE

Department of Sociology and Anthropology

ILLINOIS STATE UNIVERSITY

2018 
(C) 2018 Lindsey Grace Earl 
YOU HAVE SEVENTY-TWO HOURS: HOW THE CITY COMPLAINT SYSTEM

ENABLES CRIMINALIZATION OF THE UNSHELTERED POPULATION

LINDSEY GRACE EARL

COMMITTEE MEMBERS:

Erin Durban-Albrecht, Co-Chair

Livia K. Stone, Co-Chair

Gina Hunter 


\section{ACKNOWLEDGMENTS}

"It takes a village to raise a child." Although I am not thrilled about being the "child" in this metaphor, I think it is very accurate.

Thank you to academic and professional staff that devoted time and effort to helping me succeed. Dr. Erin Durban-Albrecht for helping me form this thesis project and set it into motion. Dr. Livia Stone for the feedback and that challenged me to become a better writer, researcher, and academic. Dr. Gina Hunter for the kindness and support offered throughout this process. Dr. Marion Willets for assistance with my survey design. Dr. Frank Beck for going above-andbeyond with jail data analysis. The Department of Sociology \& Anthropology for funding me for various conferences and allowing me to pursue my curiosities. The Stevenson Center for Community \& Economic Development for teaching me about community research and development.

Thank you to the organizations that provided me with funding and technical assistance to bring my project to fruition. The Kay and Thomas Wilson University Club for funding my research and allowing me to fly to and from Marinville. The Campus Compact for highlighting my efforts and the re-energizing me about social and economic justice.

Additionally, many friends and family members made this possible. Thank you to my parents (Ken and Mary Earl) for birthing me, my sister (Kristen Earl) for listening to me, my friends (Jacklyn Weier, Molly Cook, and Alesha Klein) for offering emotional support, and my roommates (Renee Palecek and HAUS Project Cooperative) for dealing with me when I was feeling burnout. 
Lastly, thank you to all interviewees and research participants who provided me insight into their professional lives. Specifically, the Marinville police departments that provided me illuminating datasets. Without you, this would not be possible.

L. G. E. 


\section{CONTENTS}

ACKNOWLEGEMENTS

FIGURES vi

CHAPTER I: INTRODUCTION TO ETHNOGRAPHIC STUDY 1

Of Tents and Blue Badges: Story as Exposition of Power 1

Introduction to You Have Seventy-Two Hours 4

On All Sides: Personal Connection to Study $\quad 9$

CHAPTER II: HISTORY, BACKGROUND, \& RELATED LITERATURE 13

History: The Unsheltered Population in the United States, Illinois, and Marinville 13

History: Perceptions of the Unsheltered Population 15

History: Homeless Criminalization 17

History: Policing the Unsheltered Population 19

Modern Policing Strategies: Effect on the Unsheltered Population 21

Theories of Police Culture and Assumptions of the "Other" 24

At Your Service: City Officials and Homeless Services 25

As Defined by Scholars: Best Practices in Police-Unsheltered Homeless Interactions 28

Doing it Differently: Collaborative, Humanizing Processes 30

CHAPTER III: ETHNOGRAPHIC METHODS 33

Mixed-Method Ethnography 33

Ethnography: Participant Observation $\quad 35$

$\begin{array}{ll}\text { Interviews } & 36\end{array}$

$\begin{array}{ll}\text { Online Surveys } & 37\end{array}$ 
Quantitative Analysis of the Unsheltered Population

Limitations \& Ethics

The Messiness of Ethnographic Data

The Police: Problem-Orientation

The Police: Discretion in Decisions

The Police: "Us Versus Them"

The Police: Protect, Serve \& Burnout

The Police: Brewing Incongruence

Homeless Service: Stretching to Provide

Homeless Services: Screened for Compassion and Comfort

Homeless Services: They Need Our Help

Homeless Services: Hard Work, Little Pay

Homeless Services: Under the Radar

Homeless Services: Serving Some

City Officials: Indirect \& Overhead

City Officials: We "Don't Interact at All”

City Officials: Structured for Distance

City Officials: Not in My Backyard

City Officials: Denial \& Framing the Problem 
The Public: Internet Trolls, Repeat Callers, and that Guy at the Council Meeting

Obligation: Public Servanthood as an Enabling Mechanism

Who Really is "The Public"?

Frequent Flyers: Cost of Interactions

Housing First: Prevention, Not Reaction

CHAPTER V: CONCLUSION \& RECOMMENDATIONS

Conclusion

Recommendations

REFERENCES

APPENDIX A: PARTICIPANTS IN RESEARCH OBSERVATION

APPENDIX B: INTERVIEWEES

165

APPENDIX C: SURVEY GRAPHS

166

APPENDIX D: BEST PRACTICE FLOW-CHART FOR POLICE DEPARTMENTS 


\section{FIGURES}

Figure

1. Volunteers Cleaned Up a Homeless Encampment Underneath Porcelain Cross 10

2. Timeline of Perceptions \& Criminalization 17

3. Survey Respondent Occupations 38

4. Calls to Marinville Police About Homeless Population and Whether Reasons for Calling Pertained to Violence (01/2016-04/2018) 98

5. How Marinville Dispatch Officers Coded Calls About Homeless Population (01/2016

$\begin{array}{ll}04 / 2018) & 99\end{array}$

6. Obligation in Occupations 106

7. News Article Commenter Perspectives on Marinville Groups (113 Comments; 96

Commenters)

8. Frequent Flyers Number of Violent Offenses 122

9. Cost of One Marinville Frequent Flyer Per Year 123

10. Tax Payer Cost for Housing Options: Four Individuals Over Five Years 125 


\section{CHAPTER I: INTRODUCTION TO ETHNOGRAPHIC STUDY}

\section{Of Tents and Blue Badges: Story as Exposition of Power}

Barry Cartsman laid bundled up staring up at the thin tarp above him flapping in the Marinville, Illinois breeze. It was a frigid, February morning in 2015. Barry reached to the bottom of his sleeping bag and massaged his feet that had frozen overnight. After a couple minutes spent trying to revive his limbs, Barry crawled out of the tent quietly as to not disturb the two others inside. He squinted at first as his eyes adjusted to the sunlight. He surveyed the eight or so other tents surrounding him. No one else was awake yet. Barry reflected back to how the propane for his heater had run out around 10:00 p.m. the prior night, and he resigned that he may not survive the next night. Luckily, his many layers of clothing kept him insulated enough to survive. Still, he shivered.

Barry had not always lived in a homeless encampment. Before, he had worked in food service and construction. A couple of years previously, his fiancé died, and he became too distraught to work. After a sizable employment gap, Barry was unable to find a job. While running low on money, he resorted to stealing food and supplies from the local grocery store to survive. When he was unable to pay the bills, he was evicted from his apartment. One day, a business owner caught him shoplifting and called the police. Barry was angry and resistant. The police escorted him to jail and recorded that he was "violent" at intake. After a few days in jail, Barry was released. With this criminal record, Barry was not allowed to stay in the local emergency shelters. With no other place to go, he began sleeping in the stairwell of a parking garage. After a couple of weeks in the stairwell, he became uncomfortable with the gaze of 
onlookers and desired something more private. He learned through another unsheltered individual about a tent city on the outskirts of town. Barry made his way there.

At first, he was one of four tents, but over time, more people heard about the encampment and joined. Barry did not want to live in the encampment but recognized that he was better off with a group of people in a similar situation than on his own. Although some of the residents of the encampment were interesting characters, over time they became close. Since the encampment was tucked in the woods behind an old warehouse, nobody seemed to notice or care. Over the course of a year, a woman they assumed was the property owner walked by on several occasions, made eye contact with Barry, but did not say anything.

One day, seemingly without warning, police officers showed up at the encampment. They told Barry and others that they were trespassing on private property and had seventy-two hours to pick up and leave. Additionally, police informed them that it was not suitable to move to a different location on the property but must permanently leave. Later that day, a local homeless service organization (HSO) stopped by and offered resources and assistance. They stopped by each day until the seventy-two hours were up. Of the thirteen members of the encampment, only one was placed in permanent housing, and one was given funding to take a train across the country to stay with family. Everyone else went into hiding elsewhere in Marinville. As for Barry, he and a few others set up a new encampment adjacent to a fast food restaurant.

A week earlier, across town, Councilman Wallace Spadley sat in his day-job office, scrutinizing a budget. He looked at the clock and saw it was 4:50 p.m. Perhaps, he would actually get out of work on time today. At that moment, he heard a notification from his City of Marinville email. The police department had forwarded him a message. A resident named George had taken a stroll through a rail yard and encountered a homeless encampment on the 
periphery of the woods. This resident was outraged by the garbage that was strewn around the encampment and demanded action. Councilman Spadley looked through county-level parcel data and identified the property owner. He called the phone number provided. The property owner said she was aware of the encampment but did not want to press charges. She expressed she was not happy with the presence of the unsheltered population but did not want to persecute them for their circumstances. Councilman Spadley decided since the owner was not overly concerned, he would archive this case and deal with it future weeks.

However, at the next city council meeting, George showed up to complain about the encampment. This time, he said that since his family lives a few blocks away, he was afraid his children were in danger. He expressed that it was a safety issue and public health concern. Councilman Spradley felt heightened pressure to act but first decided to contact homeless services organizations (HSOs) to see how they could help. One HSO agreed to visit the encampment and connect the residents with case managers. The next day, councilman Spadley learned George had turned to a popular right-wing blog and typed up his grievances. The blog post was receiving notable online traffic. Although not particularly thrilled, councilman Spadley spoke with the City Manager, and they both agreed that action was necessary. Councilman Spadley called the Chief of Police who agreed to deploy his officers to remove the encampment.

Councilman Spadley witnessed the outcry from homeless advocates. When he read some of the accusatory news articles, he shifted uncomfortably. Eventually, he pulled the City Manager aside and said, "Have you seen the local newspaper today?" The City Manager responded, "As a public servant, you never win. Sometimes you just have to answer to whoever is the loudest." 
Although this homeless encampment eviction was one of many that have occurred in Marinville, it evoked a mass public outcry. The local newspaper published five articles within a week covering the eviction. This sparked public interest in homeless-serving initiatives. Barry was highlighted in one article saying, "Employers see me and won't give me a chance to prove my work-ethic.” Churches, community-based organizations, and concerned residents donated propane, sleeping bags, coats, and food to the unsheltered individuals detailed in local news articles. Although media coverage created an influx of donations, it also caused public backlash. Many online comments on news articles expressed hatred towards the unsheltered population. Some of these comments were removed by the newspaper staff. Following the encampment eviction, a downtown business owner destroyed an unsheltered man's bedding where he regularly slept. This time, news coverage focused more on frustrations with the unsheltered individuals in the downtown, rather than the hate crime that had occurred. This event spurned what was described as a "cultural war" between homeless advocates and the public-at-large.

\section{Introduction to You Have Seventy-Two Hours}

The conventional homeless encampment eviction cycle is inhumane. Analysis of literature and case studies reveals conventional procedures for encampment evictions are ineffective, dehumanizing, and a cost burden (Basset et al 2012; Herring and Lutz 2015; Homeless Advocacy Policy Project 2016; Saelinger 2006). In cities like Marinville, emergency shelters are exclusive of certain populations and often reach maximum capacity, leaving unsheltered individuals to congregate in a central location outdoors or in informal structures. "Unsheltered individuals" are people without formal shelter, as compared to the sheltered homeless, or individuals who sleep in emergency shelters or "couch surf." Settlements of 
unsheltered individuals are called "tent cities," "homeless camps," or "encampments" (Herring 2010; Lotus-Farren, 2011; Speer 2016). These encampments generally do not last long, because anti-homeless ordinances engender evictions - a perpetual and costly process (Homeless Advocacy Policy Project 2016). In most cities, police post seventy-two hours' notices of eviction (Chamard 2015; Ferolito 2016; Pershan 2016; Snow \& Mulcahy 2001) an incredibly short timespan which ignores human connection to space and realistic time frames needed for relocation. Since often unsheltered individuals have nowhere to go, they setup encampments elsewhereonly to be evicted again. Thus, encampment evictions are cyclical.

Homeless encampments are the product of a broken social system. As seen throughout US history, the unsheltered population fluctuates due to decisions on how to allocate state resources (Hertzberg 1992). While encampments do not reduce certain vulnerabilities for residents (extreme temperatures, the risk of victimization, and unsanitary conditions), there is comfort and political power in the ability to congregate with individuals in a similar circumstance (Herring 2010, 8). Ideally, homeless encampments should not exist; but, while the nation is immensely stratified and lacks services for vulnerable residents, encampments are better than isolation or total erasure.

When it comes to homeless encampment evictions, public servants are placed in a dilemma. This mixed-method ethnography details how occupational structure, constraints, and interactions with the public interact to generate homeless encampment evictions. Since city officials, police officers, and homeless services workers (HSWs) have direct influence over encampment evictions, they are a focus of this research. However, the involved public became integral to explaining how these professionals exercise their power over the unsheltered population. Specifically, I look at individuals I call "vocal complainers" or the passionate, 
prolific, and often radicalized members of the public skilled at pressuring the city and police into meeting their demands. Due to the homelessness situation in Marinville, I also detail perception of "frequent flyers" or those who interact with police and HSOs regularly and/or have been incarcerated over twenty-four times in a seven-year period.

This study is unique. There are famous ethnographies of homelessness in the U.S, such as Desjarlais's (1997) Shelter Blues, Bourgois and Schonberg's (2009), Righteous Dopefiend, and Mitchell Duneier's (1999) Sidewalk, but there is little ethnographic research on how occupational groups affect the unsheltered population. Instead of focusing on the often-studied, marginalized, "marked" population, I drew from Trubetzkoy’s (1939) concept of "markedness" and Brekhus' (1998) strategy of focusing on the "unmarked," powerful occupations and members of the public. Additionally, previous researchers have conducted studies on employment circle culture (Herbert 1998; Paoline 2003; Tepeci \& Bartlett 2002; Woods 1989, 82) and personalities of occupations (Balch 1972), but there has been little consideration on how occupational constraints and the demands of the public influence perceptions and punitive actions. In this study, I detail how occupational structures such as chains of command, the city complaint system, power dynamics, anti-homeless ordinances, employment duties, and discretionary powers reinforce stigma and lead to homeless encampment evictions.

This ethnography is a study of power, and therefore, I utilize social theories of power to analyze narratives of those I interviewed and observed. In constructing this project, I drew from Nader's (1972) concept of "studying up" or studying "the middle and upper end of the power structure" (1), by focusing on the occupations that influence quality of life for the unsheltered population. Further, I use Michel Foucault's (1990) concepts of bio-power and surveillance to make sense of the strategies the city and police use to regulate unsheltered bodies. I turn to 
rationale choice (Becker 1993), general strain (Agnew 1992), order maintenance theory (Kelling \& Moore 1988) and street-level bureaucracy (Lipsky 1980 [2010]) to understand how city officials, police officers, and HSWs' decision making is produced by occupational culture and constraints. I use Dahl (1974) and Feldman (2004) to explain how democratic city government gives residents unequal contributions to city decisions. Then, I turn to Casino and Jocoy (2008), Duneier (1999), Low and Smith (2006), and Wacquant (2009) to assess how neoliberalism and privatization influence the control of unsheltered individuals in city space.

This research project unearths perceptions, experiences, and the dilemmas of city officials who can create and/or adjust ordinances, police officers who enforce them, and HSWs who offer resources to unsheltered individuals. In this research project, I posed these questions, 1) How do city officials, police officers, and homeless services workers perceive the unsheltered population? 2) What is the role of occupational constraints and culture in the homeless encampment eviction cycle? 3) What is the most influential force driving encampment evictions? In the spirit of applied anthropology, I seek not only to understand the reasons behind homeless encampment emergence and eviction, but also to improve the process. Thus, the final question is, 4) What encampment eviction processes and alternatives can achieve a more humanizing and cost-effective outcome? Ultimately, I argue that stigmatization of the unsheltered population is evident across occupations, although displayed distinctly in each occupational culture. Further, the structure, constraints, and obligations surrounding "public servanthood," for police and city officials enable the criminalization of the unsheltered population. Although problematic, pervasive stigmatization, I determined, was not as crucial a finding as to how the structure of occupations, city complaint system, the obligation of public servanthood, and policing protocol enabled stigmatization. 
It is imperative that alternatives to the homeless encampment eviction cycle are considered. In the conclusion of this study, I propose protocol recommendations and a best practice flow-chart for police officers to use when called to address the unsheltered population in the public right-of-way. Although I hope to contribute to the academic, specifically anthropological, discourse on criminalization and public servanthood, the main goal of this research is to provide recommendations to city officials, police, and HSOs.

This research is a case study of occupations and regulatory systems in a city I call Marinville, Illinois. I use pseudonyms for all places and people in this study. In many ways, Marinville is no different than most mid-sized, mid-western cities. Marinville is a somewhatisolated central Illinois city with fewer than 175,000 residents. As a hub for several, large whitecollar companies and educational institutions, Marinville residents are relatively affluent, educated, and progressive. One Marinville resident described the city as, "A quaint community with walking trails, a farmer's market, and strong non-profit and [educational] presence [and] residents appear civically engaged... It is a middle-class community." The number of individuals experiencing homelessness in Marinville is somewhat similar to surrounding cities, although point-in-time count data shows that Marinville has fewer individuals experiencing homelessness than the nearest city of a similar size.

Despite its affluence, Marinville hosts unsheltered individuals and a few notorious frequent flyers. In Marinville in 2015, there were 220-240 individuals experiencing homelessness on a single day, thirty unsheltered. In 2016, there were 276 individuals experiencing homelessness and thirty-two unsheltered. In 2017, there was a sharp drop in the numbers indicated in the point-in-time count. An HSW explained this could be due to human error. In 2017, there were 174 individuals experiencing homelessness, ten unsheltered. New 
reports show that between 2015-2017, up to fourteen unsheltered individuals congregated in homeless encampments. Within the unsheltered population, there were at least four frequent flyers that regularly visit Marinville's social services, hospital, and jail. Since Marinville is at least two and a half hours from a major metropolitan area, the services available are often the only options for unsheltered individuals.

Although Marinville has its unique qualities, generally, it is relatively ordinary. I hope this will make my recommendations more widely applicable.

\section{On All Sides: Personal Connection to Study}

In 2012, I acquired a temporary city government position for a mid-sized city in Colorado where I researched strategies and alternative ways to address the unsheltered population. For my position, I identified needs of residents, researched homelessness policy within the city, and informed the department of ways to adjust policy to improve quality of life for the unsheltered population. Throughout my research, I discovered the laws that subjected the unsheltered population to the legal system, such as anti-sleeping, anti-camping, loitering, and parking laws. I painstakingly sifted through judicial records and discovered public complaints filed about people perceived to be homeless. I found that complaints primarily pertained to people loitering outside of downtown businesses or sleeping in the park. I also learned that these complaints were mostly handled by the police. By researching other cities in the United States, I unearthed conventional strategies to reduce the visibility of the unsheltered individuals, all which push them from public and private space. I became interested in the ethics of such practices and the relationship between law enforcement and the unsheltered population in encampment evictions. For weeks, my department worked on socially progressive rezoning to reduce the instances of homeless 
criminalization. My department pushed to allow legal camping (often called "non-enforcement zones”) but had no success. Years later, after I had moved away, I learned the city had taken the opposite approach and was threatening to institute anti-sleeping laws downtown.

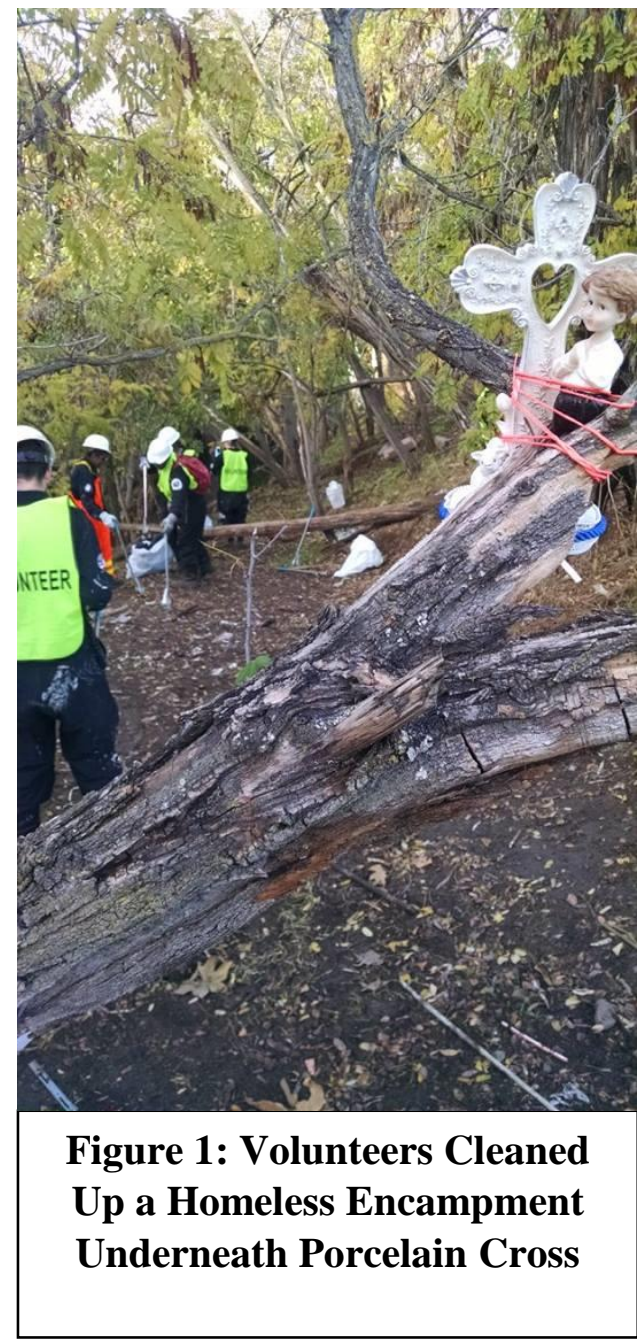

In 2015, I worked for six weeks as a volunteer manager in a metropolitan area in California removing garbage and informal structures from former homeless encampments. I was fascinated with many of the items I discovered, and these items spurned me to reflect on the individuals who had inhabited these spaces. On one occasion, I discovered a porcelain cross and 
figure of a boy roped to a branch of an oak tree next to a well-worn tent (see Figure 1). Across the path, I saw a willow tree with the words "God is Dead" engraved on the trunk. I did not know whether the same individual left the cross and engraving by the creek side or their motivation, but these items left a mark on me.

During this project, I observed the complex relationship between the police, HSOs, city, and the unsheltered population first-hand. While working, I learned about the city-instituted systems to dismantle homeless encampments. I watched how people of various occupations interacted with unsheltered individuals. At one point, I was asked to clean up a section of a creek with several tents. There, I discovered that the unsheltered individuals had not been given the legal seventy-two hours' notice to remove their belongings. For two days, my volunteers and I continued to work because we felt pressured to complete the project, but we became increasingly uncomfortable as we encountered evidence that the area was not yet abandoned.

The issue became more personal later that year. For a service program, my volunteers and I were tent camping behind a fire station in a rural area. Many of our neighbors did not know who we were, so we were perceived as a homeless encampment. One night, I woke up to the sound of two men having an argument outside my tent. They were arguing about who should enter my tent. What they wanted to do, I am not sure. After about thirty minutes of drunken argument, they decided to leave us alone. While walking away, one man yelled, "I hate the fucking homeless, we'll be back to burn down your tents." After this incident, my volunteers and I relocated the next day out of fear. Although I have never lived in a homeless encampment, I have been perceived as doing so and harassed for it.

I gained insight into the lives of my target populations through my prior experiences. These experiences influenced my motivation to study this topic as well as my personal bias. My 
experiences being on "all sides" of this system helped me to see from each occupation or group's perspective. It also helped me see how my research participants acted rationally within the expectations, time, and resources available.

My ultimate goal is to improve conditions for the unsheltered population, but my experiences helped me realize that improving quality of life for one research group does not mean degrading quality of life for another. Systemic improvements are not a zero-sum game. I believe improving the regulatory system can simultaneously benefit the unsheltered population, as well as the police, city officials, and homeless services workers. 


\section{CHAPTER II: HISTORY, BACKGROUND, \& RELATED LITERATURE}

\section{History: The Unsheltered Population in the United States, Illinois, and Marinville}

Homelessness has fluctuated throughout time but has been exceptionally difficult to quantify. The available evidence, however, indicates spikes in homelessness in the 1870s, 1890s, 1930, and 1980s prior to a singular, consistent data source (Abelson 2003; Cresswell 2001; Crouse 1986; Howard 2013; Kusmer 2002: 3-4; National Low-income Housing Coalition 2005). In 2005, the Department of Housing and Urban Development (HUD) created a funding stream which mandated that every municipality counts individuals experiencing homelessness on the same day in January (NAEH 2010). This survey, known as the point-in-time count, showed that the 2008 economic recession caused more people to become unsheltered. This is when the homeless encampments gained national attention with a media frenzy over "tent cities" (HUD 2012; HUD 2015; Herring 2010, 1).

From 2008 to 2017 the national homeless population steadily declined, yet homelessness in Illinois consistently grew (HUD 2012; HUD 2015; HUD 2016; HUD 2017). In the United States, on a single night in January 2008, there were just under 664,000 individuals experiencing homelessness. That number fell to just under 633,000 in 2012, and 564,000 in 2015 (HUD 2009, HUD 2012; HUD 2015). However, in 2017, homelessness in the United States started to grow again; there was a one percent increase in overall and the unsheltered population (HUD 2017).

This national increase was exacerbated in Illinois where homelessness has been increasing for many years (HUD 2015). In 2017, Illinois was listed as one of five states with the highest overall increase in homelessness (HUD 2017). Illinois underwent a staggering forty-five percent increase in chronically unsheltered population (2017). In Illinois, most individuals 
experiencing homelessness live in Chicago, but there are around 1,385 individuals experiencing homelessness that live in rural settings or midsized cities in Illinois (HUD 2015). The increase in homelessness in Illinois and Marinville may be due to the state budget impasse that depleted funding streams for governmental funds for HSOs.

Marinville has several social service agencies and organizations that serve individuals experiencing homelessness, but available services do not meet the demand. In Marinville, emergency shelters have existed and expanded since the 1800 s, yet shelter capacity remains inadequate, leaving individuals unsheltered.

In Marinville, law enforcement was consistently incited to address the unsheltered population. According to a local newspaper in 2012, the police evicted an encampment from city land, forcing unsheltered individuals to relocate their tents to a railroad yard. Eventually, police asked the owner of the railroad yard to demolish a run-down building and clear vegetation conducive to occupancy. Once, again unsheltered individuals relocated. In 2015, another encampment was evicted from private property when the police were incited to remove them. During this eviction, a homeless man was rousted out of his encampment in the middle of the night, slipped on ice as he was leaving, and broke his leg. News reports did not cover this injury, but stated individuals were put on "fast track" for spots in a shelter program and affordable housing. Sex-offender status and bad credit prohibited some from obtaining conventional housing. After 2015, the unsheltered population relocated and set up an encampment adjacent to a fast food restaurant. There were reports of additional unsheltered individuals camping in the woods off the side of a walking trail and near a commercial building. Although there were three occupied encampments within city limits, the average Marinville resident was not aware of them. 


\section{History: Perceptions of the Unsheltered Population}

Societal perceptions of the unsheltered population have changed throughout time, but they are consistently viewed as a problem (Amster 2008). In the United States, antipathy towards people deemed "unproductive" is tied to the Protestant work ethic, a cultural focus on work ethic and accumulation (2012 [1905]). This ideology has had destructive implications for perceptions of the unsheltered population, in part, because of traditional Protestant views of predestination. Homelessness is an indication that the individual has not been given a calling from God and is therefore destined for hell (2012 [1905]). This starkly contrasts other religious teachings in which poverty and homelessness are part of a sacred ascetic state or systems of charity. In Islam, Buddhism, and Catholicism, religious ethics and charity towards the poor are rewarded by God (Dhanani 2011).

In colonial America, denigration of the unsheltered population started with the idea of the "vagabond" (Smith 1947, 21: 138). Vagabonds were subject to British Poor Laws and were voluntarily and involuntarily shipped from Britain to the United States colonies (1947). The stigma toward the vagabond also crossed the ocean (Anderson 2015, 414). Fear heightened in the 1870s when the word "tramp" emerged and the unsheltered population was perceived as a more aggressive and organized version of the vagabond (Cresswell 2001). This era has been called the "tramp scare" or "tramp evil" (Cresswell 2001:9). In 1890, a second consecutive economic downturn provoked more structural beliefs about causes of homelessness (Abelson 2003: 105). Marginally more sympathetic feelings carried into the Great Depression, where the unsheltered population was labeled as the "new poor" and "transient" peoples (Abelson 2003: 106). During this time, the prevailing reaction to those unsheltered was of pity (Watkin 1999). 
In the 1970s and 80s, perceptions again shifted during the deinstitutionalization movement when thousands of patients were released from mental health facilities, and consequently contributed to the stereotype of the unsheltered as mentally ill (Howard 2013). Research studies from the 1980s intensified this narrow picture by emphasizing personal characteristics of unsheltered individuals (Burt 1993:6).

Since the turn of the twenty-first century, the internet has become a platform for spreading stigma of the unsheltered population, which has in turn, inspired protest from advocates (NCFTH 2009, 35). In 2001, four videos of people beating up "bums" surfaced on the web and sold 6.8 million copies. Advocates in HSOs tried to shut down "bum-bashing videos" and attempted to humanize the unsheltered population.

In the contemporary era, many factors contribute to perceptions of the unsheltered population. Since the 1980s, there have been more news stories of deviance of unsheltered individuals, the disorder they create, and the steps taken to deal with them than ever before (Buck et al 2004). Despite the overarching increase in the perception of unsheltered individuals as criminal, there is also more diversity of perceptions (McNulty 1992).

Studies suggest demographics, education level, and direct contact with individuals experiencing homelessness are tied to perceptions (Knecht \& Martinez 2009; Lee 1990; Phelan et al 1995; Tompsett et al 2006). This may be related to a person's privilege and employment prospects. Interestingly, there is little research that has been conducted on occupation as a factor, although studies of organizational cultures suggest this as a possibility (Tepeci \& Bartlett 2002; Woods 1989, 82). 


\section{History: Homeless Criminalization}

In the United States, stigma became grounds for homeless criminalization. The influence of British Poor Laws influenced American colonial leaders to use protection of space as a justification for moving transients into less visible locations and forcing them to work (Anderson $2015,414)$. Further, the ideology of the unsheltered population as "diseased," "disorderly," and the "other," was used to control when, where, and how they occupied space (Amster 2004). Restriction of space continued as repeated periods of economic deterioration materialized old perceptions of the unsheltered population (see Figure 2).

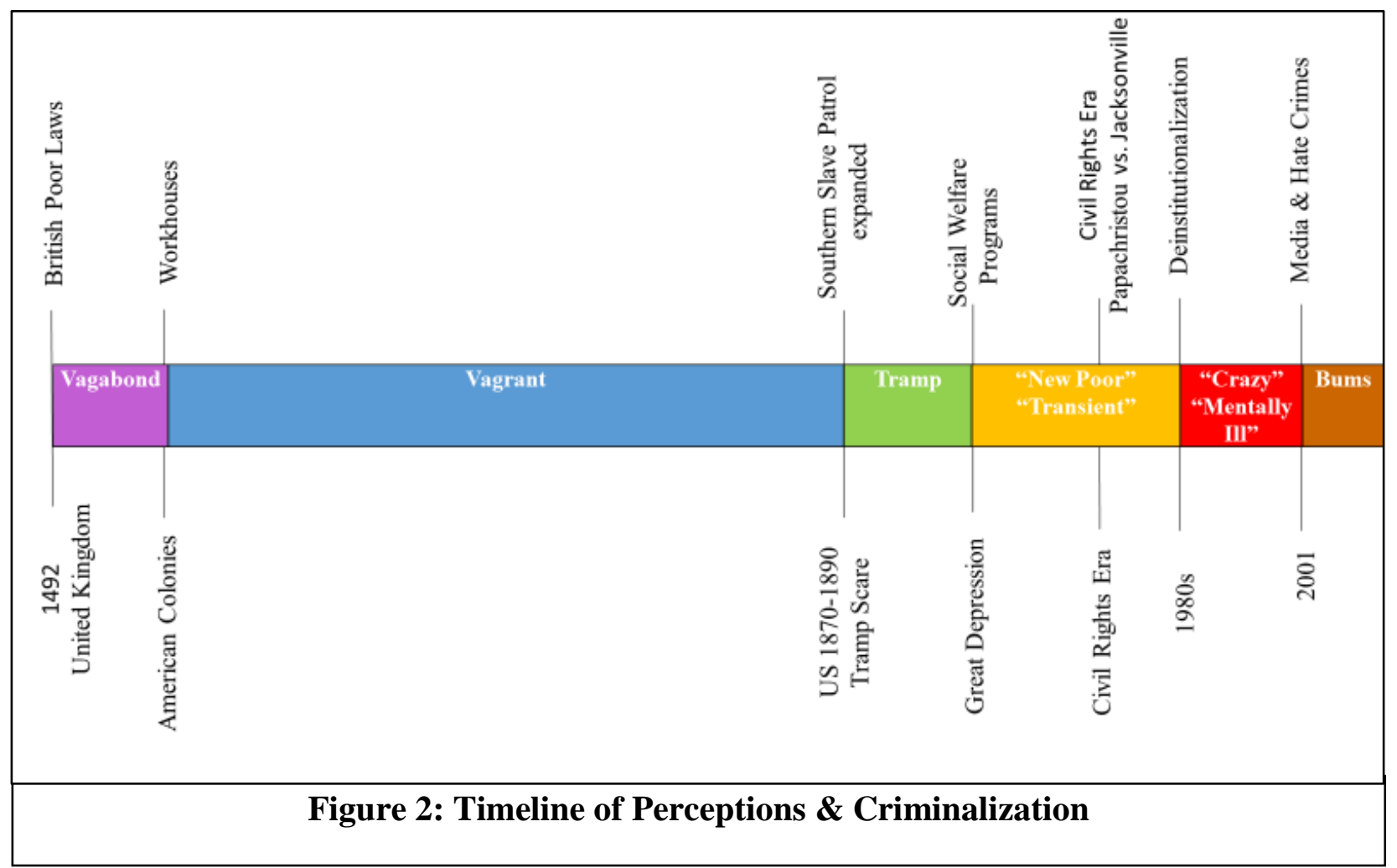


It was not until the Great Depression that the ethics of vagrancy laws came into question. City governments, as well as nearly all Western nations, are heavily influenced by what Frazzini (2015) calls the privatization ideology. According to Frazzini, in the modern age both private and public land is privatized (Frazzini 2015,30). The privatization ideology and stigma are powerful forces in shaping laws (Kohn 2004). In the US, cities have a degree of sovereignty that enables the creation of unconstitutional laws (Williams 1986). In rare instances, lawsuits use the United States Constitution to counteract anti-homeless legislation (Anderson 2015). The most monumental court case was Papachristou vs. The City of Jacksonville, in which the Supreme Court declared vagrancy laws could be used to target one specific group of people and were therefore discriminatory (Anderson 2015, 417). Still, overturning a few vagrancy laws has not prevented anti-homeless ordinances from taking shape (417). The US federal government does not dictate how to address the unsheltered population, but cities can. Localization of legislation has resulted in a regionalized, non-uniform approach (NLCHP 2014).

Anti-homeless ordinances and privatization have had disastrous consequences for people living in homeless encampments. Across the US, the unsheltered population has been subject to unethical treatment such as incarceration for petty ordinance violations, relocation every ninety days, or only twenty-four hours' notice before their personal items are confiscated (9 News 2016; Brown 2016; Herring 2010, 5; Herring and Lutz 2015, 23; Lutz 2015, 105; Simon 1992). Larger homeless encampments have been more successful in gaining political power to resist anti-homeless legislation (Herring 2010, 8). Encampments with fewer than twenty-five individuals, like the one in Marinville, do not enjoy the luxury of political power and legal protection and are rendered more vulnerable. 
In Marinville, anti-homeless ordinances and privatization of land contribute to encampment evictions. In parks, persons may not erect encampments or park vehicles overnight at non-designated times and locations; they may not litter, lounge, sleep or loiter at benches and picnic tables. Violation of these rules may result in seizure of property and/or ejection from the park for twenty-four hours or more. In addition, laws extend to other public spaces like streets, sidewalks, and business districts where obstruction of space and littering may result in removal or fines ranging from $\$ 1,000$ to $\$ 2,000$. Moreover, Marinville retains more unusual laws such as anti-scavenging and anti-bathing laws. Lastly, chronic nuisance, or behaviors resulting in three or more complaints in 180 days, encourage police officers to relocate the unsheltered population. Although these laws are written in city code, they are not always enforced.

The criminalization of the unsheltered population is problematic because it criminalizes basic functions of human life. As Duneier (1999) said, "The absence of one element in a working system... does not break the 'lifeline' of a habit" (146). Despite structural inadequacies, individuals engage in certain behaviors to survive. Furthermore, fining unsheltered individuals for engaging in necessary behaviors is inappropriate, because many have little or no financial resources. Lastly, incarceration for such behaviors traps unsheltered individuals in the cycle of homelessness due to the barriers to having a criminal record.

\section{History: Policing the Unsheltered Population}

Due to the criminalization of homelessness in the US, control of the unsheltered population's use of space was incorporated in the duties of the police. In the tenth century London, the "shire-reeve" (later called "sheriff") was "head public official" appointed to protect the king and operate the district jail (Falcone \& Wells 1995; Petersilia \& Reitz 2012). The shire- 
reeve threw the "misfits of society" in jail including, "vagrants, drunkards, the poor, homeless, orphans, [and] trespassers" $(2012,392)$. This position is said to be the forerunner of contemporary US policing.

In the American colonies, the stigma of the unsheltered population became grounds for regulatory intervention. In the colonies, individuals in power started to view vagabonds as a symbol of resistance to the changing economic systems. This may have spurred an increased proliferation of regulatory agendas (Davies 2013, 55) and the idea of the vagabond as deplorable, to maintain the status quo. Early policing prototypes enforced regulations made by the powerful, ruling class, and in some ways, served to keep them in power.

In the Southern United States, the regulatory agency tasked with controlling disorderly and parasitic individuals were the precursors to the police. In the post-revolutionary United States, slave patrols were primarily created to suppress slave revolt and organization, but duties expanded, allowing slave patrollers to apprehend drunk whites (Reichel 1998). Eventually, slave patrol duties were further expanded to include policing of "disorderly" residents, which often included the unsheltered population.

United States police have not consistently been pitted against the unsheltered population. According to George Kelling and Mark Moore (1988), the policing prototypes in the Political Era from 1840-1930 were active in social services. They worked in soup kitchens and in areas without adequate shelter space. They opened their stations at night to allow in individuals in who had nowhere else to go (Kusmer 2002). Despite this altruism, the police were criticized for being too politically connected, disorganized, and discriminatory. Eventually, due to public criticism, the police transitioned away from acting as social services for the unsheltered population (Kelling and Moore 1988). The reaction was to professionalize and distance themselves from the 
public. In what is considered the Reform Era (1930-1970s), the policing institutions attempted to decrease officers' discretion and to enforce laws, regardless of circumstances (1988). In the Modern Era that began in the 1970s, the police have once again returned to acting as social workers and serving the unsheltered population (1988). Although in Marinville, the police have little training to do so, like most other departments across the US.

\section{Modern Policing Strategies: Effect on the Unsheltered Population}

In 1982, well-publicized scholarship about the police transformed beliefs about ideal police-unsheltered population interactions. James Wilson and George Kelling's (1982) Broken Windows proposed a theory which revolutionized policing and its implications for the unsheltered population. They proposed that reducing signs of disorder can prevent the spiral of decline in a neighborhood. They created a dichotomy between "regulars" and "strangers" and claimed that the police should approach and regulate the "strangers", or "disreputable, obstreperous, and unpredictable people" (155). Since this time, various scholars have used broken windows policing to justify the "order maintenance" paradigm that encourages the police to control and remove unsheltered individuals from neighborhoods.

Since Broken Windows was published, there have been multiple policing "innovations" including problem-oriented policing (POP) community-oriented policing (COP), and zerotolerance policing (ZTP) that targets individuals who appear deviant in communities. POP is one style of policing based on the order maintenance paradigm that focuses on proactively addressing problems and bolstering public relations to creatively analyze and respond to deviance (RabeHemp 2017). Under POP, officers target high crime neighborhoods and actively approach 
"suspicious" persons. Due to the stigma of the unsheltered population, they are often seen as suspicious.

Like POP, COP encourages creativity to solve public problems. Under COP, there is even less of an emphasis on crime-fighting, rendering unsheltered individuals more central to police actions (Rabe-Hemp 2017). In COP theory, police officers are supposed to be coequals to service providers, like HSWs, but police officers are not obligated to contact them (2017). Therefore, an officer ascribing to COP may, take unsheltered individuals to services, but it is not obligated to.

More aggressive anti-homeless ordinances may fit under ZTP. ZTP is a paramilitary strategy that proactively targets perceived crime (2017). Fresno, California, and Seattle, Washington employed ZTP when establishing $\$ 1,000$ fines for camping and relocated an encampment to almost one hundred places in the city (Herring \& Lutz 2015, 693; Speer 2016).

Besides actual intervention, POP and COP act as surveillance mechanisms. A Foucauldian analysis reveals how COP and POP control behavior. As Foucault explained, those in power can engineer systems and environments to optimize control (1977). Foucault states that physically arranging people is space in a form of "bio-power," or control over human bodies (1977). Under POP and COP, the police have a larger presence in the public eye. This "panopticism," or visible displays of surveillance to control bodies, influences people to change behavior (1977). Eventually, individuals may feel the need to surveil themselves and each other; informal social control. If they do not change their behavior, they may feel the need to push their unlawful activities elsewhere.

The unsheltered population's, existence, at times, violates the law. Therefore, they may self-select to occupy spaces out of the public and the police's eye. For instance, Barry who slept in the Marinville parking garage stairwell, eventually relocated to an encampment to avoid the 
public's gaze. In general, the enforcement of anti-homeless laws in Marinville is about those in power exercising bio-power over individuals whose very existence is perceived as deviant. The panopticism is internalized by unsheltered individuals who at times elect to remove themselves from space.

In Marinville, there are multiple policing agencies that regulate space, although some have more frequent interactions with the unsheltered population than others. The larger police department's jurisdiction is an area with more unsheltered individuals, but one of the smaller departments institutes more aggressive POP and has a larger number of contacts. The largest police department shows a crime map on their website. On this map, instances when police officers contact unsheltered individuals is considered "disorderly conduct" (non-violent, petty offenses) although this category may include sheltered individuals. In 2016, Marinville police had 319 reports of disorderly conduct. The majority of contacts are concentrated in the downtown region, as well as commercial business areas. Due to POP and COP, the police undoubtedly target these areas due to their mental construction of high-crime and disorderly areas.

It is clear the public incites police officers to contact unsheltered individuals within Marinville. In my qualitative research (ride-alongs and interviews with Marinville police), I gauged policing strategy, perceptions, and treatment of the unsheltered population and analyzed police narratives to parse out what "disorderly conduct" means and how often it codes policeunsheltered population interactions. 


\section{Theories of Police Culture and Assumptions of the "Other"}

Previous researchers have studied trends in the assumptions of police officers. In 1978, researcher Peter Manning reviewed various books and articles pertaining to policing culture and summarized ten trends of postulates and assumptions of officers. Manning's ten assumptions, can be seen in interactions between the police and unsheltered individuals including; 1) People cannot be trusted, 2) Experience is better than abstract rules, 3) You must make people respect you, 4) Everyone hates cops, 5) The legal system is untrustworthy, policeman make the best decisions on guilt or innocence, 6) People who are not controlled will break the law, 7) Policemen must appear respectable and be efficient, 8) Policemen can most accurately identify crime and criminals, 9) The major jobs of the policeman are to prevent crime and to enforce laws, and 10) Stronger punishment will deter criminals from repeating crimes.

Similarly, John Van Maanen (1978) detailed the ways in which he believes the police perceive others. He said the police have, "heroic self-perceptions reflecting moral superiority" which causes them to see the world as "us" against "them" (305). He creates three typologies to explain how the police view the public 1) "Suspicious persons," individuals who the police believe may have committed a serious offense 2) "Assholes," individuals who do not accept the police definition of the situation 3) "Know nothings," individuals who fit neither of the above categories, but are not the police, so they cannot know what the police are about.

How police officers perceive "the public" dictates how police officers treat them. Lipsky (1980 [2010]) called the power to choose how and whether to enforce laws "discretionary policing." Lipsky argued that public servants (such as the police) wield exorbitant discretionary power in implementing day-to-day governmental agendas. Since the police have more direction with the public, discretion provide police officers, at times, more power than city officials. Since 
policing is independent and based on judgment calls, police culture is founded on trust and loyalty. This was evident when I observed police officers interact with Marinville residents. Miller (2005) described the prevalence of burnout, depression, and suicide in the policing profession. Police officers are two to three times more likely to commit suicide than the general population (101). In fact, they are more likely to die by their own hand than in combat. Miller theorizes high rates of suicide may be due to the culture of hyper-masculinity, polarized beliefs, self-reliance, and feelings of hopelessness, helplessness, and demoralization. Further, Miller says police officers are under high levels of stress because they could enter a life-or-death situation at any moment. Miller says police officers are invested in their work, and therefore react strongly to criticism.

Not all researcher paints a negative picture of police officers. Lester (1983) studied motivation for individuals becoming police officers and found "helping others" to be one of the most prevalent responses. Some researchers have critiqued the idea of police culture, in general. Paoline (2003) says policing is more than monolithic and culture varies by rank and style, so it cannot be generalized.

\section{At Your Service: City Officials and Homeless Services}

Lipsky (1980 [2010]) used the term “street-level bureaucrats" to describe, "public workers" beyond the police. Lipsky defined "street-level bureaucrats" as the "workers [who] interact with and have wide discretion over dispensation of benefits or allocation of public sanctions" (xi). Since police officers, city officials, and homeless services workers have direct interaction with the public (although city officials to a lesser degree) and the ability to allocate resources and services, they fit Lipsky’s definition. Apart from Lipsky’s argument about 
discretion, Lipsky claimed, "Typically [jobs] could not be performed according to the highest standards of decision-making because in the various fields because street-level workers lacked time, information, and other resources necessary to respond properly" (xi). According to Lipsky, the "dilemma of individuals in public service" is the desire to do good, but the lack of resources and capacity to do so.

Research on homeless services culture paints a negative picture, despite workers having a high public service motivation. Mann (2006) found that sixty percent of non-profit employees join the sector due to the "desire to make a difference," compared to twenty-two percent of private sector employees. However, the majority of HSO research focuses on medicalizing tendencies, stigma, and callous demeanor. Lyon-Callo (2000) wrote that HSWs tend to medicalize homeless bodies. This causes people experiencing homeless come to see their homelessness as an inescapable biological problem - that their homelessness is the result of internal, not external factors. Miller, Birkholt, and Scott (1995) looked at HSO culture from a different angle. They studied the presence of emotional burnout in human services—specifically HSOs. Stover-Wright (2018), an academic and HSW, described how HSWs, especially entrylevel employees in closer contact with the unsheltered population, experience burnout. Thompson et al. (2006) surveyed a group of homeless youth entering care and found youth perceive some "providers [as] disrespectful, rigid, or had unrealistic expectations" (34). To prevent burnout, Miller, Birkholt, and Scott (1995) recommend moderating variables of job involvement, organizational role, and attitude about service recipients.

Even fewer research studies detail city government culture, although there is profuse research on the relationship between the public and the city. Turner (2006) observed how city councilmembers interact with the public. In Turner's observations, city officials found ways to 
reduce the power of the public in decision-making. Dahl (1974), although dated, observed a different role of the public in governance. Dahl believed certain members of the public have substantial power in governmental decision-making. He looked, specifically, at whether all residents of a city are equally represented in city decisions. Dahl found that certain residents have disproportionate influence in how the city operated. Dahl's findings questioned the socalled "American Creed" that democracy means every citizen has an equal chance to influence government. Dahl's critique of city-level democracy was foundational to explaining power dynamics in Marinville.

Even less research explicitly details the relationship between city officials and the unsheltered populations, however, many researchers have detailed processes often implemented by city officials: zoning, city planning, and property management. Langegger and Koester (2017) specifically detailed how property management creates what they call "spatiotemporal camps" that or "disperse, concentrate, and conceal homeless citizens.” Law (2001) took a slightly different approach. Instead of looking at property management, she focused on zoning laws and their impact on social welfare and homelessness. Law looked at the variation between local governments and zoning laws and the impact on homelessness in the Los Angeles metropolitan area and determined that the size, income, and charter city status played a role in zoning laws. Dear (2007) discusses not-in-my-backyard (NIMBY) syndrome and how city planners feel pressures to push stigmatized residents from public space based on public attitudes, Dear also discussed strategies to avoid acting upon NIMBY. Noy (2009) drew from Dear's NIMBYism and discussed how political framing can be employed by city officials and constituents to achieve NIMBY-driven outcomes. In this thesis, I specifically assess zoning ordinances, among 
other ordinances, and use the notion of NIMBY Syndrome to explain public complaints and city official responses in Marinville.

\section{As Defined by Scholars: Best Practices in Police-Unsheltered Homeless Interactions}

Policing the unsheltered population has been a contentious, academic human rights topic for decades. Few researchers focused on policing protocol change until the 1980s. Research on homeless criminalization became a popular research topic when deinstitutionalization increased the national homeless count (Dear \& Wolch 1987). However, it was not until the 2000s the bulk of scholarship on the police's role was published. Parsing through literature on policing, I discovered two main philosophies on police-unsheltered population best practices; those who advocate that 1) The police need to target the unsheltered population, because they indicate crime and disorder (Berk \& MacDonald 2010); and 2) The police need to connect the unsheltered population to resources and services (Hartsmann, McNamara, Burns 2012; McCoy 1986).

Some criminologists who ascribe to POP and order maintenance believe that the police should target the unsheltered population. Richard Berk and John MacDonald (2010) evaluated the Safer Cities Initiative which employs a place-based approach on Skid Row (a large homeless encampment in Los Angeles). They compared this approach to adjacent police departments which did not undertake this approach. Ultimately, they found that place-based intervention at Skid Row reduced "violent, property, and nuisance crimes" (813). They say there is no evidence this crime was displaced. Their caveat is that police intervention should not be confused with policies or programs designed for social and personal problems of homelessness. 
In contrast, Hartmann, McNamara, and Burns (2012) take issue with the criminalization of the unsheltered population and instead advocate police officer training and extension of resources to the unsheltered population. They analyzed the current policies and perceptions that influence how police officers treat the unsheltered population and the subsequent victimization and criminalization. Through surveys, they gathered data on the views of police officers and unsheltered individuals. Their data revealed that the police feel burdened by addressing the unsheltered population, and the unsheltered population often feel targeted and harassed, straining relationships (367). The authors put forth their own suggestions for police officers: 1) Assess the nature and extent of the homeless problem. 2) Establish department goals and policies regarding the homeless. 3) Provide more effective police training with regard to the homeless. This may include identifying a unit or liaison officer to coordinate with social service agencies. 4) Create day centers or a place the homeless can go during the day without being cited for loitering. 5) Identify housing opportunities (370). Much of my research findings bolster Hartmann, McNamara, and Burns' recommendations for future police-unsheltered interactions.

McCoy (1986) advocates extending services to the unsheltered population for different reasons. McCoy argues that the police need to pay attention to their image as "public servants." If they harass or arrest an unsheltered individual, they are "enforcers," but if they encourage them to seek shelters they are "public servants," a much more appealing label (263). McCoy says that if the public administrators decide to be seen as the latter, they need to ensure that there is adequate housing for the unsheltered population and actively fix the problem. McCoy was the only researcher I found who mentioned the concept of "public servanthood," although he deploys it very differently than I do. McCoy argues that the public should and do hold the police accountable for serving the homeless, while he ignores the fact that the public often wants to see 
the unsheltered population addressed and erased. McCoy paints the public as made up of homeless advocates, while my research findings paint a different picture.

\section{Doing it Differently: Collaborative, Humanizing Processes}

As seen in the previous section, the increase in the unsheltered population has produced radically different legal and strategic approaches. In recent years, there have been major strides to institute best practices. Some cities have expanded the prevailing seventy-two-hour eviction notice with longer and more forgiving time frame (Beekman 2016; KING 5, 2016). Another strategy is to legalize a camping zone, called "durable camps" or non-enforcement zones (Herring \& Lutz 2015, 693). Other models advocate increased face-to-face communication to collaboratively decide how to address homeless encampments. This includes the use of thirdparty mediators to facilitate conversations between the police and unsheltered individuals. On the Navajo reservation, police officers are trained as "peacekeepers" and conflict mediators, rather than enforcers (Meyer, Paul, \& Grant 2009). Albuquerque, New Mexico has instituted a program where city employees drive around in a van and invite panhandlers to a program that offers resources as well as livable compensation for cleaning up the city (City of Albuquerque 2018). Similarly, in San Jose, California, a program called Downtown Streets Team employees the unsheltered population to clean up former homeless encampments (Downtown Streets Team 2018). Ellen Basset and Andree Tremoulet (2012) created a guide to addressing encampments on the public right-of-way. In addition, The National Law Center on Homelessness \& Poverty (2014) created a comprehensive report recommending how police officers interact with individuals experiencing homelessness. Police officers and members of the public can use this 
guide to improve relations. Although these guides are useful, I believe a flow-chart format will be a more concrete and clear guide.

Improving law enforcement-unsheltered homeless interactions is important, and it may be possible to prevent negative interactions. One preventative strategy is called the Housing First model; the primary focus on housing the homeless. The Housing First model emerged in the late 1980s and early 1990s as an innovative approach to alleviating public health problems like homelessness. According to the National Alliance to End Homelessness (NAEH) 2009), a principle of the Housing First model is that "housing is a right to which all are entitled" (1). In their 2009 report, NAEH stated, "a growing body of research is documenting the effectiveness of the Housing First approach, particularly when used in working with homeless persons who have serious behavioral health and other disabilities" (2). Frequent flyers, as a population that may struggle with behavioral health and other problems, could benefit from the Housing First model. Once they gain housing, their health may improve, and they may be less reliant on other forms of public assistance. Previous studies have shown that in two years, housing individuals could save $\$ 31,545$ per person in emergency services or $\$ 23,000$ in sheltering services (NAEH 2016; 2).

Several cities have implemented the Housing First model. In 2017, Denver, Colorado rezoned a parcel of land for a tiny house project for the chronically homeless — an idea considered by some Marinville officials (McGhee 2017). Similar programs for the homeless have taken root as tiny house communities in Seattle, WA, Austin, TX, Portland, OR, and New York City, NY (Lundahl 2017; McGhee 2017).

Although housing the unsheltered population is not free, it can ultimately save money. Case studies show the cost of erecting a tiny house project is variable but worth it. In Denver, individuals who are chronically homeless were estimated to cost taxpayers $\$ 15,733$ per year, 
while housing cost $\$ 13,400$, so Housing First ended up saving Denver taxpayers $\$ 2,333$ per year (Snyder 2015). In Detroit, New York City, and Seattle tiny house communities have also been implemented. They have ranged in size from twenty-five to 310 people (Lewis 2017; Runyan 2016). News reports show the cost has ranged between $\$ 2,200$ to $\$ 48,000$ (Lewis 2017; Lundahl 2017; Runyan 2016). On top of construction expenses, each unit costs about $\$ 32$ a month to heat (Runyan 2016). Therefore, including electric and water, utilities will likely be about $\$ 100$ per month. Still less than a one-person house estimated at $\$ 120$ or a two-person at $\$ 140$ (IRS 2018). The variation in tiny house project costs is largely due to use of charitable financial contributions, donated materials, and volunteer labor (Lundahl 2017). The majority of expenses for such a project would be up-front, so over time, the city would save money. After five years, a tiny house project could save Marinville taxpayers money, especially if donated materials and volunteer labor are used to offset costs.

Best practices and alternatives to encampment evictions, such as the use of best practices guides, expanded eviction timeframes, third-party mediators, non-enforcement zones, and Housing First, alter power dynamics and humanize the unsheltered population. However, these practices have not become widespread. Specifically, in Marinville, deconstruction of homeless criminalization has not been brought to the forefront of conversation. 


\section{CHAPTER III: ETHNOGRAPHIC METHODS}

\section{A Mixed-Method Ethnography}

This ethnography is not just another study of a vulnerable population, but rather a study of the powerful occupations that influence individuals with less power. Like Foucault (1977 [1982]), I decided to study power "to create a history of different modes by which, in our culture, human beings are made subjects" (777). I believe it is more compelling and relevant to study how the unsheltered population in Marinville is subject to "governmentality." With this knowledge, it is possible to challenge existing systems (including governing bodies) that impact the unsheltered homeless.

Studying power and powerful people is useful in other ways. As Laura Nader (1972) argued, "studying up" is a way to avoid subjecting marginalized people to academic prodding and to shift focus to powerful people whose behaviors are rarely inspected. Moreover, studying up is a way to avoid reinforcing stereotypes of marginalized populations. Brekhus (1998) echoed Nader but added that studying the "unmarked" population, or groups perceived as having an absence of social markers, is crucial because they retain the most "political salience" (34). I focused on Marinville's often unmarked public servants and vocal complainers. Further, Nader said, "studying up" is beneficial because it is "energizing and integrating... and; [offers] scientific adequacy; and democratic relevance of [anthropological] work." (2).

This thesis is a mixed-method ethnography. I used an array of techniques to uncover perceptions of the unsheltered population within the city-limits of Marinville, Illinois. I believe that multiple methodological tools yield a well-rounded view of contributions to encampment evictions and power dynamics. Although rooted in qualitative methods, this study incorporates 
quantitative measures to supplement results. Primarily, I used five methods; 1) Participant observation, 2) Semi-structured interviews, 3) Categorization of new article comments, 4) Surveys, and, 5) Quantitative analysis of the public call record as well as the cost of the unsheltered population.

My focus was on police officers, city officials, and HSWs, although I engaged with other Marinville residents for a frame of reference. I conducted and transcribed fourteen semistructured interviews. I conducted six ride-alongs with local police officers, analyzed ten local news articles with ninety-six user comments, collected ninety-five survey responses, and examined eighty-one jail bookings from three frequent flyers. I also took copious field notes of participant observation experiences. This research project followed all guidelines approved by the Illinois State University institutional review board.

Due to my own timid inclinations, I had to mentally prepare myself for interviewing or engaging in participant observation. Admittedly, I embodied my own version of John Jackson's (2005) "Anthro-man" to approach research participants and immerse myself in groups of powerful people. However, once I began participant observation and interviews, the trepidation was replaced by the confidence and energy Nader described. As Nader explained, when I walked up four flights of stairs to interview a city councilmember or a police officer showed me how to use his gun in case he dies in combat, I felt "energized" and more "integrated" into Marinville. Perhaps, this was due to the adrenaline and associating myself with powerful people. 


\section{Ethnography: Participant Observation}

Ethnography is an atypical method for studying this topic. In my prior research, I did not encounter studies that used ethnography to study the creation and enforcement of anti-homeless ordinances or occupations that affect the homeless camp eviction cycle. The lack of prior

ethnographies may be due to the difficulty of gaining entrance to powerful groups of people and the time-consuming nature of participant observation (an estimated 180 hours of participant observation). As an anthropologist, I felt it important to immerse myself in the communities of Marinville to gather information.

My goal was to use aspects of Charmaz's (1996) grounded theory to form my analytical framework. Specifically, as Charmaz illustrated, I created "analytic codes and categories developed from data, not from preconceived hypotheses" and used, mostly, "middle-range theories to explain behavior and processes." I allowed my pre-conceived notions to be changed through the process of research. Throughout the research process, my mental model of target occupations was changed significantly.

Initially, I gained entrance into the HSOs through volunteer opportunities. I served an average of fourteen hours per month at three HSOs in Marinville. There, I observed my surroundings, built-relationships with workers/volunteers, and attempted to see life from their perspective. Luckily, I gained several key informants who guided me to others I should speak with.

To gather information from city officials, I attended eight events listed on the official Marinville website including; city council, board, and open house meetings. There, I took my own meeting minutes and incorporated them into my field notes along with my observations and analysis. On several occasions after meetings, city councilmembers would linger to ask me about 
my research and converse with me about the unsheltered population problem, forces and factors, and prior city initiatives.

For the police, participant observation was more formalized. I submitted ride-along requests to five departments and was approved by four. With two departments, I conducted more than one ride-along, for a total of six. The shortest ride-along was three hours long and the longest was nine. During that time, I sat in the passenger seat conversing with the officer about an array of topics. My questions were employment-related, but sometimes conversations drifted into their worldview and/or life stories. While on these rides, I listened to radio communications and observed strategies officers used to control deviance. Unfortunately, I was never on a call involving an unsheltered individual, although I heard radio communications of two calls from the public to address unsheltered individuals. Further, I observed passing interactions between the police and an unsheltered individual as well as members of the public seeking advice from police officers on how to address the unsheltered population (see Appendix A).

\section{Interviews}

I conducted a total of fourteen interviews with police officers, city officials, HSWs, and one news reporter to gain a full understanding of perceptions of the unsheltered population, criminalization, and past encampment evictions. Of the fourteen, ten were one-hour, semistructured, in-person interviews. One interviewee opted out of being recorded, and thus thirteen were recorded and all were transcribed. The remaining four interviewees preferred written responses and sent them to me. Of the interviewees, seven were city officials, five were HSWs, one was a police officer, and one was a news reporter who has written several articles about homeless encampments and city debates surrounding it (see Appendix B). 


\section{Online Surveys}

Surveys were distributed to city officials, police officers, and HSWs via Qualtrics software. Contact information was gathered on publicly accessible websites. Surveys were distributed to 667 individuals in nineteen mid-sized, Illinois cities, and ninety-five were returned (fourteen percent response rate). I received survey responses from individuals in thirteen cities with no less than 12,600 residents and no more than 200,000 residents. All cities were within two hours' driving time from Marinville. Cities surveyed did not include the Chicago suburbs. Twenty-six respondents lived in Marinville. Of responses, twenty-three were police officers, nineteen were city officials, and seventeen were HSWs (see Figure 3). Interestingly, since this survey was distributed via a link, ten members of the public responded, although not originally invited. I theorize that those invited to participate may have forwarded the invitation to those who found the topic interesting and have a high level of involvement in public affairs. Since my project findings became largely entangled with the public's stigma, I included these responses and refer to them as the "involved public." It should be noted that this respondent group is an imperfect measure and is not meant to represent the average Marinville resident. In addition, the "involved public" is not one cohesive group, but rather an overarching category to describe residents involved in city affairs. The remaining twenty-six surveys were thrown out because they were either incomplete or the respondent did not indicate whether they worked for the police, city, a HSO, or other organization. 


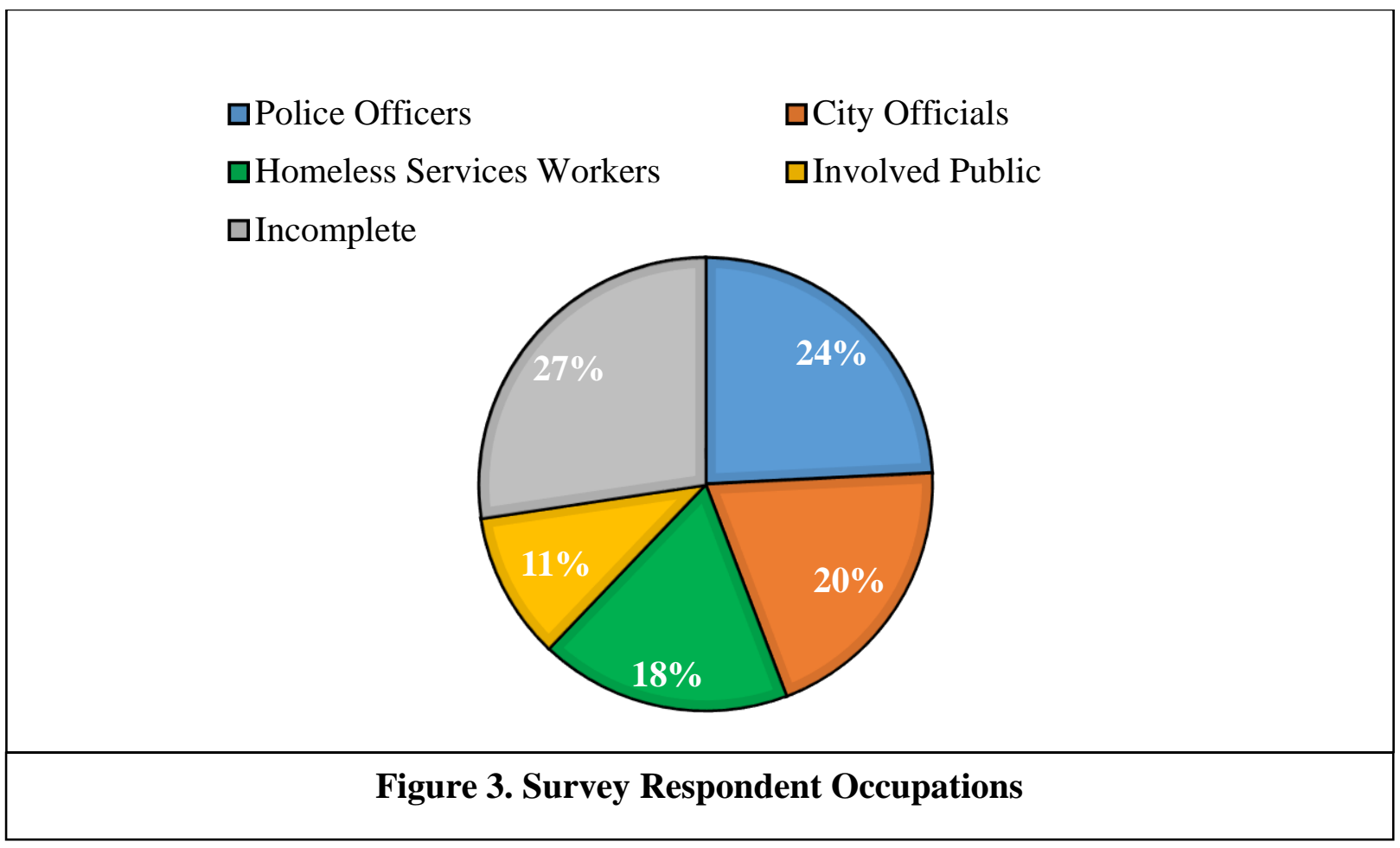

The survey aimed to gain a general idea of how professionals regard the unsheltered populations that they regularly encounter. For instance, I asked, "Do most of your coworkers believe unsheltered individuals have a mental illness?" Therefore, responses are rooted in what they have observed and heard in their organization/department. I used seven-point Likert-scale questions in order to assess responses quantitatively. At the end of the survey, there was a space for respondents to provide additional information relevant to the research. Overall, twenty-three of ninety-five respondents included written responses to the final question. These responses offered critiques, recommended informants, and/or explained their personal stance.

\section{Categorization and Coding for News Article Comments}

All news articles assessed were written between 2016 and 2017, so I could understand perspectives of the recent internet-active Marinville news-followers. I used thematic coding to 
arrange online comments in a variety of categories. Comments were arranged as "positive," "negative," or "victims" for five groups: the city, individuals experiencing homelessness, HSOs/HSWs, the police, or the public. For example, descriptors like "wonderful," "kind," "fun," and "helpful" were categorized as positive, "lazy," "mean," "criminal," "mentally ill," and "dirty" were categorized as negative, and "lost", "confused," "hopeless," "needs help" were considered victimizing. Occasionally, comments did not fit into these categories, so they were sorted as "informative" or "calls to action". After sorting, trends in narratives emerged revealing a general sense of how the public feels about various Marinville entities.

\section{Quantitative Analysis of the Unsheltered Population}

I gained jail data for three, anonymous, Marinville frequent flyers identified by the police. I reviewed eighty-one bookings for three individuals across seven years in Marinville. This dataset also revealed the type of charge, the arresting officer, and jail intake information. Each frequent flyers' record contained at least twenty-four bookings at a nearby jail. I determined the average cost of a night in jail to calculate the jail cost. Then, through numerous phone calls and emails, I calculated the cost of frequent flyer interactions with other agencies (hospitals, law enforcement, HSOs). I sourced the number of hours Marinville police departments and HSOs spend on one frequent flyer per year and the hourly wage of these employees. Additionally, the Marinville hospital staff quantified the average cost generated per

person experiencing homelessness per year. I combined each agencies' calculations. I decided to exclude sheltering costs in my calculation since most frequent flyers are prohibited or ineligible at shelters. Then, I sought the approximate cost of Housing First options. Ultimately, I compared 
the cost of conventional strategies to address frequent flyers in Marinville to the estimated cost of Housing First alternatives.

\section{Limitations \& Ethics}

This study was limited by participant hesitation. Some departments and individuals were skeptical of my intent and refused to work with me, however, most were accommodating. At times, police officers resisted due to the political climate that was critical of law enforcement. Generally, I was surprised to find how willing police departments were to assist me. Like any politician with re-election concerns, elected officials tended to be guarded and diplomatic to avoid criticism. HSWs may have avoided participation due to fear of impacted employability. In addition, all occupational groups were constrained by time and priorities. I mitigated limitations by using pseudonyms (people and places) and by stripping personal information from my writing. Additionally, for news articles and comments, I changed minor, insignificant words to synonyms to reduce the reader's ability to find the original article on the internet. I allowed multiple avenues for participation in the project and focused on solutions to problems professionals encountered. Ultimately, I explained to participants that I thought that they were part of the solution, not just the problem. Therefore, at the end of interviews or ride-alongs we brainstormed solutions.

At times, as a critical, applied researcher, I felt uncomfortable with the level of participant disclosure. Often, after about thirty minutes of interaction, it seemed that participants forgot they were being studied. Although this was beneficial for the purposes of my research, I felt the need to remind participants they were being studied. Intermittently, I struggled with feeling as though I was building trust with a participant in order to critique them later. To uphold 
the most ethical standards possible, I executed transparency and confidentiality, so I could tell the story of Marinville from each occupational group's perspective without demeaning participants.

In the introductory vignette, Wallace Spadley, George, and details of Barry's experience are fictionalized. I wrote in this style to show viewpoints that were not explicitly revealed in my dataset, but important. To ensure this depiction was fair and reasonable, I sent this vignette to three city officials in Marinville. I altered these characters based on their feedback. The portrayal of Barry's situation is based on secondary data and my interview with a news reporter I call Fe Wilponi who met Barry. However, Barry's thoughts and feelings were fictionalized to cultivate empathy.

Further, the quantitative analysis is limited by available information and small sample sizes. Only seventy individuals completed my survey, a sample size too small to be statistically significant. Therefore, my conclusions drawn from surveys are suggestive, not conclusive. In addition, data that supports the Housing First model is limited, because as of 2018, there is little (or no) evidence to show the extent that housing frequent flyers will reduce their interaction with the police, HSOs, jails, and hospitals. These expenses would be significantly reduced, but not nullified. 


\section{CHAPTER IV: DATA ANALYSIS}

\section{The Messiness of Ethnographic Data}

After I had been volunteering in a particular soup kitchen for about three months, one of the kitchen staff members, a woman I call Rosalie, asked me to prepare grilled cheese sandwiches for the next meal. After a few hours of buttering bread and about twenty minutes before clients would arrive for a meal, Rosalie pulled a piece of fish out of the freezer and presented it to me, saying "Heat this up for Helen, she's gluten-free." I unwrapped the salmon and noticed some sort of breading on top. I assumed it must not have gluten, so I put it in the microwave. While the fish was heating up, I began to question this. When the timer dinged, I took the salmon out and walked it over to Rosalie. I said, "Do you know what this breading is? If Helen is gluten-free, I don't want to accidentally poison her." Rosalie took the salmon out of my hands, slammed it down on the counter, and said, "I don't care whether she chokes." She lifted her head and laughed. Later at dinner, Helen took a bite of the salmon and I watched her nervously. Although she appeared unharmed, I was upset that Rosalie's callousness subjected her to a dangerous situation.

On another occasion, I was on a ride-along with a police officer I refer to as officer Peterson. As we drove through downtown Marinville, I told him about the purpose of my research and he listened without saying much. Eventually, we began chatting about where we are from, what we studied, and our hobbies. All the while, he gazed out the front window of the vehicle. I was not exactly sure what he was looking for. Like most officers I had interacted with, he seemed courteous but slightly tense in my presence. After winding through the downtown streets for several minutes, Officer Peterson pulled off on the side of the road. At this point, I 
decided to start asking some of my research questions, "Have you ever interacted with unsheltered individuals in Marinville?" I asked. He responded that he had many times. Following up, I asked what those interactions usually looked like. He responded that "Sometimes, on colder nights, I'll stop and ask them how they are doing and if they need a ride anywhere." $\mathrm{He}$ continued, "If they don't want to go anywhere, I do this..." He reached into the back of the vehicle and pulled a large, black trash bag to the front. I was very confused. He untied the bag and pulled out a heavy, winter coat. He said, "My heart goes out for them. It's cold out some nights and some people don't have warm clothing. No one deserves that."

Several weeks later, I sat down with City Official Willy Foster in an over-sized City Hall conference room. My immediate impression of him was that he was well-versed in talking with students and residents. Upon asking a few introductory questions, I found out that he had worked for the city for over fifteen years. About thirty minutes into the interview, I asked him how he felt about the criminalization of the unsheltered population. He said, "It is very bad. Homelessness is not a crime." Then, he launched into a story from his personal life. Foster's wife had encountered a mother and her children in Marinville who had lost everything. His wife decided to take the mother and kids home and bought them some clothes. Then, the Fosters paid for a few weeks for the family to stay in a hotel. Eventually, they decided to let them stay at their house for a few months. They loved the kids and started to see them as their own. City Official Foster said that the mother had a small criminal record, although nothing serious, he said it "haunted her." One day, the Fosters asked the mom, "What's your plan?" She got upset, and she left with her kids. The Fosters tried reaching her but were never able to get in contact with her again. City Official Foster stared off into the distance for a moment deep in thought. He left me 
with, "If you have resources, you should give. We have incredible affluence here. Most homeless folks are like you and I and are just down on their luck."

These three stories are not what I expected to see during my fieldwork. Based on an idea of grounded-theory, I allowed conversation, observation, and data to change my pre-conceived notions. Many of my observations of participants did not fit the occupational archetypes I expected. I thought I would find punitive police officers, uncaring public officials, and compassionate HSWs. At times, this was confusing. I set out to learn how the unsheltered population was being dehumanized, and I learned how I had reductive perceptions of the police and city officials. Over time, I began to see the police officer and city's perspective and understand how their occupational structures and constraints altered worldviews. I also found that there was wide variability in individual attitudes toward homelessness and unsheltered individuals within and across the populations of workers that I was primarily interested in. As Paoline (2003) said, policing culture is complex and more diverse than some anticipate. Specifically, I found police officers to be vastly different from my reductive pre-conceived notion. They had vastly different life stories, personalities, political beliefs, perspectives, and approaches to addressing the unsheltered population. Of the officers, I observed, some were vegetarians, naturopaths, non-violent activists, adventurers, self-identified nerds, dog-lovers, and social justice advocates. My ethnographic data do not support stereotypical or archetypal roles of police officers, city officials, and HWS. Although I found discrimination, I also found sympathetic and ambiguous data. Although multiple forms of data reveal trends in occupational experiences and perspectives, this ethnography is not meant to reinforce stereotypes, but rather critique occupational structures and discriminatory systems. 
Although there were individuals who contradicted the general trend, I generally found stigma of the unsheltered population across occupations. I argue that police officers and city officials are incited to cultivate and act on stigma under a logic of public service. In the following sections, I explain the occupational culture, worldview, structure of city officials. Then, I discuss the police and HSWs. Next, I discuss the concept of public servanthood and the role of the public. Lastly, I reveal the cost of frequent flyers, housing alternatives, and recommendations.

\section{The Police: That Frequent Flyer is "Not Your Guy"}

I sat in the corner of a table in during a city meeting. As usual, when city councilmembers and residents spoke, I transcribed their conversations. I looked up from my notes and squinted in the bright City Hall lighting. A highly decorated police officer walked inside at that moment. I recognized him as Chief Watson. Throughout the meeting, he walked in and out of the room, perhaps taking calls. After the meeting, I walked over to him and said, "Hi, I'm Lindsey I'm a graduate student, I have spoken to you over the phone." He said, "I was wondering if that was you." He said all this without looking up from his phone. At first, I thought he was disinterested. He seemed tired. Then, he looked up and shook my hand. He asked me if I did a ride-along yet. I told him, yes and I got a lot of good information from it. Chief Watson gave me his business card and I gave him mine joking, "I hardly ever get to pass these out." He saw "Anthropology" and said, "What's that got to do with this?" I told him I'm interested in occupational culture. I re-explained some of my research. He began telling me about homelessness in Marinville. Chief Watson said, "I've been out to San Francisco and places like that and what people don't understand is that, this is nothing. You've been out there, right?" I 
said I had. He said, "A lot of the people here are transient, those who want to be homeless, and they break a lot of laws." Chief Watson told stories about a homeless man stabbed three people downtown last year. He said that many of the homeless steal from liquor stores and the business owners call the police. Then, he talked about an unsheltered man who was walking around a nearby street. He said, “I admit he looked bad, but he wasn’t doing anything but walking around... Now, the reason why he's there is that he's getting something, maybe food or whatever." Chief Watson looked me dead in the eyes and said, "Of all people, why would you pick that guy to be your poster child... if you care about the homeless, this is not your guy." I left this interaction feeling confused because I was not seeking a "poster child." It appeared that he reduced the entire unsheltered population down to his experience with one unsheltered man. It was clear Chief Watson did not have much sympathy left for the unsheltered population.

This vignette portrays how many police officers come to view the unsheltered population. As a long-time officer, Chief Watson's views exemplified how the policing worldview is shaped by the structure and constraints of his occupation. This interaction with Chief Watson shows some of my primary observations of police officers. The police turn to story-telling to describe how many unsheltered individuals in Marinville are criminals and drink alcohol or do drugs. To me, Chief Watson's initial disinterest indicated jadedness and burnout. Additionally, through ride-alongs with police officers, an interview with Officer Mayweather, and survey responses, I observed police officers had a general loss of hope for the unsheltered population based on repetitive interactions with those perceived to have a severe mental illness. Due to the structure of their occupations, police officers rarely observed success stories for the unsheltered population in Marinville. 


\section{The Police: Problem-Orientation}

Marinville used the problem-oriented and community-oriented policing strategies. During a public, city meeting, the Mayor described his push for the COP style to a mother of a boy with mental illness, "Community policing is knowing reflag behavior. If the police know your son has mental illness, they will know if he's walking around after dark, it is normal.” Unfortunately, COP also means targeting certain locations that are either higher crime or perceived to have "suspicious individuals." A few months after hearing the Mayor describe COP, I asked Officer Larkens about Marinville's policing strategy during a ride-along. I asked if his department focused more on law enforcement or order maintenance (COP and POP). When he seemed confused, I explained to him how order maintenance policing is about maintaining social norms. He recognized this and said, "I think we're seventy to eighty percent order maintenance. We are proactive. We are always in the community getting to know people, making sure everything is ok." I said, "Like community policing?" He agreed and seemed content with this description.

Throughout ride-alongs, I observed POP indicators. I noticed Officer Peterson looped in his police vehicle repeatedly back to the same impoverished neighborhood. I asked where he prefers to patrol, and he said, "We use problem-oriented policing, so we like to stay near this apartment complex." He proceeded to tell me stories about certain apartment complex residents with a history of illegal drug use. On another ride-along, I witnessed officer Mayweather circled the same apartment complex that Officer Peterson seemed to target. I asked Officer Mayweather if he prefers to stay in "low-key" neighborhoods or high-crime ones. He responded, "I like to be in the action. Not all officers are this way, but I like to." Officer Peterson and Mayweather's attention on these apartments shows how they perceived these residents as a problem. POP is problematic because it meets of Agnew's (1992) criteria for general strain: 1) Removal of 
positive stimuli and, 2) Anticipation of negative stimuli. Officers Peterson and Mayweather spent their time avoiding positive public interactions and anticipating negative ones in poorer neighborhoods. This resulted in a higher likelihood for apartment complex residents to be penalized.

Order maintenance policing has implications for the unsheltered population in Marinville. Although the officers I spoke with framed it as "keeping the community safe" and "focusing on crime," it means that the police disproportionately contact certain individuals. As Marinville is an affluent city, individuals perceived as impoverished violate the hegemonic norm of affluence. On one of the policing websites, I found text that illustrated Marinville's hegemonic norms. The purpose of the webpage was for residents to inform the police department if they witnessed signs of threats to public safety. On this webpage, "suspicious behavior" included; 1) Loitering 2) Acting furtively and suspiciously and trying not to be seen, 3) Departing quickly when seen or approached, 4) Being in locations where he/she doesn't seem to belong, 5) Strong odor coming from a building or vehicle, 6) Overloaded vehicle or vehicle in an unexpected location, and 7) Being overdressed for the temperature.

This list of "suspicious behaviors" is uncannily like behaviors unsheltered individual enact out of necessity. With no formal residence, unsheltered individuals may wear multiple layers of clothing, pack vehicles with personal possessions, or spend "excessive" time in public places. To avoid harassment generated by stigma and POP style, they may depart quickly when noticed. This list reinforces hegemonic norms and expectations for public behaviors, labeling unsheltered individuals as "suspicious" or Wilson and Kelling’s (1982) "stranger." By posting this list publicly, this police department called upon the public to increase informal social 
control, the most effective type of surveillance. Whether the description of suspicious behavior was intended to target the unsheltered population or not was less clear.

Since unsheltered individuals violated hegemonic norms, so they are easy for the police to identify. During a ride-along, I explained how I am studying the homeless encampment eviction cycle to Officer Marrich. Immediately, he said, “Oh, I'll show the homeless.” He drove me to every location he had found unsheltered individuals sleeping, including homeless encampments, the downtown, parking garages, and the emergency shelters. He referred to this as "bum hunting" which made me squirm. Officer Marrich drove to one of the sheltered and stopped outside. He yelled out the window to a black woman smoking, "How ya doing?" To me, this question sounded less like a friendly greeting and more accusatory. She responded, “Good..." sounding skeptical. Officer Marrich turned to me and said, "People don’t like talkin' to the po-lice." I realized Officer Marrich had yelled out to this woman to show how the individuals experiencing homelessness treat the police.

Officer Marrich’s style of policing was a perfect example of COP. Officer Marrich had been on the job for twelve years and seemed very comfortable with his understanding of the Marinville norms. This contributed to some generalizations he made. Additionally, he seemed to know everyone and greet them. He had a boisterous laugh and thoroughly enjoyed teasing people. Everyone we encountered (besides the unsheltered woman outside the shelter) seemed to like him. He explained his philosophy to me; officers should get to know the community. I recognized he was the first officer who seemed not to hide behind the walls of the police vehicle. After the ride-along, I felt confused, because I felt he was a good officer, but I thoroughly disagreed with many of his reductive perceptions. For me, this was hard to reconcile. 
After the ride-along with Officer Marrich, I realized that Officer Marrich and I clicked because I do not fit his idea of "suspicious." As a petite, white woman, he likely saw me as nonthreatening, while the black, homeless woman loitering outside the emergency shelter was in violation of what he perceived as Marinville norms. Similarly, as a sheltered person, to him, I am Wilson and Kelling's (1982) notion of a "regular," while an unsheltered woman, was a “stranger." Dominant narratives of COP paint this strategy as a focus on building relationships, but COP also strategically severs relationships between the public-at-large and individuals perceived as deviant. In Marinville, COP increased social capital but destroyed bridging capital.

\section{The Police: Discretion in Decisions}

Another aspect of the order maintenance paradigm is discretionary policing. Officers do not need legal backing to ask individuals to change their behavior. In fact, officers are encouraged to be creative in their approach to handling situations (Rabe-Hemp 2018). Marinville officers told me they employed a variety of approaches when addressing unsheltered individuals. Depending on the situation they told me, they can ask unsheltered individuals to relocate or issue a warning. Otherwise, officers can also drive unsheltered individuals to HSOs or other social services. Officers only need to document a code violation when issuing a ticket, using force, arresting, or incarcerating. However, I found out from Marinville officers, that when they decide to fine, arrest, or incarcerate, they can do so prior to identifying a violation. Officer Mayweather explained to me that due to the vast nature of federal, state, and city laws it is relatively easy to identify a violation of almost any community norm. Officer Mayweather said he "just finds something that fits." As Foucault (1977 [1979]) said, "Discipline... is a modest, suspicious power, which functions as a calculated, but permanent economy" (170). In other words, the 
structure of the policing profession allows officers to act upon their suspicions as well as discipline to maintain their idea of Marinville's "economy", or livelihood.

The retroactive nature of documentation was clarified during a ride-along with Officer Smith. I asked him whether Marinville has anti-homeless ordinances. He perked up and told me he is very interested in the city, state, and federal laws. He asked me to give him an example of a specific law. I inquired about Marinville's anti-panhandling laws. He extracted what looked like a thick textbook off the back seat of the police vehicle. He asked me what I had heard about antipanhandling in Marinville. I told him that one officer told me anti-panhandling was a state law and was listed under "informal business." However, I told him someone else had told me that panhandling is protected under the first amendment. He spent a few minutes flipping through the codebook. He said obstruction of a motorway, soliciting a ride, unauthorized business ordinances are in the state law that can be used in certain instances, but there was no law titled "antipanhandling." Officer Smith described how residents in Marinville can be ticketed, removed, or incarcerated for violating these ordinances. He even told me, bluntly, that Marinville police "use laws to target people" Officer Smith said all he had to do was scan through the city and state code to find ordinances that justified his desired outcome. Officer Smith described the code as a tool, not a rulebook.

Officer Smith provided a couple examples of using the code to justify officer actions. Officer Smith told me, he used code to keep a cyberstalker in jail and away from a mother and her kids. Officer Smith said, "When I took him in, I knew he broke some sort of laws. I just didn't know what." Retroactively, Officer Smith used the code as a tool to keep the mother and kids safe. Officer Smith said, in some instances, the police use discretion for compassion rather than harsher punishment. He said previously, college-aged minors caught using someone else's 
license were given a felony. Then, he found a section in city code that "fit." He told me he now classifies it as a misdemeanor.

Not all officers used discretion to avoid punitive action. Officer Smith showed me records to prove this. He looked up the name of a well-known frequent flyer on his laptop. This unsheltered man had been issued six fines by Marinville officers. Officer Smith said, "This. THIS is what makes me mad. He can't pay it, what's the point? These are the types of police officers I disagree with." In this case, the unsheltered man violated Marinville norms, and police officers used their discretion for disciplinary action. In my opinion, fining this frequent flyer was an inappropriate punishment.

A major factor in how officers use discretion is their perception of attitude. I wanted to learn more about this factor, so I asked three officers their criteria for writing tickets. Most officers admitted that attitude was a huge factor in whether they write a ticket. Officer Damien said, "Honestly, attitude goes a long way." Later, I brought attitude this up with Officer Larkens. She told me, "Yes, [attitude] makes a difference. If you give me attitude, why should I be nice to you?" Officer Peterson was the firmest about the importance of attitude. When I asked whether attitude matters in writing tickets, he said, "Absolutely" with no hesitations. Perhaps, the unsheltered man with six tickets was perceived to have an attitude. As Lipsky (1980 [2010]) argued, discretionary policing allows police to have a huge amount of power when interacting with the unsheltered population. Thus, officers can make decision-based on factors as subjective as attitude. My data suggests that, in Marinville, discretionary power was occasionally used to exacerbate difficult circumstances for the unsheltered population.

In my observations, Marinville police did not have a partner and were alone on the street, so they have to trust each other's discretion. In the policing occupation, I discovered trust is 
paramount. During a ride-along, I asked Officer Libold about the level of discretion she had as an officer, and she said, "A lot, our supervisors trust us." I asked if she ever feels caught in between interests. She said, "I’ve never felt trapped by my supervisor. He trusts all of us.” She seemed to really appreciate this. The language Marinville police used to speak to each other was of undying loyalty. Folk terms I heard that illustrated trust were "comradery," "loyalty," "we all bleed blue," and "have each other's back." After my first few ride-alongs, I came to think that the policing occupation is so unique, that police might develop a sense of intense comradery as a coping mechanism for the difficulties and frustrations that civilians cannot understand.

\section{The Police: "Us Versus Them"}

The inter-department trust and comradery may be beneficial, but I observed it exacerbate an unhealthy "us versus them" mentality. Specifically, the term "we all bleed blue" indicates that police officers see themselves as distinct from other humans - that the policing identity is more important than other identities. To me, it seemed police officers perceived an intense publicpolice dichotomy.

Some of my interactions with police officers exemplified this divide. Officer Libold expressed she did not feel trapped by her supervisor, but "Feels trapped by the public." Another

time, I witnessed Officer Peterson pull over a man for a traffic violation. The man was defensive and angry. Officer Peterson kept calm during the interaction, but the next time he saw a police vehicle on the street, he flagged him to pull over. Then, he ranted about the interaction. Officer Peterson told the other officer, "They don't get it," referring to the members of the public. The negative interaction with the man and the proceeding positive interaction with another police officer increased intradepartmental social capital but destroyed bridging capital with the public. 
Police officers showed me there is a disconnect between anticipated interactions with the public and true interactions. As Lester (1983) said, it seems Marinville police officers joined the force due to the desire to make a difference. During ride-alongs, I asked why officers decided to join the police academy. I was told, "To help people" four out of five times. Initially, individuals entered the policing occupation because they wanted to protect and serve. Repeatedly, participants told me they get gratification from "keeping people safe." However, in Marinville, it seemed officers started feeling distance from the people they signed up to keep safe. Over time, they began to feel the public does not trust them to protect and serve. Manning (1978) explained how the "us versus them" mentally takes shape in the policing occupation. He postulated that police officers start to believe: 4) everyone hates cops. Then, police officers cope by reciprocating. Police officers start to believe Manning's postulate: 1) people cannot be trusted. This "us versus them" mentality was especially true for the unsheltered population. As Hartmann, McNamara, and Burns (2012) described, police officers feel burdened by repeatedly addressing the unsheltered population. Officer Mayweather said sometimes police officers were called to approach unsheltered individuals four times per day. Like Hartmann, McNamara, and Burns described, frequent interactions cause the unsheltered population to feel targeted and harassed. After repeated contacts with the police, unsheltered individuals may become upset, defensive, obstinate, and frustrated. In turn, police officers may perceive this as an attitude. Then, police come to dread these interactions. I asked Officer Libold how her department feels about the unsheltered population, and she told me, "Thirty-percent really want to help, thirtypercent don't care, thirty-percent think they are a nuisance." I suspect that overtime, the number who originally "want[ed] to help" started to see the unsheltered population as a "nuisance." It 
seemed to me that the regulatory system sends the police and the unsheltered population into a spiral of decline.

Frequent flyer-police interactions are the most exaggerated of "us versus them" relationships. The regulatory system forces these groups to interact. Officer Mayweather told me this occurred "sometimes four times per day," and often resulted in incarceration. When I asked police officers, to tell me about frequent flyers they seemed relieved to have the opportunity to discuss their experiences. I heard stories of frequent flyers dropping rocks off parking garages, picking bugs off their bodies in the police station, watching porn in coffee shops, offering officers sexual favors, hiding in library restrooms, licking people's toes, yelling, cursing, spitting, and stealing. Officers laughed when telling these stories, but I could see exhaustion engraved on their faces.

Unlike most occupations, police officers only deal with a small, often unruly, segment of the population. The police are called, almost exclusively, when the public perceives there is a problem. Other than the occasional wellness check, or person who locked their keys in the car, the police often interact with criminals or those violating hegemonic norms. Police officers come to transpose qualities of the unruly frequent flyers whom they know well onto the entire homeless population.

I believe these repeated unruly interactions reinforces stereotypes. Survey results suggest police officers may be more inclined to believe unsheltered individuals use drugs or alcohol (see Appendix C: Chart 1). About seventy-four percent of police officers "somewhat agreed," "agreed," or "strongly agreed" that most of their coworkers believe unsheltered individuals use drugs or alcohol, followed by almost fifty-three percent on city officials, thirty-seven percent of HSWs, and thirty percent of the involved public. I asked multiple agencies in Marinville if they 
had data on the prevalence of drug and alcohol use in the unsheltered population. All agencies said they did not. I believe it is likely that some unsheltered individuals in Marinville used drugs or alcohol, but unlikely that all did. However, I found that multiple police officers that believe all unsheltered individuals use drugs or alcohol.

Another common stereotype of the unsheltered individuals is that they all have mental illness. Surveys suggest that police officers and HSWs may be more inclined to believe unsheltered individuals have a mental illness than other groups (see Appendix C: Chart 2). Almost eighty-three percent of police officers "somewhat agreed", "agreed", or "strongly agreed" that most of their coworkers believe that unsheltered individuals have mental illness, compared to HSWS (seventy-five percent), city officials (forty-two percent), and the involved public (forty percent). During ride-alongs, I noticed multiple officers explained the unsheltered population is result of mental illness and drug/alcohol use. I asked Officer Peterson if he believes the unsheltered population of Marinville is comprised of people suffering with mental illness. He said, "Yes, the four I can think of do." He told me the code for someone with mental illness was a “10-69." He told me about a 10-69 named Sandy Cheney. He described her as an attractive girl who dresses nicely but is very mentally ill. He said she called him a fake cop and claimed he is a soldier when he gave her rides. He conceded she probably had a terrible home life and her family refuses to take her in. He told me, people in Marinville do not want to deal with a person with a mental illness even the hospital or other police stations.

Police officers were not timid about telling me stories of frequent flyers with mental illness. Like Officer Peterson, Officer Damien discussed Sandy’s mental illness. She told me she arrested Sandy in a coffee shop the week prior. Officer Damien explained Sandy would stare at patrons and make them uncomfortable. In order to retain business, the owners did not want her 
there anymore. Officer Smith also told me about an unsheltered man with mental illness, Jacob Cookson. Jacob was a man with schizophrenia I had seen often in Marinville. He told me Jacob studied science at the university and was going to get his Ph.D. He was housed in 2015 but then had a mental break. He said at that point, he started sleeping outside. Officer Smith told me Jacob is very intelligent and coherent one moment, and then "talks about zika on the sidewalk" the next. Officer Smith said he was called to interact with Jacob multiple times per day because he "looked scary" and would "stare at people." Interestingly, this was the same description Officer Damien provided for why the public called the police department on Sandy. Although "staring" and "looking scary" did not violate the law, it violated hegemonic norms and elicited a response. In fact, Officer Smith was so frustrated with dealing with Jacob several times per day, he documented interactions and created a massive, sixty-page portfolio. He explained his intention was to involuntarily commit Jacob to mental health treatment. Officer Smith reported, "It took me and another police officer hours to build this case. Then, my partner and I found out he was released from treatment after two weeks." I asked why Jacob was released, and he said, "I don't know. All I know is that suddenly, he was back in our downtown.” Officer Smith appeared downtrodden when he said this.

My observations suggest police officers reduced the unsheltered population in Marinville to the mentally ill and alcohol users. Officer Damien brought up on at least three occasions, "mental health issues" as the reason for why people are homeless. When I inquired about the root causes of homelessness, she simply said, "mental illness" and "alcoholism." Officer Marrich was perhaps the most blunt in describing unsheltered individuals and mental illness. I asked him what he believes are the root causes of homelessness and he callously said, "mental disease and defect". He explained to me unsheltered individuals usually refuse to take medication they do not 
legally have to take. He generalized, "In twelve years, I've never seen a bum that doesn't drink in excess... Our town has a real problem with alcohol."

In fact, the stereotype of the unsheltered population as only mentally ill people was so rampant, three of five police officers started to think my research was about mental illness. Officer Smith confused my target population with individuals with mental illness. In reflecting on the frequency of this mistake, I realized this mistake revealed stereotypes of the unsheltered population. Marinville occupants, especially police officers, seemed to perceive the unsheltered population as mentally unstable and incapable. Although some studies suggest psychotic illness and personality disorders occur at higher rates for individuals experiencing homelessness (Koegel, Burnam, Farr 1988), in Marinvillle, only one unsheltered person reported having severe mental illness in the 2017 point-in-time count. Mental illness was either vastly underreported, or vastly overgeneralized. Perhaps, both.

One police officer survey response described the negative outcome of the police attempting to address unsheltered individuals with mental illness:

"The vast majority [of the unsheltered population] do not accept these services, don't like the rules about intoxication, or they have mental health issues that cause them to be unable to live in a group setting. The latter is very difficult to deal with, as most of the mental health facilities have been closed. The police are not, and should never be, a replacement for legitimate mental health professionals. Yet, circumstances have placed the police in the position to have increasing amounts of contact with those who have mental health issues. As a result, there are greater reports of negative outcomes in police interactions with this segment of the population. I don't know that many people consider the full context of why 
there might be an increase, so they conclude erroneously that the police had malice in their heart at the time."

In Marinville, police officers received Crisis Training, a week-long course on preventing and intervening in times of crisis (including mental health), but Officer Turk told me they were not specifically trained on how to interact with unsheltered individuals. The police underwent continuing education, but because the unsheltered population was relatively small in Marinville, this type of training was not a priority. Therefore, newer officers were not as aware of services and resources available to the unsheltered population. Marinville police officers learned of the resources and services available to the unsheltered population through experiences rather than training.

As seen in the cases of Sandy and Jacob, Marinville police did not hear success stories often. In fact, the structure of the policing profession created a system where police officers were only called when there was a problem. City Official Foster described this, "Only when there is disruption, police are called." On top of this, the lack of mental health and substance use rehabilitation facilities in Marinville increased the likelihood of negative interactions. Inadequate services meant certain populations ended up on the street. Then, when contacted by the police, officers had little options for how to proceed other than penal action. Police officers told me after repetitive, tense interactions with the unsheltered population, they started to lose faith. In Marinville, police officers hardly ever heard about upward mobility. The police were not informed if an unsheltered individual they interacted with entered a shelter program, gained employment, and/or entered housing. Due to the structure of their occupation, police officers saw a small number of residents stuck in the cycle of poverty and justice-involvement. From their vantage point, there was no escaping this cycle... so why try? 
In fact, some police officers seemed to have lost sympathy for the unsheltered population. When I asked Officer Libold how she approaches addressing an unsheltered individual she said, "I take them to jail, and I don't even feel bad." She explained there are hardly any other options when shelters are at capacity and it is cold outside. She implied that she feels limited in her ability to help and has given up feeling guilty about it. As Becker (1993) stated, "Opportunities are largely determined by the private and collective actions of other individuals and organizations" (3) Officer Libold did not have control over the shelter capacity or resources available to the unsheltered population, she only had control over the discretion she employed when dispatched. As Becker said, "the most fundamental constraint is limited time" Officer Libold was constrained by the hours of her shift. However insensitive, for her, the quickest solution was the most rational in her time-constrained occupation.

\section{The Police: Protect, Serve \& Burnout}

Furthermore, police officers told me they feel desensitized due to on-the-job trauma. At one point, Officer Rodriguez told me about how desensitized he feels after seeing so many horrific things. He said his kids asked him, "Have you seen the inside of people? Have you seen their brain?" He implied on-the-job trauma caused a degree of post-traumatic stress that distanced him from his children. Another time, I was told a story of how an officer was traumatized by an unsheltered individual. In Marinville, I met a woman named Kara Jag, who told me about her friend, a woman police officer. She told me her friend became close with an unsheltered man and checked on him occasionally. One day, he attacked her without warning and she felt betrayed. 
A traumatic event can make officers less inclined to help. Kara told the woman officer attacked by the unsheltered man now suffers from post-traumatic stress disorder and stays inside the police vehicle. Kara told me, "She doesn't feel safe anymore." She stated, "You've got to think about how officers must feel.” Past experienced with violence undoubtedly influenced how officers approached future situations. In this case, the officer was initially willing to exceed her duties to serve this unsheltered man, but after experiencing trauma, felt unsafe doing so. Officer Smith told me a similarly traumatic story that deterred him from serving residents in Marinville encampments. He told me he was incited to enter a Marinville homeless encampment and, upon entering, discovered traps, wires, and knives that were set up to prevent external infiltration. Although I had never expressed interest in entering a Marinville homeless encampment, he begged me not to enter for my safety. Officer Smith said, he preferred not to go anywhere near homeless encampments in Marinville. He told me, "Neither should you."

Although some officers experienced these real, traumatic events, others simply heard of them. These stories prevented new officers from going above-and-beyond to serve the unsheltered population. Although there are undeniably violent, unsheltered individuals, these instances are rare. The National Law Center on Homelessness and Poverty (NLCHP) (2010) found that although individuals experiencing homelessness are more likely to commit nonviolent crimes (likely out of survival). They commit fewer violent crimes than the housed population. Further, they are more likely to be victims of violent crime than perpetrators (Novac et al 2009).

Novelist Chimamanda Adichie (2009) codified these phenomena as the "danger of a single story," or the danger of using one story to justify a perspective. In Marinville, I heard a 
teacher explain how she often heard her students justify their inaction surrounding homelessness because they overheard a single story that reinforced stereotypes. Like this teacher, during my time in Marinville, I heard "single stories" often. Specifically, an acquaintance in Marinville explained to me he no longer gives money to unsheltered individuals because once, he heard that a panhandler walked directly into the liquor store with someone's twenty dollars. On another occasion, a Marinville resident told me that he gave a panhandler money outside of a fast food restaurant and the person took the money into an expensive convertible. Due to these singular testimonies or experiences, Marinville residents no longer had sympathy for the unsheltered population. Then, others who heard these stories become less inclined to help.

"Single stories" were particularly rampant within police culture. Of all the occupations I interacted with, police officers told the most stories. The purpose of storytelling seemed to be in some ways cathartic. One officer told me a story of when he tackled a naked, unsheltered man. He laughed about it but acted very disturbed by the situation. This officer told me that after these interactions he felt more hardened. Many times, I observed police officers exchanging stories with each other, ranting, or trying to make light of a situation with the public. Each time, they strengthened their bond with other officers but distanced themselves from the public and the unsheltered population.

In totality, the structure and constraints of the police occupations lead to burnout. Adams and Buck (2010) said relationships with civilians causes "psychological distress and emotional exhaustion.” Police officers work long, lonely hours. Marinville police told me their work distanced them from family and friends. During ride-alongs, police officers seemed initially skeptical of my presence in their vehicle, but then realized I was willing to listen to their 
frustrations, fears, disappointments, and realizations, they gushed their stories, thoughts, and feelings. Often, I felt I was used as a substitute for a therapist. Lipsky (1980 [2010) said, “Often street level bureaucrats often attempt to involve clients in the difficulties of their job in order to gain an understanding or sympathy for their position" (64). This was evident as, six of six officers told me, unsolicited, that their job is difficult. Even more, six of six told me they have experienced burnout and feel jaded. Officer Libold told me the hardest part of her job is disappointing people. This component of the policing occupation fulfills the final type of Agnew's (1992) general strain: 1) strain as the actual or anticipated failure to achieve positively valued goals. A few months into my fieldwork, I determined the policing occupation sets officers up to fail.

Time-constraints and unrealistic expectations exacerbate police officer burnout. Although some ride-alongs shifts were undeniably slow, others are fast-paced and busy. Even on busy days, officers are expected to be counselors, mentors, social workers, and conflict mediators, while the majority of their training was law-enforcement. During a ride-along, I told officer Damien I have heard police officers are expected to do too much, and they cannot accomplish everything they are tasked with. This seemed to resonate with her. Officer Damien said, "We're expected to do everything, but I can only do so much." Later in the ridealong, she told me "I'm not a social worker, why do people expect me to be one." As Kelling and Moore (1988) described, in the modern era, police officers are expected to be social workers. Officer Damien felt this was too much to ask of Marinville police. Officer Damien told me that a few times she had not wanted to come to work. She explained each time was because she saw on the news that unruly civilians had killed police officers. She said, "I don't want to come to work if I know people want to kill me for the uniform I wear.” 
Like Officer Damien, Officer Smith felt a similar way about how the public views him. He told me about how he hides his police identity off the clock. He said, at first during social events, he asks individuals their occupation. Once he heard the responses, he falsely claimed he was in a different occupation. He said his favorite responses are garbage truck driver and finance officer. He said his wife lies on his behalf. I asked Officer Smith why he felt compelled to lie. He said, “People don't like cops. When you leave here today, if you see me in street clothes, you won't recognize me. If I see you, I will. I might not remember your name, but I'll recognize you and probably not say anything. All people can see if blue, not the person.” To Officer Smith, his uniform was a symbol of his occupation in the midst of a legitimacy crisis.

Some Marinville police internalized criticism from the public. Like Manning (1978) listed in assumptions of policing, Officer Smith believes the public hates him, due to his role as an officer. A few Marinville officers expressed feeling disgusted by themselves and the policing occupation. Officer Libold confirmed, "A lot of the work that police officers do is a Band-Aid." Furthermore, Officer Peterson said, “I can't believe I'm a fucking cop... I ruin people's lives sometimes... The whole systems fucked up, and I can't do anything about it." He even developed a catchphrase for when he had to deal with situations he found unimportant. Whenever he was sent to a call that criminalized something petty (such as a non-violent unsheltered individual), he said, "Just cleaning up the streets" sarcastically. One time, he apologized and said, "I'm sorry, I've worked three doubles. I'm normally nice." The self-loathing, I witnessed, may contribute to the high rates of suicide among police officers (Miller 2005).

Ultimately, the policing occupation subjects police officers to members of the public and situations that reinforce stereotypes. One police officer survey response exemplified the turn to 
stereotyping the unsheltered population. This officer's "all” language over-generalized the unsheltered population.

Every unsheltered homeless individual we have experience with chose to live the way they do and when given help to get out of the situation, those individuals returned to homelessness shortly after receiving the assistance. All subjects were diagnosed with some sort of mental health disease.

I believe the reductive nature of the statements made by police officers, similar to the one above, are products of the structure of the police occupation.

\section{The Police: Brewing Incongruence}

Despite time-constraints, traumatic experiences, problem-orientation, high expectations of the public, I observed police officers had little desire and willingness to remove or evict homeless encampments. Marinville police officers, like other occupations, report little desire to punish, reprimand, or remove the unsheltered population, but news report show evictions have occurred. While in conversations with Marinville police officers, most expressed they wanted to avoid the unsheltered population. However, incarceration data demonstrated Marinville police regularly arrested frequent flyers for non-violent crimes. To me there appeared to be a disconnect between police officer beliefs and opinions and their actions. One police officer survey response troubled me: "How my colleagues think and how they act are very different things."

It is evident there are structural reasons why police officers' actions do not align with their beliefs. Marinville police are caught in the middle of a complex, ingrained, regulatory system. It seems the "general strain" produced by the policing occupation produces misconduct and incongruent actions. Over time, police officers act in ways that prevent burnout and maintain 
their own mental health. Unfortunately, in Marinville, I found that self-preservation within the constraints of the policing occupation was at the expense of the unsheltered population. When incited, the rational choice for police officers was to evict Marinville homeless encampments despite little desire to do so.

\section{Homeless Service: Stretching to Provide}

I arrived at a HSO as a volunteer and found Eugena Palups, Marie Jameson, and Ed Redders working. When I walked into the room, I said, “Hi Ed, how are you doing?" He looked over at me and said, "Why would a nice girl like you be in a place like this?" I was confused and defensive because Ed had always been the most optimistic person there. I replied, "Just volunteering... but this isn't such a bad place, I want to be here." In retrospect, I admitted, I did not always want to be there. The HSO did not always have the welcoming vibes I was seeking. It made me feel uncomfortable when employees clearly wanted to be elsewhere. I reconciled, Ed must be having a bad day. Also, I realized, he is no longer a client (for about a month) and was now considered an employee of the agency. I wondered, the shift in position caused an attitude change. I asked another HSW, Eugena, about how her day off was, and she said, "Short. I only got one day off this week." Later that shift, I asked Ed and Eugena to describe their clients, and Ed said, "Some people can't deal with the rules. Their section looks like... No wonder they end up here. They have problems with authority. For me, even though I'm older, I still say, 'yes ma'am', out of respect. Many of them have always had problems with authority and maybe that's why they're here." Eugena joined in and told me many clients get fussy or ungrateful with the food. She said, "Better than nothing! It's free!" 
Later that week, I interviewed Jonathan Carl, and upper-manager of this HSO. I asked him if his employees become more optimistic or pessimist over time. He said, "In a faith-based, mission-driven organization like ours, people become more optimistic. They have the faith to stay persistent..." Jonathan's answer shocked me. His perception of his employees' emotional state was incongruous from what Ed and Eugena expressed.

This vignette exemplifies some the structures, constraints, and perceptions I discovered at HSO. Overall, I determined Marinville HSOs screened for employees with sympathy, compassion, and comfort working with the unsheltered population. Unlike the police and city officials, HSWs received specific training for working with individuals experiencing homelessness. However, as seen in the case of $\mathrm{Ed}$ and Eugena, the low pay, intensive emotional labor, and ability to only assist certain individuals cultivated burnout and pessimism. Over the course of one year of fieldwork at the HSO in the vignette above, I watched Ed, a formerly unsheltered, entry-level HSW go from positive, friendly and welcoming to stressed, surly, disillusioned, to perceiving clients as anti-authoritative. In contrast, his manager, Jonathan, reported the faith-based and mission-oriented nature of their HSO prevented this. Clearly, Jonathan was ignorant of the experiences of his entry-level HSWs. I discovered that larger HSOs, like the one in the story above, are hierarchical, so there was a sizable distinction between entry-level HSWs and upper managers.

\section{Homeless Services: Screened for Compassion and Comfort}

It did not surprise me that surveys suggest that HSWs believed that their coworkers think about the unsheltered population more often than city officials and the police (see Appendix C: Chart 3). Just over eighty-seven percent of HSWs "somewhat agreed," “agreed," or "strongly 
agreed" that most of their coworkers put a lot of thought into how to address the unsheltered population, followed by the involved public (forty percent), police officers (thirty percent), and city officials (twenty-one percent).

A noticeable difference between HSWs, city officials, and police officers was that HSOs have different applicant screening processes. Five of five HSW interviewees reported their HSO screens for compassion, sympathy, and empathy towards the unsheltered population when hiring. Patricia Pale told me screening for compassion was purposeful. She said, "Staff are expected to care for clients using an emphatic approach.” Survey responses suggest HSOs may have a greater culture of compassion for the unsheltered population. In response to the statement "most of my coworkers are compassionate towards the unsheltered population," over sixty-two percent of HSWs respondents "strongly agreed" and no respondents "somewhat disagreed," "disagreed," or "strongly disagreed" (see Appendix C: Chart 4). The majority of responses from other occupations were mostly within the range of "agree," but they were more modest. In addition, two interviewees described to me the types of screening questions asked. Milton Wells reported being asked scenario-based questions during his interview. Erin Jones gave me an example of a scenario-based question, "How would you feel working with a person with body odor who hadn't showered in days?" Although they used different language, interviewees explained to me these questions gauged compassion for individuals who deviate from hegemonic norms. Perhaps, screening may contribute to the fact that, in surveys, HSWs reported at comparatively higher rates that they think their coworkers believe unsheltered individuals are "good people" and "productive members of society" (see Appendix C: Chart 5; Chart 6). Just over thirty-five percent of respondents "neither agreed nor disagreed" that "most of their coworkers believe homeless individuals are good people." Of non-HSW respondents, forty-seven fell on the side of 
"agree" and almost eighteen percent fell on the side of "disagree." Overall, responses about the unsheltered population as "good people" were relatively affirmative. In contrast, the statement about the unsheltered population as productive received wildly different responses. Over seventy-six percent of all respondents "somewhat disagreed," "disagree," or "strongly disagreed" that most of their coworkers believe unsheltered individuals are productive members of society. Zero police responses fell within the range of "agree." Even HSWs were skewed towards "disagree." I suspect this is because "productivity" is often defined through a capitalist lens, or that to be "productive" a person must be a moneymaking contributor to the economy.

Although HSW may not see unsheltered individuals as productive, surveys suggest that they may be comparatively more comfortable entering a homeless encampment than city officials and the police (see Appendix C: Chart 7). In fact, one survey respondent mentioned the positive experience they had when entering an encampment, describing it as, "A beautiful experience [that] has profoundly affected [their] work today." This experience contributed to their comfort working in encampments. Just over sixty-two percent of HSW survey respondents reported their coworkers would feel "slightly comfortable", "moderately comfortable", or "extremely comfortable" entering a homeless camp, compared to thirty-nine percent on police officers and twenty-one percent of city officials. In fact, over twenty-six percent of city official respondents said their coworkers would feel "extremely uncomfortable."

HSWs may feel more comfortable entering homeless encampments compared to other occupations, because HSWs offer resources, rather than taking them away. For that reason, I believe HSWs fear less backlash or retaliation. Offering services, compared to removing them, set the HSO occupations apart from the police and the city. Although city officials and police 
officers sometimes make decisions to provide resources and services to the unsheltered population, their occupation sets them up to remove individuals.

\section{Homeless Services: They Need Our Help}

Surveys and interviews suggest HSWs were more compassionate and sympathetic towards the unsheltered population, but I wanted to gauge whether this led to perceiving the unsheltered populations as victims. Sure enough, survey responses suggest that HSWs "somewhat agreed," "agreed," or "strongly agreed" that most of their coworkers believe unsheltered individuals need help (see Appendix C: Chart 8). The mean of other occupational responses were in a similar range. The survey question about feelings of hopelessness also shows HSWs may be disproportionately likely to believe unsheltered individuals feel disempowered. Seventy-five percent of HSW respondents said they "somewhat agree," "agree," or "strongly" agree" that unsheltered individuals feel hopeless. City officials, police officers, and the involved public responses also mostly fell on the side of agree, but HSWs had the highest proportion of affirmative responses (see Appendix C: Chart 9). During fieldwork, I witnessed examples of how HSWs perceive the unsheltered population as needing help. When I interviewed Jonathan, we discussed the topic of employment assistance. He said, "It's not realistic to think they can do it on their own." As employees of HSOs, HSWs provided resources and assistance, thus it was logical that they would perceive their work as necessary.

My observations of HSOs culture affirmed Lyon-Callo (2000) observations that HSWs are inclined to describe their clients in terms of diagnoses and bodily capabilities. Like police officers, surveys suggest that HSWs may be inclined to think their coworkers believe unsheltered individuals have mental illness (see Appendix C: Chart 2). When I asked HSWs about the root 
causes of homelessness four of five interviewees listed "mental health" or "mental illness". Upper-managers Kristin Promise and Milton Wells said, "addiction concerns" and "substance abuse" contribute to homelessness. Two HSWs also mentioned physical health as a barrier; Patricia listed "disabilities" and Kristin, "PTSD". Milton described how homeless physical and mental health issues translated to problems with social interactions, "Mental health issues that cause them to have problems when around groups of people, and at times being banned from a shelter due to behavior." Jonathan told me to alleviate homelessness, "there need to be initiatives around [mental health] issues." I was also told by an upper manager that HSOs try to equip HSWs with skills to work with individuals with mental illness, "All [HSWs] get training on being trauma-informed as well as intervention skills." Although this type of training is important, it may have reinforced the belief that all unsheltered individuals have mental illness in Marinville.

In addition to the perception of the unsheltered population as mentally ill, I witnessed many HSWs describe their clients as anti-authoritative. Milton told me, "Unsheltered homelessness tends to stem from individuals not wanting to follow certain rules at the shelter... and at times being banned from a shelter due to behavior." Erin Jones echoed this, "For some, there like the freedom of being out on their own. Some don't want to adhere to the rules in the shelter. They don't want to be back by ten." HSW survey responses alluded to the unsheltered population as anti-authoritative; "I have found most just don't really want to follow other's rules or standards and would rather chance it living outside than in a shelter." Another survey respondent said, "The unsheltered homeless usually have trust issues which cause them to remain unsheltered." Ed took this to the extent of saying anti-authoritative tendencies contribute to individuals becoming homeless in the first place. 


\section{Homeless Services: Hard Work, Little Pay}

Perhaps due to perceiving their clients as victims of physical, mental, and emotional barriers, interviewees described how many HSWs lose hope that their unsheltered clients will escape the cycle of poverty. When I asked HSW interviewees about whether their coworkers become more or less optimistic about alleviating homelessness over time, I received hesitant responses from five different interviewees:

I think that depends on the staff person and how they are connected to the people they serve. There is a lot of burnout in the social service field and sometimes this happens with our staff. I think that it helps when we are able to get a person housed and help them stay housed.

I have seen homeless service services employees become both optimistic and pessimistic about client outcomes. Ultimately, the client's self-determination will trump anything that the service provider sets out for the client.

I think it ebbs and flows. I think with a good work/life balance, a healthy work environment, and proper supervision, employees feel that their work matters and that they are making a difference. There are times that can be frustrating and overwhelming, but in general, there is enough success that keeps employees passionate about their work.

In general, that is probably not the case... We need to shift away from acting as though we have all the answers. Then, we are able to see more success. 
Erin was most blunt:

Over time, more pessimistic. Some people have been here a long time and are tired. Some are starting to see population we work with as a hindrance. Overall, the goal is to help them, but there is some burnout. We see same people year after year. When new clients come in, you feel like, "well are they going to become like the other people?"

Erin was frank about the pessimism and burnout that creeps into HSOs. Her description of HSO culture was strikingly similar to Miller, Birkholt, and Scott's (1995) and Stover-Wright's (2018) description of HSO emotional labor and burnout. Later in the interview, she told me: Most [HSWs] [are sympathetic and empathetic], but there are some who are not. I hear most of the staff people who meet with [the unsheltered population] saying, "that's hard..." They realize most people are trying to get out of their situations. But there are one or two [staff], who don't show that.

Like Stover-Wright (2018) described, the accounts from Marinville HSWs, especially entry-level employees, demonstrated how the high stress, low pay aspect of working in HSOs contributed to burnout. Based on a review of job postings in Marinville, on average, HSWs were paid less than police officers and city officials (besides councilmembers). Salaries for full-time positions ranged from $\$ 20,000$ - $\$ 50,000$. On top of low pay, these HSWs dealt with a vulnerable population making their job demanding. HSWs were not compensated for this. For this reason, like police, HSW experienced a degree of Agnew's (1992) “general strain.” As the youth in Thompson et al.'s (2006) study observed, sometimes over-worked HSWs, like Rosalie Almora, displayed "disrespectful" or "rigid" behavior. I believe the general strain of low pay and hard 
work, contributed to Rosalie lacking consideration for various dietary restrictions, Eugena alluding to unsheltered individuals as ungrateful, and Ed saying individuals experiencing homelessness were anti-authoritative.

\section{Homeless Services: Under the Radar}

Another primary finding was that there was a mass cultural distinction between entrylevel HSWs and upper-management. As Stover-Wright (2018) described, HSOs are hierarchical. I noticed entry-level HSWs were more culturally similar to police officers. I perceived these HSWs as more blunt, valuing honesty, physical labor, and direct service to clients. Additionally, I noticed both police officer and entry-level HSWs positions were, in some ways, structurally similar; they had somewhat dangerous jobs, approaching strangers and initiating difficult conversations. However, HSO upper-managers seemed more removed from their clients, perhaps more educated, and careful with their speech. These upper-managers used "people first" and less charged language. Like city officials, these employees spoke in ways that provoked the least backlash, but in some situations, stigma was still evident. Like city officials, as Noy (2009) described, HSO upper-managers used political framing when discussing the unsheltered population.

Despite the political framing of HSO managers, I observed HSWs display stigma towards the unsheltered population. This stigma was, however, more nuanced ways. My second time volunteering at a HSO in Marinville, after a few hours, a HSW told me to take a break. I sat outside at a table with some women for the next three hours chatting. At one point, I got up and went to the restroom in the main lobby. When I returned from the bathroom, an HSW named Carry Jenkins asked me to follow her. Carry showed me a private bathroom that the volunteers 
used. Later I reflected on why this HSO established segregated bathrooms between HSWs and the unsheltered population. Although Carry was well-intentioned, it revealed her desire to keep me (and other volunteers) separated from the unsheltered clients. A "volunteers only" bathroom indicated an underlying belief that the unsheltered clients are dangerous, unclean, or perverted in some way. At the very least, that unsheltered individuals should be served with a degree of social and physical distance.

At another HSO I noticed nuanced stigmatization. I was volunteering for the homelessness point-in-time count. Kristin, a seasoned HSW, instructed volunteers to approach and survey unsheltered individuals. I raised my hand and asked, "How will we know if they are homeless?" Kristin responded, "You will know," without going in depth. Like police officers, it seemed HSWs made assumptions based on physical appearance, violation of hegemonic norms, or perception of "suspiciousness."

In Marinville, I noticed stigma at HSOs was obscured by seemingly positive homelessness alleviation initiatives. Marinville started an initiative to put money slots throughout the downtown where residents could drop cash rather than handing it to an unsheltered individual. The logic of this project was described to me by Jonathan, "Some business owners don't want [unsheltered individuals] to be [in the downtown]. We wanted to figure out how to provide income in other ways." In this quote, Jonathan said the intention was to appease business owners, and "provide income." What he did not mention was that the "income" went towards sheltering organizations such as his own. Ineligible unsheltered individuals only received some services from sheltering HSOs. Further, these money slots perpetuated the idea that the unsheltered populations spend money irresponsibly and should be denied financial autonomy. 


\section{Homeless Services: Serving Some}

In Marinville, some unsheltered individuals were denied access to emergency shelters. In Marinville, emergency shelters have various eligibility criteria. Patricia told me, one shelter did not accept those under the influence of drugs or alcohol. The shelter that does was considered "low-barrier." However, some circumstances prevented unsheltered individuals access to either Marinville shelter. Neither shelter accepted individuals with a recent, violent criminal record or individuals on the sex offender list. Jonathan told me this was because his shelter was near a playground. Patricia, from a different HSO, described her organization's reasoning for disallowing sex offenders: "We are required to turn away persons who are registered sex offenders [since we have an] afterschool program and a church next door." Further, neither emergency shelter took pets. In Marinville, unsheltered individuals had to choose between relinquishing pets for the sake of shelter or keeping pets and remaining unsheltered.

Even when individuals were allowed entrance to Marinville shelters, the set up was not always conducive. During the day, clients were not allowed to stay in their dormitory or common space and must find somewhere to go. Previously, there was a faith-based organization in Marinville that allowed unsheltered individuals to occupy their building for long periods of time. In 2016, it closed. After this closure, unsheltered individuals had nowhere to go while shelter dormitories were blocked off during the day. Additionally, Marinville shelters split up families; men in one wing and women in another. Family wings did not take "children" over the age of eighteen. Erin explained how she saw this as a problem, "If there is a dad with an eighteen-yearold girl, there is no [dorm] for them..." In the hypothetical scenario, Erin described, the eighteenyear-old female would be sent to a separate dorm from her dad. 
Further, most shelters did not have adequate services for unsheltered individuals who needed specialized services. One survey respondent focused in specifically on lack of resources for mental illness: "There is no one to advocate for them. Under the current law, a person receiving mental health help must be a danger to himself or others to receive the appropriate help.” In Marinville, the closest inpatient mental health facility was a little less than seventy miles away. Milton echoed this sentiment, but also mentioned how addiction services were missing; "Mental health services and substance abuse services [are] still lacking..." Marinville's substance abuse rehabilitation center had limited capacity.

Another aspect that set HSOs apart from city officials and the police was that most HSOs were faith-based. In Marinville three of five major HSOs, including two shelters, were Christian. This was evident in interviews. Multiple HSWs described how religiousness guided their actions, including Jonathan who said, "We are a Christian ministry, so this imbues everything we do. We figure out ways to welcome people rather than turn them away. Show grace to people." Although many HSWs in Marinville believed God's called them to welcome the poor, religiosity may have deterred some unsheltered individuals from seeking services. During fieldwork, I learned HSOs asked clients to pray before eating. Although it was impossible to force clients to pray, being asked to do so may have felt uncomfortable for non-Christians.

The population that remained unsheltered, indicates who the continuum of care (the network of HSOs) believes is most deserving of services - and who was not. It seemed in some cases, the continuum of care priorities were based on the greatest need, but other times it showed the HSO network's priorities. For instance, Jonathan told me veterans were allocated a certain number of beds in shelters, so they were more likely to be served. However, it was evident that sex offenders, individuals who committed violent crimes in the last five years, and individuals 
with pets were the lowest priority. To learn more, I sent an email to Jonathan, inquiring about the shelter waitlist system. He responded:

We call it a Prioritization List, and people are placed on the list based on their scores on the VI-SPDAT (Vulnerability Index - Service Prioritization Decision Assistance Tool). We contact people with the highest scores first as space becomes available. It is common for one or more of our bed types (single male, single female, family rooms) to be full - that's when the list comes into play.

Jonathan explained how HSWs did not decide who their HSO served. The eligibility criteria and VI-SPDAT system were built into the continuum of care, so HSWs had little discretion in choosing who enters the shelter and who was forbidden. These structures and systems determined whether as many as 240 Marinville residents had food, water, and shelter on a daily basis.

Although I found stigma of the unsheltered population existed in HSOs, HSWs were less subject to criticism than the police and the city. HSWs were tasked with providing resources and services; actions perceived by the public as positive. Since most Marinville residents had an aversion to associating with the unsheltered population, they were thankful that HSWs bore the “burden.” Since HSWs specifically serve individuals experiencing homelessness, their occupation enabled them to focus their efforts. HSWs were only obligated to a small fact of the Marinville public, while public servants were obligated to the entire city. 


\section{City Officials: Indirect \& Overhead}

I hovered near the entrance of a large city building, occasionally checking my email to see if I had a message from Palli Johanesburg, an upper-level city official. Eventually, I spotted a woman in a long coat across the street scanning left and right, as though looking for someone. I walked closer, and she immediately knew it was me. She gave me a firm handshake and invited me to follow her downstairs to her office. Her office was large and modern in appearance. It took a few minutes to set up my laptop and audio recording device. I could tell that one of city official Johanesburg's primary values was efficiency. She told me, "Well if it takes you a moment, I'm going to answer a few emails." When I was ready, I began asking her questions. Her responses were quick and concise. When she did not have a factual answer, she asked me for the facts. I explained about ordinances that target the homeless and asked if Marinville has any of these ordinances. Quickly, she responded:

There is nothing in the zoning code that targets the homeless. I deal with zoning, nothing in zoning says that. Maybe loitering, maybe nuisance. Now, we're having a problem with people coming in and showering in the downtown bus station. We knew we were going to have a number of homeless people coming in, and we need a strategy.

I asked her how she feels about anti-homeless ordinances. She replied, "I guess it's a little heartbreaking. I don't feel good about it. But if there were a massive problem in downtown, I could see where it would come into play." Johanesburg described anti-homeless ordinances as unfortunate but necessary.

City officials such city councilmembers, city managers, and city planners occupy an interesting position within the homeless encampment eviction process, as distant lawmakers and 
strategists. This vignette exemplifies some of my major findings on the relationship between city officials and the unsheltered population. City officials retained a high degree of social distance from the unsheltered population. This contributed to them not thinking about the unsheltered population often. I felt city officials were not fully informed about anti-homeless ordinances in city code. In addition, city officials admitted they were not fully aware of the situation for unsheltered individuals in Marinville. I noticed city officials often made decisions based on strategic "improvements."

\section{City Officials: We "Don't Interact at All"}

I found city officials had the lowest level of contact with the unsheltered population of target occupations. Even less contact than the involved public. When three city officials were asked in interviews in what capacity, they interact with the unsheltered population, responses included, "I don't at all," "Personally, I have, but not the council as a whole. We haven't engaged with this issue" and, "Typically [we only] interact when there is a problem. Not sure whether this is good or not. As long as they aren't disrupting, we leave them alone." Survey responses suggest that city officials interact with unsheltered individuals infrequently (see Appendix C: Chart 10). In fact, a little over forty-seven percent of city official survey respondents reported that they interact "almost never." During interviews, all city officials, other than one who regularly volunteered at HSOs, expressed they seldom interact with unsheltered individuals. Contrastingly, a little over fifty-six percent of HSWs said they interact daily.

City officials had an indirect relationship with the unsheltered population. Councilwoman Jaster described this relationship: "[We interact] directly, very little. This is not uncommon for city council due to structure and how we are set up." Councilwoman Jaster may have been 
referring to city council's social distance from unsheltered individuals, but potentially the physical distance as well. In Marinville, city official offices were in the heart of City Hall or annex buildings. Some offices were in a multi-level building above the downtown, where employees gained an aerial perspective of the downtown and observe shoppers and the unsheltered population without having direct contact with them. Often cities are built so that city officials can surveil downtown patrons and engineer policies to influence their actions, reminiscent of Foucault's panopticon (1977 [1979]).

After spending a few weeks attending city meetings, I realized homelessness was not a priority city issue. The unsheltered population was rarely a topic of conversations between city officials. In fact, the topic was never brought up during one of the eight meetings I attended. During interviews, I asked the question, "How often is the unsheltered population discussed between city officials?" All five city interviewees responded that they did not discuss homelessness often. Responses included, "No, no. I was disappointed [to find this out]," "Hardly at all," "No, not discussed often," "Almost never," and, "Randomly. Rarely." Councilwoman Jaster said, "[The unsheltered population] is often [not] talked about. They are almost the distant child we refuse to acknowledge, but they exist. The potential of population growth is there. That plays a part in the community. We don't talk about it." Marinville city officials may not prioritize homelessness because the unsheltered population is comparatively similar to or proportionally smaller than surrounding cities. Before conducting fieldwork, I expected Marinville city officials would periodically discuss this topic as an educated and relatively progressive city. I found that, like most cities, the problem with homelessness was chronic, and chronically ignored. 


\section{City Officials: Structured for Distance}

The surveys that I distributed suggest, of target occupational groups, city officials may put the least amount of thought into how to address the unsheltered population, survey results suggest less so than the involved public (see Appendix C: Chart 3). From what city officials told me, in the last decade, there has only been one councilmember who was elected on a platform to alleviate homelessness. Generally, councilmembers focus on other issues. Survey results indicated that the average city official "somewhat disagrees" that "Most of their coworkers put thought into how to address the unsheltered population" while the average HSW "agrees." Councilwoman Jaster informed me due to the Open Meetings Act groups of three or more city officials cannot discuss a topic without releasing notes from the interaction publicly. The purpose of this act was transparency, but she said it limited the flow of conversation and the ability to brainstorm or process with each other. City Official Saral described this:

The Open Meetings Act and FOIA are well-intentioned laws that are poorly crafted. They constrain good government in the name of transparency and are burdensome/expensive to follow (FOIA in particular). They make it appear public interest is being protected, when, in fact, some matters that need public discussion are suppressed.

The Freedom of Information Act (FOIA), allowed Marinville residents to request information on city processes. I suspect the public pushed for the FOIA for greater governmental transparency, but as City Official Saral said, it became a time-consuming process that took away from other city initiatives.

City officials, like other occupations studied, had competing priorities and limited time. Still, multiple city officials took steps to improve conditions for the unsheltered population, such 
as the creating a Homeless Task Force and considering the creation of a tiny house project for individuals experiencing chronic homelessness. However, it was clear there were limits to the capacity of city officials. Becker (1993) said, “Actions are constrained by income, time, imperfect memory and calculating capacities, and other limited resources, and also by the opportunities available in the economy and elsewhere" (3). In Marinville, city officials were not paid a standard wage and thus, had outside employment. City Official Saral told me their yearly salary amounts to less than $\$ 5,000$ dollars. He said this was to encourage residents to "run for the right reason." Once elected, most city councilmembers work full-time in addition to serving in city government. As most are middle-aged, many have families to take care of. Ultimately, these policy-makers were incredibly time-constrained and did not have time to leaf through city code and/or change anti-homeless ordinance, if they were even aware of them. For city officials, there was little "time" or "money" to alter city code or protocol to meet the needs of unsheltered individuals. Acting rationally, they put their energy elsewhere.

During interviews, city officials were hesitant to participate because they admitted lack of knowledge and involvement. On at least three occasions, when I emailed city councilmembers to set up an interview, they responded recommending I speak with other people. City Official Johanesburg's email response was, “I'm not sure I'm the right person...I'm never involved in that sort of incident," and Councilwoman Palser said, "I do not know a lot about the encampment evictions." One city official who declined my interview invitation said, "I don't know that I would be a very good subject for you... [but] I am trying to do what I can to educate myself about the homeless situations." Then, during the interview, when I asked city officials to, "Describe the current homelessness situation in Marinville," I evoked many uncomfortable shifts 
and looks. I felt most city officials were a little ashamed of their lack of knowledge of the unsheltered population.

Not only were city officials ignorant of unsheltered circumstances, they were also unaware of whether adequate resources and services were available to them. Of city official participants, one was unaware of services available to the unsheltered population, and one believed that there were adequate services in Marinville. When I asked City Official Johanesburg, "If there are adequate services in Marinville for the unsheltered population?" she replied honestly, “I don't know. No idea.” One city official survey respondent said, "It seems like there a[re] options for housing of unsheltered individuals other than tents." In Marinville, there were multiple emergency shelters and HSOs, however, there were restrictions based on age, gender, sobriety, and criminal history (discussed further in the section on HSWs). Additionally, there was a stark lack of inpatient mental health facilities. This concerned me because, in theory, city officials who believed there were adequate services could this as justification to remove encampments without offering services (such as housing or emergency assistance).

Additionally, many city officials believed homelessness was not a problem in Marinville. Four of five city officials interviewed said the unsheltered population was either not a problem or comparatively a small problem. It did not surprise me that the two city officials who had direct contact with the unsheltered population expressed the most concern. I perceived City Official Foster, who had housing a family experiencing homelessness, as extremely concerned. Councilwoman Jaster, a volunteer of a Marinville HSO, was the only city official who saw the lack of acknowledgment of the unsheltered population an issue of city government, "I don't 
think [Marinville offers enough resources]. One thing I said is that we have a growing population and growing homeless populations. Maybe at one point, it was adequate, but now it's not."

Further, it seemed that city officials also had low contact with HSOs but high contact with the police. Councilwoman Mary Palser said, "We interact with homeless services very little. Once, the council was invited to the expansion of [a local shelter]. But we have a lot of interactions with the police. We interact with them on priorities, pensions, and managing crime." Councilwoman Palser's description about interacting with the police was further explained in an interview with City Official Justin Saral:

Well, the police are a function of the town itself. There is a considerable amount of interaction, at least on the department head basis. On a day-to-day interaction with the homeless, we probably wouldn't hear about that, unless it rose to our level. Then, it could be raised to the ordinance level. Something needs to be produced. On an administrative level, city manager runs the town. The Mayor is a policy-type body. We aren't involved in the day-to-day operations unless it comes to our attention. Or the city manager come to us and says, "We have a problem." Those are the kind of interactions we have.

City Official Saral described how since the police are a function of city government, the police had a lot more ease in contacting them. Additionally, if the police deemed something an issue, they could bring it up with policymaking bodies, such as city council, city manager, or the Mayor. Since HSOs are traditionally an advocacy entity, and the police, a crime management entity, city officials heard about the unsheltered population law-breaking more frequently than from their advocates. 
When city officials were asked if they were, "Aware of any prior homeless camp evictions in the city," they were either unaware or only knowledgeable of the highly publicized homeless camp eviction in the local newspaper. Responses included, "No, I'm just aware of that large eviction," "Yeah, that one on the border of [Marinville]," "Not specifically," and "Just that one, I have a vague recollection.” Although there are continual, small-scale encampment evictions in Marinville, it only rose to the level of city official knowledge when it was largescale and highly publicized. Even some city councilmembers who had encampments in their ward were not aware of their existence. Although there have been at least five homeless encampments evictions within two years and at least two encampments at any given time, city officials were not fully informed on what has happened.

\section{City Officials: Not in My Backyard}

The creation of anti-homeless ordinances may be due to not-in-my-backyard (NIMBY) syndrome. When I asked City Official Johanesburg about whether city officials are compassionate, she said, “Compassion, but plenty NIMBY.” As Dear (2007) and Law (2001) described, NIMBY syndrome influences city decisions, especially in terms of zoning and property management. City officials, specifically planners, have a high level of investment in the cityscape; they come to see the city itself (especially the downtown) as their "backyard." Therefore, city officials create laws to push the unsheltered population out of their "territory," but they rarely interact with the unsheltered population that the decisions impact. City Official Johanesburg said the zoning laws for the bus station were created to avoid, "homeless people come in and wrecking the bathroom." This statement shows City Official Johanesburg believed unsheltered individuals were more likely to deface public facilities than the public-at-large. She 
wanted to protect her "territory" from them. In this case, NIMBY syndrome, on grounds of preserving beauty and safety, was used as a justification for spatial exclusion of the unsheltered population.

Survey responses suggest that city officials were slightly more inclined to think homeless encampment evictions are ethical (see Appendix C: Chart 11). Almost fifty-three percent of city officials responded to the statement "Most of my coworkers believe homeless camp evictions are ethical” with "somewhat disagree," "agree," or "strongly agree.” About twenty-one percent of city officials "somewhat disagreed," "disagreed," or "strongly disagreed.” In contrast, thirty-one percent of HSWs "somewhat disagreed," "agreed," or "strongly agreed." For HSW, there were equal number of responses on either side of "neither agree nor disagree" while city official had more responses on the side of "agree." Responses from the police officer were highly variable, although slightly weighted towards "agree."

Moreover, although surveys suggest city officials may be slightly more inclined to see homeless encampment evictions as ethical, they may be least likely feel comfortable entering a homeless encampment (see Appendix C: Chart 7). Therefore, city officials may desire to see homeless encampments removed, but they do not desire to be the entity to removed them. City officials' comparative belief that evictions are ethical and discomfort could be due to their indirect relationship with the unsheltered population; lack of exposure or training. Generally, I believe exposure to and training generates comfort. In Marinville, neither were built into the structure of city official occupations. 


\section{City Officials: Denial \& Framing the Problem}

Although city officials seemed aware of how they controlled the outward appearance of Marinville, when asked directly if the city has anti-homeless ordinances, four of five said no. Responses included, "Not that I've heard of," "We don't, but we have rules in our parks about camping," "I should be familiar with [city code]. There is nothing in the zoning code that targets the homeless" and, "I have not worked on any policies that would affect the unsheltered population directly, [maybe] indirectly." One city official was aware of anti-homeless ordinances, and said, "We have some [anti-homeless ordinances], but certainly not antipanhandling." When I told this city official I overheard, on the police radio, a panhandler arrested within the city limits, she insisted it was illegal and did not happen.

Upon hearing this denial of the existence of anti-homeless ordinances, I became interested in whether city officials were genuinely unaware. After discussing with city officials, I learned lack of knowledge was the product of how city code was written. Councilwomen Palser said, "A lot of ordinances are reactionary. Usually not preventative." This was later confirmed by Marinville police. In Marinville, ordinances were usually created when a problem emerged and there were no legal grounds to address it. In addition, I was informed that many of these ordinances have been "on the books" for decades. Therefore, I felt city officials were genuinely unaware of city ordinances, including those that target the unsheltered population. These "legacy ordinances," such as anti-scavenging, may have been created in reaction to an unsheltered individual in public space, but then remained unknown or untouched in city code until it resurfaced during a complaint. In Marinville, city officials had no incentive to revisit legacy ordinances unless there was a problem. Even if city officials were aware, no city official has had 
the passion to prove anti-homeless ordinances unconstitutional, even the city official whose "single issue" was homelessness.

Although surveys suggest city officials may have comparatively less knowledge and regard for the unsheltered population compared to other occupations, their diplomatic means of communicating made this less evident. As Noy (2009) detailed, city politicians frame certain issues in ways that appeal to their intended audience. During interviews, I noticed city officials were knowledgeable of inclusive, or politically correct, means of communicating. Additionally, if they did not know an answer to a question (or desire to answer), they tended to circumvent the answer, rather than attempting to answer it. Generally, city officials seemed more careful about their responses. It is possible this careful speech offended fewer people and may have contributed to why the public initially elected them. The problem was, however, that "political framing" also enabled city officials to act on stigma in undetected ways.

Anti-homeless ordinances and lack of regard for the unsheltered population exists within almost all US cities. Nearly all cities have a code, elected officials, city council structure, indirect relations with the unsheltered population, reactionary law-making, legacy ordinances, and accountability to the public. Thus, almost all city officials retain social distance, competing priorities, and constraints of FOIA and the Open Meetings Act. Therefore, across the US, city officials are constrained by their occupations similarly.

Although data revealed most city officials did not vehemently target and expel the unsheltered population, as powerful decision-makers, their relative indifference compounded the problem. If city officials are not actively pursuing options to house the unsheltered population or reduce the burden of frequently flyer interaction, the problem will persist indefinitely. 


\section{Neoliberalism, Privatization, Classism, and the City Complaint System}

In order to piece together how the public uses the Marinville city complaint system, I selected a few days out of the public call record with an unusually large volume of calls about unsheltered individuals. With this dataset, I reconstructed interactions between the public, police officers, and unsheltered population for five days.

In the second week of September 2017 around 6:30a.m., the Marinville police department received one of the first calls of the day. The caller was downtown and said a person stole a few of their personal possessions. The caller claimed that this person is homeless. The dispatch officer coded this event as "theft" in the documentation narrative. At 10:15a.m., a few streets over, a different resident called the police department and said that there are "two homeless [who] have been staying and sleeping on their property for days." This time, the dispatch officer coded the event as "trespassing." At 2:30p.m., a third resident called the police department from one of the main highways expressing grievances about the unsheltered population in Marinville. The dispatcher officer categorized this call as a "PC" or public complaint. This officer wrote shorthand in the narrative "Out w the homeless." Shortly before 5:00p.m., the police department received a fourth phone call not too far from the public complaint that had occurred a few hours prior. This caller was concerned about the presence of a man experiencing homelessness. The dispatcher officer wrote in the narrative, "Caller believes that man is homeless and it is scary." A few minutes later, the same resident called back and said, "I don't feel safe going downtown anymore due to the ongoing homeless presence." This time, the dispatch officer documented this as "disorderly conduct." In total, this Marinville police department received six calls in twentyfour hours about Marinville's relatively small unsheltered population. Each time, the dispatch officer sent at least two patrol officers to the scene. 
Within the next three days, this police department received seven more calls about individuals experiencing homelessness. When I reviewed this call record, some of these calls seemed laughably insignificant and based in stigma. Other calls felt shockingly serious and were eye-opening. One call was about a resident "looking for someone in a homeless area." Although the nature of this call was unclear to me, it seemed that the caller wanted to notify the police they were entering a "homeless area" in case something bad happened, as if entering a "homeless area" put them at risk. In addition, the department received a call about a "suspicious person" and how he/she "look[ed] homeless." There was no further explanation as to why this person seemed suspicious other than the fact that they were homeless. Further, one caller notified the police department about an unsheltered individual's locations and whereabouts, "homeless left stuff this morning and was heading in direction of school-business." It seemed as though the caller wanted the police to know that an individual experiencing homelessness was moving towards these establishments, as if the individual was a threat to the establishments. There was one call about an individual's intoxication status, "drinking, possibly homeless", although an individual drinking inside a home is not illegal or notable. I was intrigued and perturbed by two calls about the clothing that individuals experiencing homelessness were wearing, " 3 homeless... wearing jeans," and "homeless subj wearing stocking cap." Disturbingly, during this time, a homeless man was assaulted and the call was coded as, "hemorrhage/laceration."

Marinville's public call record illuminates the experiences Marinville's unsheltered population has with law enforcement and the reasons that compel the public to call the police department. Prior to receiving this dataset, public servants told me members of the public called them to interact with the unsheltered population, but I did not fully grasp the extent. Ultimately, I found the group I expected to have the least amount of influence had the most. Initially, I viewed 
the public as a neutral body with little to no influence over the unsheltered population. I perceived the public as bystanders in the homeless encampment eviction cycle. I could not have been more incorrect.

Classism in Marinville is omnipresent. In Marinville, like most Western cities, socioeconomic status is a pervasive dividing factor. The public perceives the unsheltered population as poor and stigmatized them. In Marinville, I witnessed residents experience social repercussions for saying they felt uncomfortable around a person of color, immigrant, or person of a religious group, but they could express discomfort around an unsheltered individual without comment. In fact, classism is so entrenched in Marinville culture that I witnessed several socialjustice-oriented residents talk about equality, equity, and battling oppression in one sentence, and then refer to someone as a "bum" or tell me they feel unsafe around the unsheltered population the next. The unsheltered population is so marginalized, that their plight has not reached the consciousness of most residents.

In Marinville, privatization justifies classist regulation. A close friend of mine in Marinville said, "A business cannot kick someone out due to their race, ethnicity, language, or gender, without experiencing community backlash or fear of a lawsuit, but they can openly remove someone based on homelessness without repercussion.” This was the case when Sandy was removed from the coffee shop for staring at patrons and making them feel uncomfortable. In fact, the term "no shirt, no shoes, no service" may have originated in the 1900s when shoes were a sign of wealth, and shoelessness, poverty. The Civil Rights Act of 1964, banned discrimination on the basis of race, color, religion, sex or national origin, but did the act did not include socioeconomic status (US Constitution 1964). Therefore, if someone appears poor, they can be pushed away and "private property" is considered a valid justification. Classist civil rights 
omissions and privatization enable Marinville business owner to remove unsheltered individuals like Sandy. These omissions allow business owners to skirt legal repercussions for discrimination. Furthermore, the legal structure enables the public-at-large to expel and erase all that is not valuable to the Marinville economy. City Official Saral described members of the public who utilize privatization to meet their ends, "My experience is those that would complain about something like the encampment are those who take a hard line about property rights and advocate for the rule of law and strict enforcement." Once again, my research participants described the phenomena of using laws, like property rights, as a tool.

In Marinville, privatization is so all-encompassing that the unsheltered population is never free from the possibility of penalization. Although the privatization paradigm has existed since the formation of the US, the ideology intensified during the Reagan administration (Henig 1989-1990). During the Reagan administration, there was a push for neoliberal economic policies. As Frazzini (2015) described, the privatization ideology engenders privatization of private and public land. Privatization, in this conceptualization, does not mean private ownership. Low and Smith (2006) the state privatizes public land if it is "severe[ly] regulat[ed]" (148). In a way, public land is privatized because of "exclusion and limiting access" (148). If public land excludes certain groups, it is not truly open to the public. Therefore, in Marinville, the unsheltered population has nowhere to go. There are no geographic locations free from the potential of expulsion. I witnessed, in Marinville, that the unsheltered population could not escape public complaints and cyclical relocation. Marinville frequent flyers are perpetually "on the run", hopping from one privatized location to the next.

In a capitalist society, neoliberalism bolsters the privatization paradigm. Duneier (1999) shed light on this regarding the unsheltered population. He said, “...local social, political, and 
economic forces have deeply influenced lives... [and] the spatial distribution and redistribution of some members of the population... [is] unplanned result of particular forces that operate together..." (123). Like Duneier argued, unsheltered circumstances are not planned, but certainly not random. Generally, public servants do not sit down and decide how to arrange the unsheltered population in city-space, but neoliberalism consistently undergirds their decisionmaking. The ideology of neoliberalism protects the rights of businesses and free market economics over the rights of unsheltered individuals. At its core, neoliberalism is about deregulation, but ironically, in order to protect the economy, decision-makers must regulate individuals perceived as economic inhibitors.

Neoliberalism influences the way the public creates categories. The construction of unsheltered population in Marinville is produced and perpetuated by systems built around neoliberal ideology: a positive perception of the rich and stigma of the poor. Casino and Jocoy (2008) argued that the entire construction of the terms "homeless" and "chronically homeless" are product of neoliberal forces. By constructing unsheltered individuals as "incapable, lazy, deviant, parasitic, and diseased", it is easier to push them from public space and reinforce neoliberal concepts of "citizenship, productivity, and accountability" (192). Wacquant (2009) said neoliberalism is about defining and "managing the 'problem' categories", or the individuals that prevent the success of the free market (xix).

Neoliberalism teaches an anti-homeless bias. Only Marinville residents, who have taken the time to unlearn how they have been socialized, begin to perceive the unsheltered population outside the "problem" category. However, I found that most Marinville residents have not taken the time to unlearn stereotypes of the unsheltered population and/or spend time with them. In Marinville, business owners acted upon this anti-homeless bias. The public call record indicated 
the public regularly called police officers downtown to businesses or the library to remove individuals. Due to the privatization paradigm, if an unsheltered individual is on private property, all the property owner needs to do is complain to set the eviction process in motion. This was the case for Sandy who was removed a police officer from the Marinville coffee shop. The business owner issued a restraining order and, when it was violated, called the police. The police removed her for trespassing. The business owner did not need to consult the coffee shop patrons or survey Marinville public before making this decision. The business owner(s) did not need the momentum of the public-at-large to remove unsheltered individuals from public space.

Similarly, the public does not need the backing of business/property owners to initiate the eviction cycle. It is possible for members of the public to initiate the homeless encampment eviction cycle on others' property. Under chronic nuisance laws, if the public complains about the same individual three or more times the police or city can fine, arrest, or incarcerate them. Since some unsheltered individuals are called on (sometimes four times per day), chronic nuisance law can go into effect quickly. Yet, due to discretionary policing, the public does not need to trigger chronic nuisance to ask the police to tell an unsheltered individual to vacate. It is easy for the public to push away individuals they perceive as uncomfortable. For this reason, in Marinville, the public constantly called upon public servants to ask the unsheltered population to move, perpetuating the eviction cycle.

The Marinville city complaint system enables the public to demand punitive actions against the unsheltered population despite finite resources. As Lipsky (1980 [2010]) said, "streetlevel bureaucrats work in situations where the resources in most cases is not resolvable" (37). Nothing prevents members of the public from demanding public servants remove unsheltered individuals from public space, but lack of time and resources prevents public servants from 
finding compassionate, humane alternatives. In the Marinville regulatory system, the comfortlevel of complainers takes precedence over the availability of housing options.

In Marinville, it does not matter where the complaint originates. What matters is the complaint's alignment with neoliberal ideology. If the complaint is in the interest of the free market, there is a clear path for regulatory actions. The city complaint system the confidential vessel in which neoliberalism regulates the occupancy of public space.

\section{The Public: Internet Trolls, Repeat Callers, and that Guy at the Council Meeting}

In Marinville, there is a faction of passionate, prolific members of the public exceedingly involved in city affairs. For the purposes of this paper, I call them "vocal complainers". Vocal complainers are passionate, radicalized members of the public who often, have time to devote to public affairs because of retirement. After a few city meetings, I noticed familiar faces. These vocal complainers, I called, "Marijuana Guy" and "Roads Joe.” Both vocal complainers were extremely invested in their causes: legalization of marijuana and fixing potholes in Marinville roads. City Official Saral described vocal complainers as, "Citizens who frequently contact councilmembers... They might consider themselves opinion leaders, but for many of them I doubt the general public would agree." As City Official Saral said, vocal complainers do not necessarily represent the interests of the public-at-large.

Marinville vocal complainers, despite being loud and identifiable, fit Brekhus (1998) description of "unmarked" individuals. Most members of the Marinville public involved in city affairs appeared to fit a certain profile. I perceived the typical vocal complainer as older, affluent, educated, residents. Of the four vocal complainers I regularly observed, all were white and three were men. In Marinville, as Brekhus's described, these individuals were, “"politically unnoticed' 
and taken-for-granted elements of social reality" (34). Other than their publicized demands, vocal complainers go about their daily lives in Marinville without attracting attention. They embody dominant identities and therefore, are less subject to discrimination. Although relatively unnoticed, as Dahl (1974) described in his book, the privileged of a city, like vocal complainers, have more weight in decision-making. In Marinville, they use their privilege to discriminate against marked populations, such as the unsheltered population. As privileged individuals, they have more power and use it to push away people who do not look like them. Brekhus argued, these unmarked vocal complainers are "politically salient" and essential to study (34). Although I never witnessed a vocal complainer protest the unsheltered population in a city meeting, according to news articles, this has occurred in the past.

Vocal complainers certainly do not refrain from calling the Marinville police department. Officer Seigh shared data with me pertaining to calls about the homeless from January 2016 to April 2018. In the year 2017, there were at least 401 calls to one Marinville police department about individuals experiencing homelessness. Of the 401 calls, police officers recorded phone numbers for 298 calls (seventy-four percent). Within the 298, there were at least 220 distinct phone numbers. Thirty-seven of the 220 called more than once (seventeen percent), for an average of three times per year. Although many repeat callers called a moderate amount, several callers I assumed were infamous for Marinville police officers. In Marinville, seventeen percent of callers made up thirty-eight percent of calls about homelessness. Further, one percent of callers made up eight percent of these calls. This indicates persistence of a few vocal complainers in pressuring the police to address the problem.

Stigma is a primary reason for many calls to the police department. In Marinville, when a member of the public called the police station, a dispatch officer wrote a "narrative" that was 
passed onto the patrol officer. I reviewed these narratives to assess public reasoning. Most calls were not about violence. I determined that out of 401 calls, thirty-four were flagged for "potential violence" (eight percent) and thirty-five for "violence" (verbal and physical) (eight percent). Of the thirty-five calls, most were about inter-homeless fighting or a suicide attempt. Only six calls out of 401 were due to a person experiencing homelessness acting violently towards someone who was not homeless (one percent) (see Figure 4).

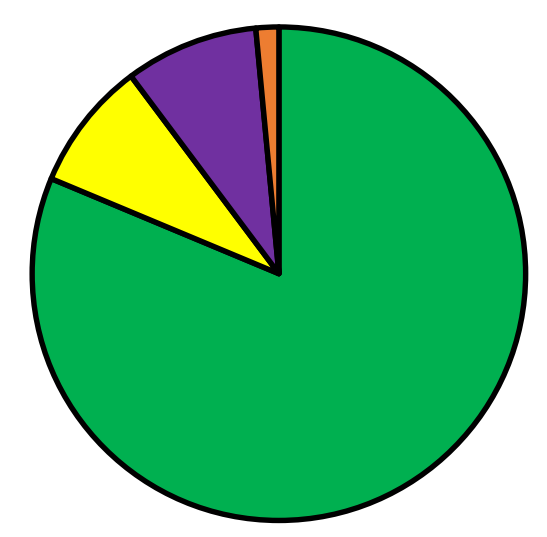

$\square$ Not About Violence

口Flagged as Potential for Violence

$\square$ Violence within Homeless Population (including self-harm)

口Violence by Individual Experiencing Homelessness Against Housed Individuals

Figure 4: Calls to Marinville Police About Homeless Population and Whether Reasons for Calling Pertained to Violence (01/2016-04/2018)

How the Marinville dispatch officers coded calls also illuminates reasons why the public called the Marinville police department (see Figure 5). Thirty-four calls were derived of the public's concern for individuals experiencing homeless (coded as "well-being check") (eight percent), yet the majority of calls were derived of fear, discomfort, or violation of hegemonic norms; 127 were coded as "disorderly conduct," forty-three "public complaint," thirty-five 
"relocation," thirty-four "trespassing," eighteen "suspicious person," and fourteen were “intoxication." In 2017, there were ten calls specifically about homeless encampments.

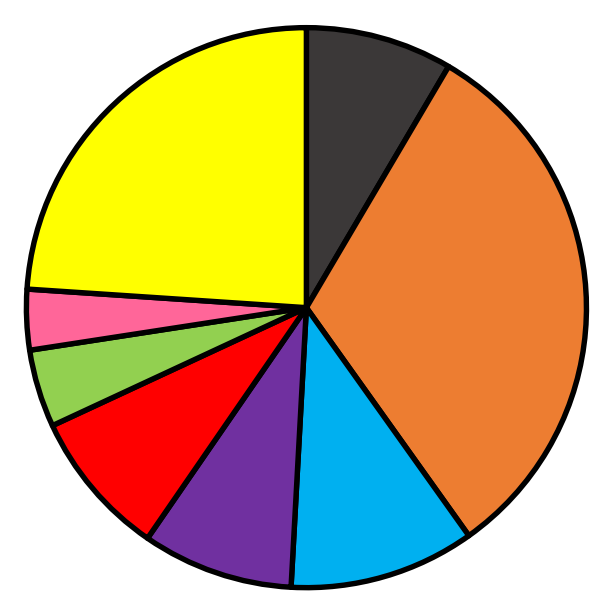

口Well-being Check aDisorderly Conduct $\square$ Public Complaint

口Relocation aTrespassing aSuspicious Person

口Intoxication $\quad$ OOther

Figure 5: How Marinville Dispatch Officers Coded Calls About Homeless Population (01/2016-04/2018)

In 2017, one vocal complainer called the police department thirteen times. Narratives for these calls included, "Homeless male leaning up against door of business," "2 homeless [women] near crossroads," "2 [male] and 1 [female] homeless," "[Ben] the homeless guy [with] guitar," and "Group of "homeless degenerates" The use of quotes around "homeless degenerates" indicates the dispatch officer wanted to show that the words were not theirs. It seems the dispatch officer desired a degree of separation from the ferocious persistence of this vocal complainer. To me, this vocal complainer seemed to call the police department about unsheltered individuals simply existing, as if their existence was a disturbance of the peace. Specifically, the 
vocal complainer's call about an unsheltered person owning a guitar shows they believed this observation was notable enough to call the police about.

In Marinville, vocal complainers put pressure on decision-makers. On several occasions, I witnessed them raise concerns and call for action at city meetings. Once, a vocal complainer verbally prodded the Mayor about city transparency. After the vocal complainer stumbled out of the meeting halfway through, the Mayor said, "[That] guy comes pretty regularly to meetings and public comments. He sues us regularly in attorney general's office.” Another time, I recorded an interaction between Roads Joe and the Mayor. On this particular day, Roads Joe said, "I hate to keep bringing this up, but... the streets. How is there money for everything else but the streets?" The Mayor seemed annoyed. He said, "No part of the budget has increased as much as the streets." Roads Joe continued sarcastically, "Welcome to Marinville, home of the pothole and crooked politicians." Then, he brought up having the City Hall open more frequently. Mayor said, "That would be nice, but I would have to raise taxes and you also don't want that." Roads Joe put pressure on the Mayor by repeatedly bringing up inaction and mocking city officials in a public fashion.

In Marinville, at least one vocal complainer was able to gain legitimate authority. During my fieldwork, I was shocked to find out Roads Joe is a city councilmember. He had effectively transitioned from a vocal complainer to a city official. During a city meeting, the Mayor jokingly told a story about how Roads Joe "just started showing up to city meetings and never left." Whether beneficial or counterproductive, radicalized members of the public like Roads Joe have been elected, magnifying their voice, while other residents did not have the time, energy, “political salience," and/or knowledge to pressure city officials. 
I also found the public did not just speak their mind in city meetings but also online. A woman who proclaimed herself "The Guardian" regularly filed under FOIA for more information about internal workings of the Marinville. After gaining FOIA information, The Guardian went to her popular, right-wing blog and defamed the use of city taxpayer dollars. One city official told me it takes hundreds of hours per year to fulfill The Guardian's requests. Upon looking into her blog, The Guardian (named after her own self-proclaimed title), I found an article from 2014 titled, "Welfare City." It started off like this:

Collecting money from government has turned millions of people into government slaves. Government is NOT being compassionate, they did it on purpose. The population must look to government to solve their problems or government is unnecessary. What better way to establish job security than having peons beg at your feet just to survive. It used to be a way of life for a small portion of society, but not anymore.

This type of news, although radical, had many followers. Each article had multiple comments. This was about the same number of comments as the mainstream, local newspaper. Due to the blog's popularity, almost all Marinville city officials anticipated the next post in The Guardian and how it would affect them.

Members of the public also use online news forums to put pressure on public servants. City Official Saral described online commenters, "Just as there are individuals who frequently contact councilmembers directly via email and phone, there are those who frequent blogs or comment spaces, creating communities of those who think alike or sound off." In the local, online newspaper, residents commented underneath articles with the guise of usernames. Across two years of news, I documented ninety-six online commenters on eleven articles related to the 
unsheltered population in Marinville. Most of the commenters only weighed in on one article, but there were five individuals that commented on more than three. These commenters had strong viewpoints on the subject matter. For the purposes of this project, I call them "serial commenters," although the folk term I heard in Marinville was "internet trolls." Serial commenters and The Guardian were powerful players in Marinville because they knew how to use technology to influence city affairs. In some ways, serial commenters were the online version of the vocal complainers I observed in city meetings.

Serial commenters often expressed inordinately stigmatized perception of the unsheltered population. In news articles, four of five (eighty percent) serial commenters expressed language and ideas that indicated stigma towards the unsheltered population, while forty-four of ninety-six (forty-six percent) of all users expressed indicators of stigma. Notable comments from different serial commenters included:

No healthy-minded person is homeless for very long. You work multiple jobs if you have to.

How about just try looking for a job?...lol...just sayin'...lol... I think we should give them a free college education, no-cost cars, free homes, free money for food and beer. I think we should give them a clothing allowance, we need to build bridges and bring more freeloaders over I have a couple dollars left...lol.....lol.

I have, [another commenter], and when a guy says he wants a sandwich I buy a sandwich. When a guy says it is none of my business, I go about my way. If 
you are just giving them money you are part of the issue. That is called enabling....

Ok reality check! $98 \%$ of homeless love being homeless! They don't want to put any of their social security checks towards keeping a roof over their heads. They don't want rent, electric bills. Those people that stand at the end of interstate ramps, Wal-Mart entrances and the like rake in hundreds of dollars daily! They do not want a place to live. If you bleeding hearts want to help someone then HELP SENIORS AND THE DISABLED! And when I say disabled, I mean those in wheelchairs! Do you know how hard it is for these kinds of people to find sufficient housing? It is a joke! Then you have those people who stand in the middle of lanes collecting money and not only do they collect a check but they panhandle and rake in hundreds of dollars per day. They make a better living doing that than a paycheck and this money is taxfree! They take advantage of good-hearted people. This is seriously stealing by deception!... You have something worse wrong with you for doing this than the homeless drunk you wanted to get a push away! Remember, what goes around comes around! And it will, it always does! So, when something negative happens to you, don't cry in your oats and scream "why is this happening to me"?

Additionally, there were users who commented so frequently on an article they became notorious. One such user called himself "Idealist," although it turned out his version of the "ideal" Marinville was opposite of mine. In the news article covering the situation when the 
business owner destroyed an unsheltered man's bedding, Idealist commented eleven times, sparking heated debate. Several other commenters told Idealist he was being insensitive. $\mathrm{He}$ responded defensively:

So, are we now to be tricked into the ridiculous theory that hobos are the newest members of the "protected class?" People CHOOSE to be homeless and if this man has been looking for employment for a year, he obviously cannot read or is not looking very hard. There are numerous businesses in the [Marinville] who have perpetual now hiring signs. If this man really wanted employment he would have applied for one while using the restrooms of these restaurants. Disabled people are seldom disabled by choice. The race of a person is a matter of birth and not by choice. However, when it comes to homelessness and sexual preference; these are conscious choices people make every day. Life choices should not be confused with legitimate disadvantages that many Americans face daily that are NOT of their choosing. The victims, in this case, are the property owners who pay their taxes, open their businesses every day in the hopes of providing a livelihood for their families. Why should they be burdened with having to tolerate the irresponsible choices of someone who CHOOSES to be a homeless drunk?.. Does it not seem strange to you that the newspaper just happened to be in the neighborhood to interview this bum the EXACT time it was discovered that his belongings were destroyed? Come on now, just what are the odds of that happening in the middle of downtown in [Marinville]? One other thing is who is that is pointing the finger and making the threat of discrimination????? 
Serial commenters, FOIA-filers, bloggers, and vocal complainers may seem like a passionate, harmless faction of the public, but they are powerful. Alone, their well-publicized verbal and written complaints make an impact. On top of that, if they are passionate enough to write lengthy news article comments, blog posts, of FOIA paperwork, they are likely to shift that energy to utilizing formal city processes for complaints. If desired, their energy can be utilized to initiate the homeless encampment eviction cycle and remove an unsheltered individual from space.

This study evidences how the stigma of the unsheltered population is imbued in the city, the police, and HSO occupations, but also the public-at-large. I argue that the primary starting point for targeted action is not derived from these occupations, but rather the public: internet trolls, repeat callers, and that guy at the council meeting.

\section{Obligation: Public Servanthood as an Enabling Mechanism}

Since the anti-homeless bias is widespread in the public, obligation to the public is problematic. Officer Benson gave me an example of how obligation can be problematic. During a ride-along, he described the how the public constantly called him downtown to address Jacob. Officer Benson seemed annoyed. He vented, “I can’t do anything about it. [Jacob] isn't doing anything wrong. It's a waste of my time." I asked if he must go check on Jacob even though he knows he is harmless, and he replied, "Yeah, I'm obligated." Officer Benson's statement encapsulates the problem with public servanthood.

Maintaining "public servanthood" means working with and responding to the demands of the public-at-large. Police officers and city officials have an obligation to the public-at-large while HSWs are only obligated to their client base (see Figure 6). Although public servanthood 
is generally regarded with nationalist revelry, it has dramatic, and largely unspoken, implications for the unsheltered population. In the following sections, I detail how the election of public servants is classed and the power of obligation in spurning public servants to erase the unsheltered population. Then, I discuss how public servants are criticized for classist actions, although actions are usually proposed and pressed by the public.

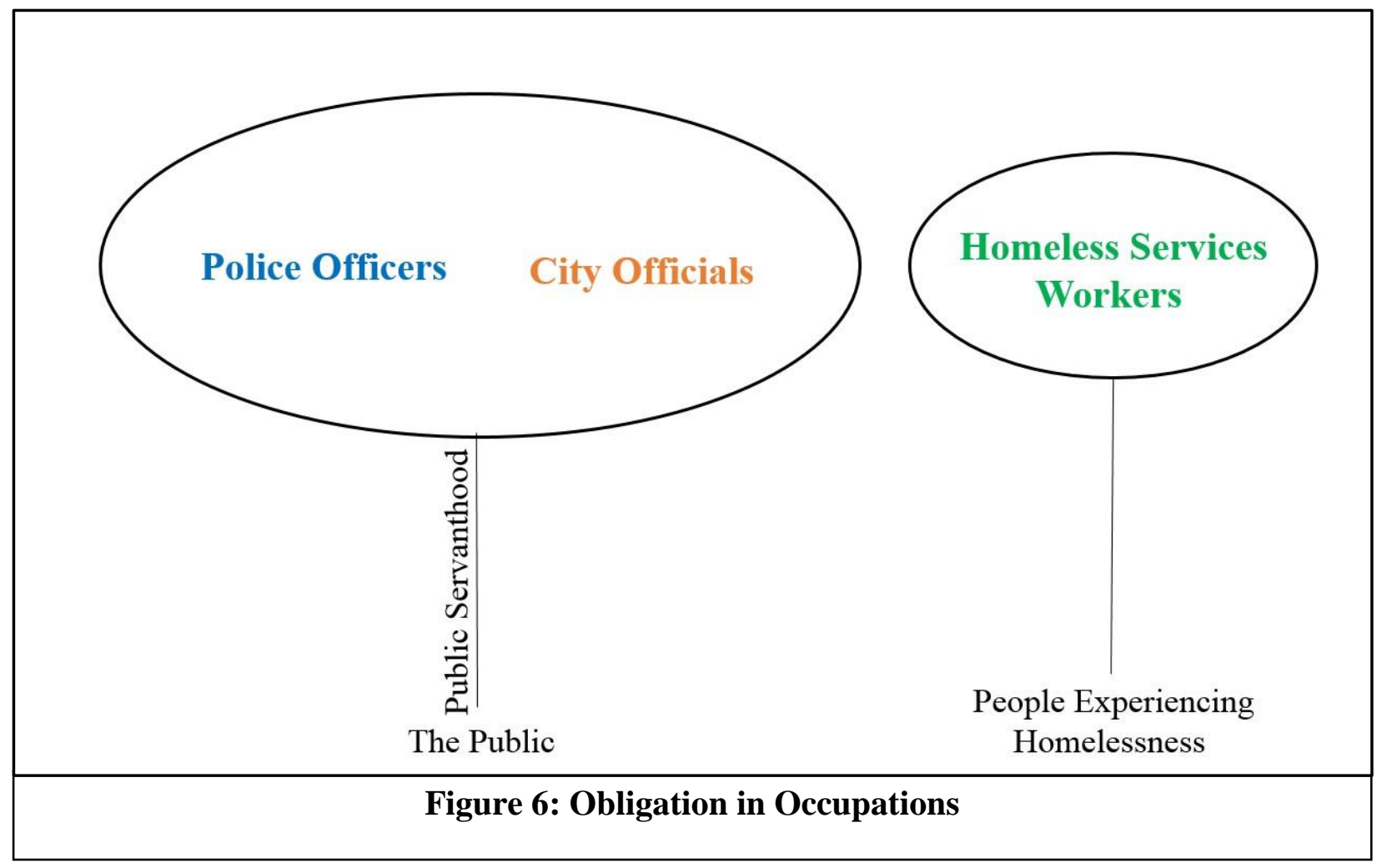

Firstly, it is important to acknowledge how the election process can empower discriminatory politicians. In an ideal, democratic system, constituents use their votes to support those with similar interests. In theory, elected officials represent their constituents. Dahl (1974) explained that democracy does not mean equal representation—especially, for the unsheltered population. If the public has classist views, they will not resist the empowerment of a similarly 
classist politician (this can be seen in the election of Donald Trump). On a smaller scale, if the public stigmatizes the unsheltered population, they can vote for an official who does as well. The average member of the public would have no qualms voting in a Mayor or councilmember who plans to push unsheltered individuals from space to "improve the downtown" under the guise of beautification or safety.

Additionally, some sectors of the public have less voter turnout, and therefore elected officials do not represent their interests. A study from Krauss (2015) at the Institute for Research on Labor and Employment revealed that individuals perceived as lower class are less likely to be politically active (voting and running for office). Thus, elected officials tend to represent the platforms of the upper and middle-class. For these reasons, elected officials tend to represent the most privileged citizens. Although I never asked Marinville city officials or police officers about their upbringing or income, it is likely most City officials in Marinville were raised in affluent families. Therefore, they cannot fully understand the experiences of unsheltered individuals.

Despite finding stigma amongst all occupations studied, surveys suggest that many public servants and HSWs believed their coworkers are compassionate towards the unsheltered population (see Appendix C: Chart 4). As one city official interviewee said, "Most people, yes, [they are compassionate]. Probably not all." In surveys, when pressed with the statement, "Most of my coworkers are compassionate towards the unsheltered homeless" just short of fourteen percent of police officers and less than six percent of city officials said their coworkers “somewhat disagree," "disagree," or "strongly disagree." Zero HSWs "disagreed" that their coworkers were compassionate. Almost all responses, regardless of occupations or group responded between "agree" and "strongly agree." 
Further, my survey suggests the majority of survey respondents felt their coworkers "might or might not" want to evict homeless camps in public space (see Appendix C: Chart 12). Police officer and city officials responses were slightly skewed towards "probably yes" and "definitely yes" and HSWs were skewed towards "probably not" and "definitely not." In order to understand if police officers, city officials, and HSWs actually would act upon such desires to evict homeless encampments, my survey included the statement, "If they had the power, most of my coworkers would remove homeless camps from public space" (see Appendix C: Chart 13). Compared to the question pertaining to desire, responses to this statement were slightly more affirmative. Forty-seven percent of all respondents said their coworkers "probably" or "definitely" would remove homeless encampments, while just over thirty-eight percent said their coworkers would "probably" or "definitely" want to. Like the question pertaining to desire, police officers and city officials were more likely to respond with a "yes" and HSW were more likely to respond with a "no." The slight change in the phrasing of these statements and variation in responses indicates that not all public servants wanted to evict homeless encampments, but if they were in a position of power some would. This signifies that there may be some sort of pressure causing public servants to act.

Even if, when elected, public servants desire to serve the unsheltered population, they quickly realize their obligations to the public-at-large trumps their obligation to the unsheltered population. I observed there was a disconnect between who public servants anticipated serving and who they actually served. City officials and police officers expressed they entered their occupation due to the desire to help. Officer Larkens said, "As lame as it is, [I entered the policing occupation because] I really wanted to help. I want to be there for people- the light in the darkness." Public servants told me they wanted to improve quality of life for the public, 
especially residents in need. Although at times, public servants served the city's marginalized population, generally they served vocal complainers: Marinville internet trolls, repeat callers, regular city meeting attendees. Public servanthood is problematic because people like Idealist, Marijuana Guy, and The Guardian indirectly controlled an unsheltered individual's use of public space. Involved, demanding, and passionate members of the public know how to work the system to get want they want—even if it is discriminatory.

In this study, I encountered occupational stigma towards the unsheltered population, but I realized this is not the main problem; the most pertinent issue is that the structure of powerful occupations allows problematic requests from the public to become reality. The Marinville regulatory system allows the public to use city officials and police officers as tools to carry out the requests the public has no legitimate authority to enact. Public servants, in a sense, are puppets to carry out the wishes of vocal, radical residents.

The city and the police are not just encouraged but obligated to serve wealthy residents like Idealist, Marijuana Guy, and The Guardian. In the past, Marinville residents had sued the city and its employees. Even though it is relatively difficult to file litigation against a government entity, it is possible. One of the most successful ways to sue a government is negligence. The threat of employment termination and lawsuit cumulatively pressures public servants to respond to complaints. Officer Smith explained how the police formalized this pressure. He told me, he is obligated to follow up on public calls and the only way to "get out of it" is if the Chief of Police or Sergeant "clears it." He told me the only way to ignore a request, is if he receives a direct order from his supervisor to disobey the public. Police officers told me they felt like they did not have a choice when dispatched. At one point during a ride-along, I asked an Officer Smith why he carried out an order that he was convinced was unnecessary. He said, "There was a call" as if 
this premise was not up for questioning. Although police officers have discretion, they do not have the power to choose where they are dispatched. Additionally, they have little ability to decide who they are dispatched to address. When dispatched, they do not have the power to decide if to address someone, only how. The power of "if" rests with the public.

Public servants are trapped in a violent system of reciprocity. Members of the public elect public servants. Then, in exchange, the public expects public servants to carry out their wishes. Marcel Mauss (1954) wrote how this moral obligation permeates modern society. He said, "The unreciprocated gift still makes the person who has accepted it inferior..." (83). When the public elects a public servant, they were "gifting" a job, but this gift makes the public servant "inferior," or obligated; flipping the power dynamic. As Mauss explained, this system forges strong social relationships, but the system of indebtedness is problematic for marginalized residents. In this case, the unsheltered population felt the harshest repercussions. In Marinville, members of the public use their "superiority" to elect or impeach public servants as means to demand action against the unsheltered population.

Interviewees confirmed the powerful role the public-at-large played in city processes. Although one outlier downplayed the role of the public, “[The public] probably doesn't know [the unsheltered population] exists. The unsheltered are isolated. Most people are unaware." Two interviewees (HSWs and city officials) reaffirmed the power the public has:

I can see [the role of the public]. I see churches and businesses in downtown Marinville that are frustrated about these people. It ostracizes [the unsheltered population]. I see what you are saying absolutely. Especially, with businesses. 
[The public] plays a huge role. They don't dive into the issues and figure out how to stretch selves. They don't want the homeless around when they are shopping, but they don't have the same energy or passion to come to solutions. I am a spiritual person and God says the homeless will always be with you, but it doesn't mean we shouldn't care for them. People do things because it looks good socially.

These participants described the unwillingness of the public to deal with root causes of the unsheltered homelessness, but willingness to ask others to do so. In this study, I observed members of the public such as Idealist, Marijuana Guy, and The Guardian, were exceedingly active in pressuring politicians to act, but disturbingly passive in solving issues themselves.

When city officials take action on a request from the public, they are subject to backlash. City Official Foster, one of my final interviewees, summed up the phenomena of stigma, power, and the obligation of public servanthood:

The public in a town like this... they see something different and it scares them. Here's an example: There are two African American kids out at 2:00a.m.

Someone calls upon the police, police have obligation to respond. [The kids are contacted.] How do the kids feel now? If it was two white kids, would the public respond the same way? Probably not. It's the same with the homelesspeople and the public feeling uncomfortable.

In Marinville, the structure of the city complaint system enables the discrimination such as in the above hypothetical situation. City Official Foster showed how, in this situation, the police would be criticized for discrimination derived from the public. This phenomenon can be applied beyond race and with the unsheltered population. Like most of the public, I realized I 
have displaced the blame for similar scenarios. When the Marinville business owners complained and incited the police to remove Sandy from the coffee shop, I directed my anger at Officer Damien who removed her, not the business owner who requested to have her removed. Criticism of public servants is especially rampant on the internet. In Marinville, while members of the public skated by without criticism, public servants were openly criticized in new article comments (see Figure 7). I determined public perceptions of city officials, police officers, HSWs and each other by analyzing comments from Marinville's most popular news source. I counted each news article comment separately and categorized it as "positive," "negative," or "victimizing" toward the public, HSWs, the police, the city, and unsheltered individuals. The below graph displays the number of times each group was spoken about positively or negatively. I analyzed almost 200 comments and 113 fit into the categories displayed in Figure 7. Based on what I had observed in Marinville, it did not surprise me to find that the unsheltered population was criticized most frequently (forty-five times). The group most criticized after the unsheltered population was city employees (twenty) followed by HSWs (eleven) and then police (nine). The public (not including in fighting on the news articles) was only spoken of negatively four times. The structure of public servanthood simultaneously obligates public servants to push unsheltered individuals for public space, but also endure outcry from another faction of the public; homeless advocates. 


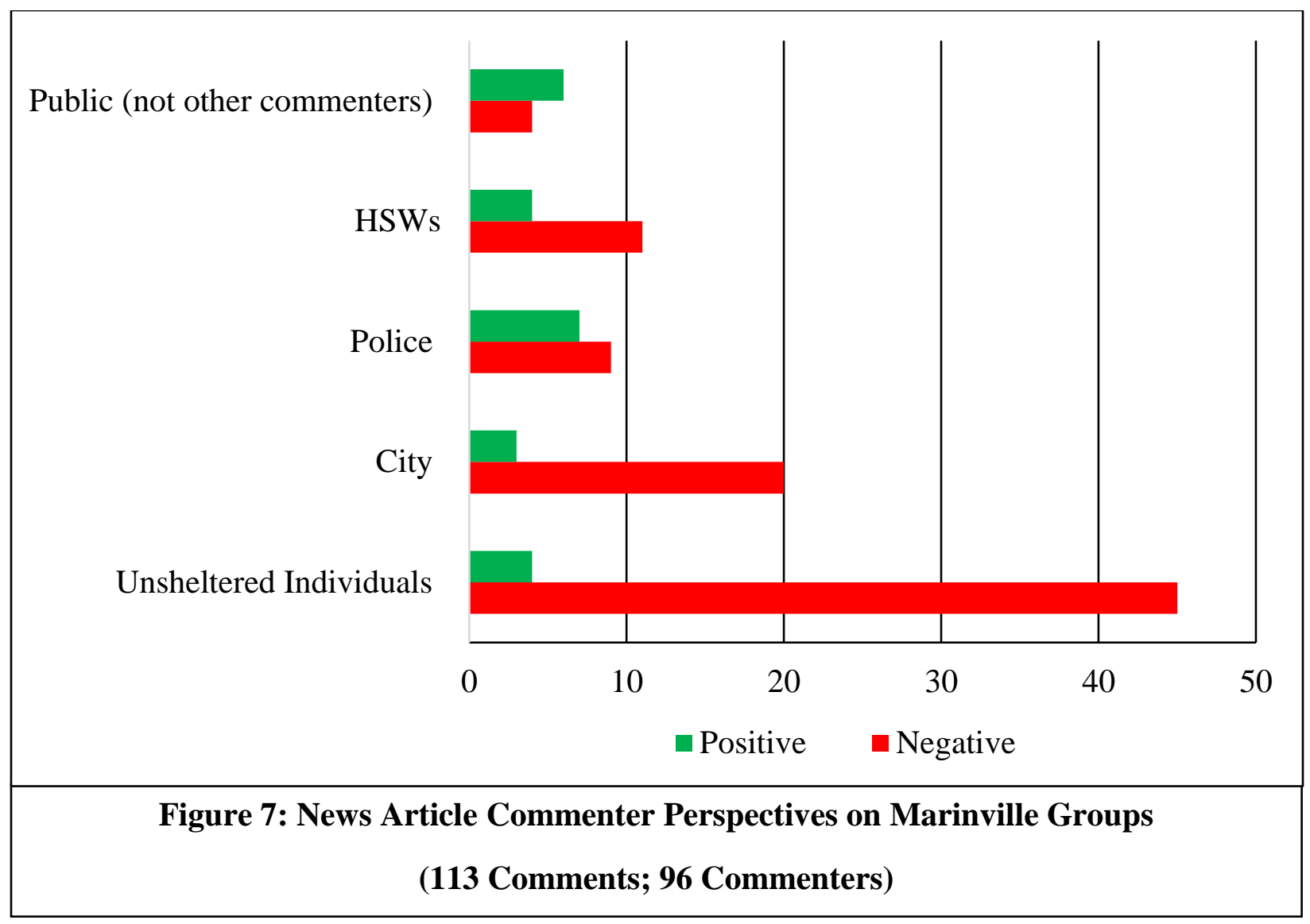

The heightened criticism of public servants may be due to the confidentiality that protects individuals who utilize the formal city complaint system. In Marinville, the public call record was not readily available to the public, so the requests enlaced in stigma were not visible. Contrastingly, due to transparency, the actions of city officials and police officers were on record. All city meetings of three or more individuals had a note-taker who posted meeting minute to the city website. All officers I observed told me they are required to wear body cameras. Therefore, a request to remove an unsheltered individual from public space is confidential but the actions that result are public.

In an interview, City Official Foster expressed his exasperation with the public: 
There is a line around here, "The public is scary." A friend of mine always jokes, 'local government is a great job if it weren't for the citizens.' People seem willing to call the police. The police provide very good service. They are responsive but feel an obligation.

Public servants in the City of Marinville are placed in a dilemma. They want to help the public but as Officer Libold said, "Feel trapped by the public." They want to abide by their personal ethics but also desire re-election. Blatant disregard of public requests means losing job security. One police officer survey respondent spelled out the dilemma brought on by public requests, "Even though most of us want to eliminate the camps, we want [unsheltered individuals] to find housing. The reason we want the camps eliminated is because the public calls us on them ALL THE TIME!" Public servants feel pressure to please members of the public who "call on them all the time." Public servants are "strained" (Agnew 1992) and stretched in opposite directions.

The Marinville regulatory system is problematic because adhering to discriminatory public demands is rationale. Becker (1993) argued that "Individuals maximize welfare as they conceive it." Further, he said, "Their behavior is forward-looking...In particular, [individuals] try as best they can to anticipate the uncertain consequences of their actions" (3). As "forwardlooking" individuals, Marinville police address unsheltered individuals because ignoring the dispatcher could be perceived as insubordinate. This could be grounds for termination. Additionally, as Becker said, "While goods and services have expanded enormously in rich countries, the total time available to consume has not." When Marinville police contacted unsheltered individuals, some officers took them to jail because pursuing other options was difficult and time-consuming. HSO resources are available in Marinville, but police officer time 
is finite. For public servants, there is an opportunity cost to devoting time to frequent flyers. Vocal complainers have more political power than unsheltered individuals, so following requests from vocal complainers may not be ethical, but is most logical. In Marinville, the most rational way for public servants to maintain job security is to obey vocal complainers and dispossess unsheltered individuals.

\section{Who Really is "The Public"?}

In Marinville, the unsheltered population is left out of the notion of "the public" due to marginalization, uneven distribution of resources, and the structure of the city complaint system. Many unsheltered individuals are pushed out of the public eye. Others, like Barry, decide to exist in the geographic and social periphery to avoid harassment. Due to past experiences, unsheltered individuals are less likely to call the police department or write an online complaint due to fear. I believe it is more likely that Marijuana Guy and The Guardian will show up at Marinville City Hall and voice their opinions than an unsheltered individual who is trying to exist unnoticed.

Even when unsheltered individuals attempt to be heard, many lack communication devices to do so; a computer or cell phone. This is especially true for frequent flyers. For the unsheltered population, the system of political involvement itself is a barrier.

For the above reasons, in Marinville, the unsheltered population is not the first group public servants thought of when picturing "the public." Over email, I asked City Official Johanesburg who comes to mind when she thinks of "the public." She replied saying, Like most people, when I think of "the public" I tend to think of people like myself initially - white, nuclear family, heterosexual, upper middle class. However, I am pretty good about taking a second to think about what "the 
public" really means and broaden my thinking to as many types of people that I can think of.

Initially, City Official Johanesburg described qualities of Brekhus's (1998) unmarked population; "white," "nuclear family," "heterosexual," and, "upper middle class." Although Johanesburg described making a concerted effort to broaden her mental model of "the public" to include marked individuals, the reality was that, in Marinville, the unsheltered population is an after-thought; a population only considered when city officials channel a palpable mental effort. As Feldman (2004) laid out, unsheltered homelessness is not just a product of inadequate distribution, but also lack of recognition.

City Official Johanesburg described how her idea of "the public" included vocal complainers depending on the situation,

When I'm going into a public hearing and think "the public," I typically go to the potential negative version of "the public" - the person who may provide really negative and off-topic criticism of government overall.

In Marinville, public servants, like Johanesburg, are more likely to picture vocal complainers as "the public" than the city's marginalized individuals. Police officers and city officials come to think of "the public" as their domineering constituents; radicals who attend city meetings, call the city or police department, and file complaints and FOIAs. Public servants see "the public" as the affluent, white vocal complainers they frequently hear from and answer to. They first think of individuals who align with Marinville's hegemonic norms. This means in times of hasty decision-making, public servants are more likely to make decisions based on vocal complainers than the unsheltered population. 
The social construction of "the public" is largely connected to the construction of "citizenship." Feldman (2004) said individuals who live outside are not afforded some rights of citizenship and thus, face exclusion from the political realm. Like Feldman, Smith (1997) said that "through most of US history, lawmakers pervasively and unapologetically structured US citizenship in terms of illiberal and undemocratic racial, ethnic, and gender hierarchies for reasons rooted in basic, enduring imperatives of political life" (1). He then goes onto explain how citizenship was initially interconnected with property rights. In 1776, the state only extended US citizenship to white men who owned property. Advocates of this definition said owning property means "responsibility on financial issues" and "economic self-sufficiency" (100). Over time, the definition of US citizenship changed allowing women and racial minorities to own property and thus, consider themselves citizens. In modern times, the definition of citizenship remains structured around owning property. That the state functions to protect private property, not necessarily individuals. Since many unsheltered individuals do not own property, they are in some respects, not seen as US citizens. Wacquant (2009) goes as far to say, "The legal construction of homelessness as bare life abridges his or her rights and effectively reduces him to a noncitizen and facilitates criminal proceedings" (xxii). Wacquant (2009) continued, "The state no longer cares to treat at its roots and the prison operates as a judicial garbage disposal into which the human refuse of the market society are thrown" (xxii). If an individual does not own property, they are seen as a hindrance or "refuse of the market society." Thus, the state excludes the unsheltered population from some rights of citizenship.

Most notably, the unsheltered population is not protected under the fourth amendment: The right of the people to be secure in their persons, houses, papers, and effects, against unreasonable searches and seizures, shall not be violated, and 
no Warrants shall issue, but upon probable cause, supported by Oath or affirmation, and particularly describing the place to be searched, and the persons or things to be seized (Bill of Rights Institute 2018).

The state does not consider unsheltered individual's residences as their "houses" or property, because they do not own the land they reside on. Therefore, police officers do not need a search warrant to enter or seize an unsheltered person's tent. In rare cases, this has been deputed, but it has rarely been overturned (Schultz 1992). Through exclusion from the Civil Rights Act of 1964, unsheltered individuals are not a protected class (as discussed earlier). While most Marinville residents can exist unbothered in public space or businesses, visibly unsheltered people are subject to penal action.

The ironic part of political and civil rights exclusion of the unsheltered population is that they have the most to gain from political participation. As a vulnerable population, most unsheltered individuals need a robust social safety net. However, I found in Marinville, public servants to do not serve their most vulnerable constituents, only individuals with enough resources and social leverage to vote, complain, the pressure politicians.

Marinville, like most cities, employs a utilitarian approach to decision-making. Over email, City Official Johanesburg described how the City of Marinville made decisions based on “...long-term best interest of the larger community." In other words, the greatest good for the greatest amount of people. I argue that this is problematic. Since Marinville is comprised of predominantly white, middle class, educated residents, making decisions based on the "larger community" means making decisions based on maintaining hegemonic norms; maintaining what is comfortable for most residents. Johanesburg described how Marinville city officials tried to avoid being "derailed by a few lone, super-negative voices." Although this strategy may be 
beneficial for ignoring radical requests from vocal complainers, it also means ignoring requests from the small group of unsheltered individuals and/or homeless advocates for the sake of the "larger community." Since I observed in Marinville, the larger community preferred to ignore homelessness and the systems that caused it, basing decisions on what the larger community wants means enabling homeless erasure and perpetuating the problem.

The false dichotomy between the public and the unsheltered population is destructive. In Marinville, the obligations of public servanthood only extended to members of the sheltered public with enough power and resources to be heard. If city officials and the police officers improve quality of life... improve it for who? If public servants desire to keep the city safe... safe for who?

\section{Frequent Flyers: Cost of Interactions}

In Marinville, frequent flyers were the group the public called City Hall and the police station about the most. Officer Seigh provided me a public call record from a Marinville police department. The dataset showed the public called the police about one frequent flyer at least 127 times in one year. Even this amount may be underestimated. Officer Seigh expressed, the dataset "severely under count[s] the actual scope of the problem." This is especially true considering Marinville has more than one police department.

In Marinville, police officers confirmed there are at least four frequent flyers at any time. The three frequent flyers I studied had been in and out of the county jail. All three were incarcerated over twenty-four times in the last seven years. Almost all their offenses were classified as misdemeanors or ordinance violations, rather than felonies. 
In Marinville, frequent flyers are well known by police officers. During ride-alongs, whenever I brought up a frequent flyer's name, there was an immediate wave of recognition that went across the officers' face. This was typically followed by lengthy stories. On one of my last ride-alongs, I asked Officer Mayweather if he knows specific unsheltered individuals well. He laughed and said, “Absolutely. I know everything. Their addictions, family members, criminal record. Everything." He went on to tell me, in detail, the story one female frequent flyer. He told me how she became homeless, what her family was like, her mental health diagnosis, interactions with officers, and prior offenses. On a whim, I asked, "How often do you interact with her?" He laughed but seemed worn-out, "Sometimes four times per day."

At first, this level of frequent flyer-police interaction seemed difficult to believe. I emailed all the Marinville police departments to see how much time they spend addressing frequent flyers. Each Marinville department provided officer time estimates. I found steep, but slightly lower totals than Officer Mayweather's estimate. One department said their officers interact with one frequent flyer almost seventy hours per year. Officer Mendez stated, "I do believe that these [numbers] are severely under-reported." Officer Turk at another department estimated police officers interact with frequent flyers twice per week, for a total of three interactions (one to two and a half hours each). He estimated one of three interactions results in an arrest. He noted, "Keep in mind, most of these "arrest" situations are for criminal trespass to property, which is a very minor crime."

I decided to calculate the total cost of frequent flyers to Marinville taxpayers. In Marinville, based on geographic location of an unsheltered individual, there was typically a "primary" police department. The primary department interacts with that individual most, but all departments may interact with the same individual. I translated this into my calculation. I call the 
primary department "Police Department 1." I estimate the Police Department 1 would address an unsheltered individual three times more than the others. Therefore, Police Departments 2 and 3 would accrue one-third each of the costs of Police Department 1. When asked, all Marinville police departments provided me their employee salary information to help with my calculations, so I was able to calculate the total cost of frequent flyers to the Marinville police departments for one year: $\$ 5,886$.

Marinville also has an array of HSOs. Two of these HSOs targets the unsheltered population and three focus on the sheltered homeless. For the purposes of calculation, I call the two organizations that focus on the unsheltered homeless "Homeless Services 1" and "Homeless Services 2." Homeless Services 1 and 2 reported spending about $\$ 400$ each per frequent flyer per year. The three HSO that focus on the sheltered homeless still offer food and shelter for the unsheltered population on cold nights, but their financial contribution is comparatively less. For this reason, I calculated the three other HSOs spend one-third of the amount that Homeless Services 1 or 2 spend. I estimate each of the other HSOs spends $\$ 133.33$ each per frequent flyer. In full, the cost of homeless services for one frequent flyer was $\$ 1,200$ per person per year.

Moreover, frequent flyers generate huge medical expenses. Multiple times, police officers told me that they take individuals experiencing homelessness to the hospital to detox if they were publicly intoxicated. The emergency room is another drop-off option on cold nights when the emergency shelters are full. To quantify this cost, I requested the Marinville hospital pull data on average charges for frequent flyers. Since the hospital sorted data via home address, they used the address of the local homeless shelter to generate averages. This was an imperfect measure for frequent flyers but can be used to estimate the yearly cost of medical expenses: $\$ 4,022.05$. This is an expense that is usually unpaid. 
Lastly, there is a cost to housing the unsheltered population in jail. By using county-level jail data, I calculated the number of nights frequent flyers spent in jail on average per year. I obtained jail data for three frequent flyers who had been in Marinville for seven years; I found each frequent flyer spent an average of forty-five nights in jail per year, approximately twelve percent of their year. Of the three frequent flyers, two individuals had not committed a violent offense within the last seven years. However, one frequent flyer was incarcerated thirty-one percent of their jail time for violent offenses (see Figure 8). A professor who frequently works with county-level jail data told me it costs forty dollars per night to house an individual in jail. Therefore, the cost of incarceration was $\$ 1,800$ per frequent flyer per year.

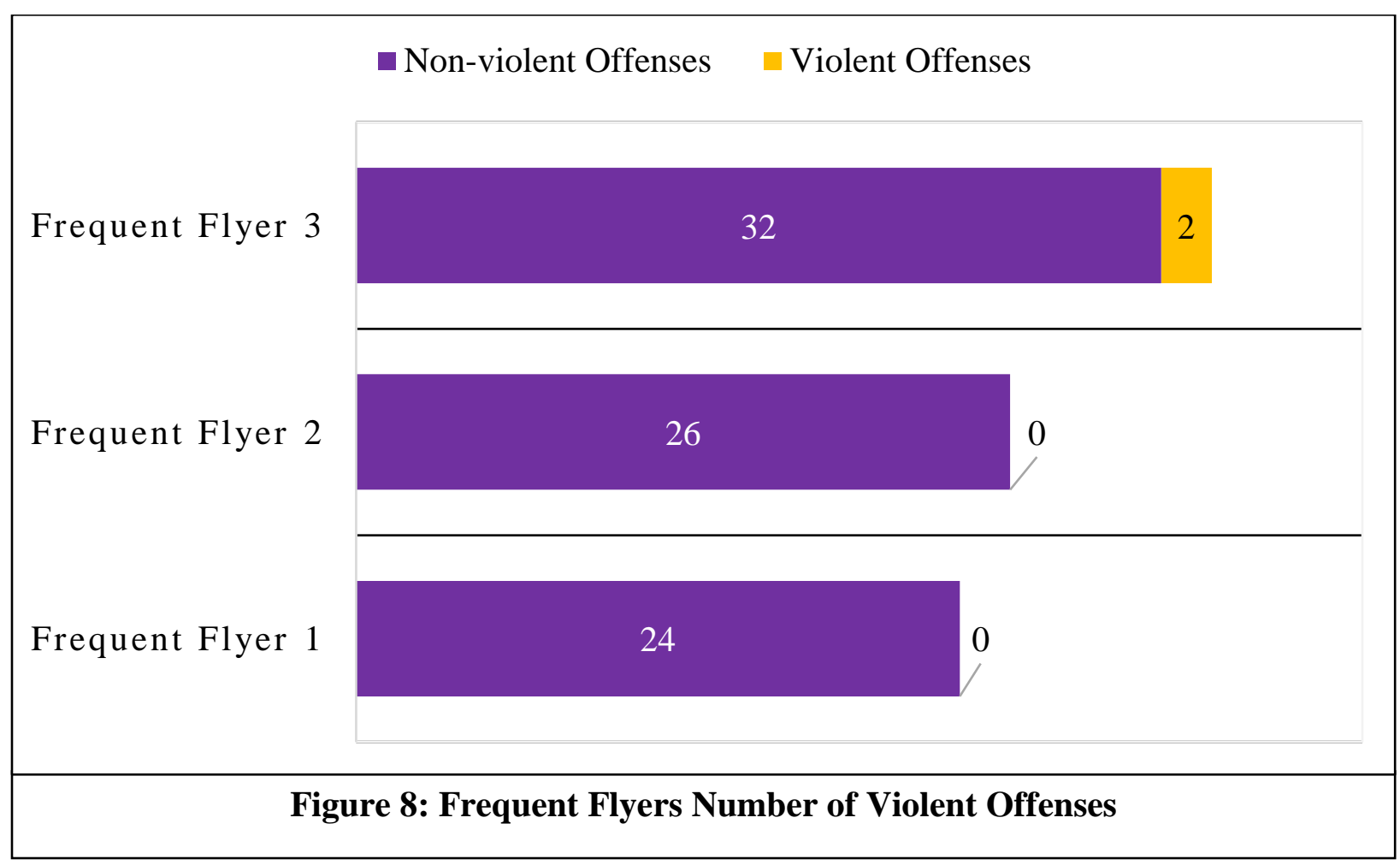

Tax dollars pay for nearly all interactions with the above entities. In Marinville, federal, state, county, and city-level governments pay for jails and police departments. Therefore, taxes 
paid for frequent flyer interactions with the criminal justice system. Tax revenue also covered unpaid emergency room visits. In Marinville, HSOs utilized a variety of funding streams (individual donors, private, and public funding), but the majority of funding was from the Department of Housing and Urban Development, a federal funding stream.

I added the above estimates together to reveal the cost of one year of frequent flyers interaction with the Marinville criminal, homeless, and medical systems. For the average Marinville frequent flyer, the cost of jail, police officer, and homeless services interactions was about $\$ 12,908$ - a cost similar to $\$ 15,377$ calculated for individuals experiencing homelessness in Denver (Synder 2015) (see Figure 9). I believe $\$ 12,908$ is a conservative estimate and does not include the cost of mental health services, sheltering, institutionalization, and/or the loss of property value or business revenue. Although housing would not prevent all misdemeanors, ordinance violations, and resource utilization, it would significantly decrease interactions with the criminal justice system and reliance on social and medical services.

\begin{tabular}{|l|l|}
\hline \multicolumn{1}{|c|}{ Type of Service } & \multicolumn{1}{c|}{ Cost } \\
\hline Jail & $\$ 1,800$ \\
\hline Police Department 1 (primary) & $\$ 4,212$ \\
\hline Police Department 2 & $\$ 1,007$ \\
\hline Police Department 3 & $\$ 667$ \\
\hline Homeless Services 1 & $\$ 400$ \\
\hline Homeless Services 2 & $\$ 400$ \\
\hline Three Other Homeless Organizations & $\$ 400(\$ 133.33$ each) \\
\hline Emergency Room & $\$ 4022$ \\
\hline Grand Total: & $\$ \mathbf{1 2 , 9 0 8}$ \\
\hline \multicolumn{2}{|c|}{ Figure 9: Cost of One Marinville Frequent Flyer Per Year } \\
\hline
\end{tabular}


With this cost analysis, I insist lawmakers, enforcers, and service providers assess if it is worth funneling $\$ 12,908$ towards preventative costs, rather than reactionary costs.

\section{Housing First: Prevention, Not Reaction}

Past researchers have shown Housing First can be a cost-effective solution (NAEH 2016; Snyder 2015). Upon discussing the Housing First model with city officials and police officers, I received some pushback about certain strategies. Especially, from City Official Johanesburg:

[I want to tell you] about tiny homes after Katrina... They put people in those awful trailers. The architect came up with this "Katrina Cottages." They weren't designed to be permanent. I think the population after Katrina is not the same as the homeless population. I just don't think it would work. You need to attach the tiny homes to utilities. I find it inefficient. Why not four-bedroom home? I think tiny homes are kind of a fad. I just don't know how you could justify that kind of expense. If you start putting up a separate building and that's a lot of infrastructure. I'm skeptical. I'm not opposed to the tiny space; my issue is the cost of four-walls and a roof.

City official Johanesburg was skeptical about whether a tiny house project made sense for Marinville. She was concerned about whether the infrastructure of a tiny home is the most suitable and cost-effective. In order to answer her questions, I analyzed the cost of several Housing First options in comparison to the status quo: 1) Tiny houses, 2) Working with property owners and, 3) Renovating a four-bedroom house (see Figure 10). I calculated the cost across five years for four frequent flyers since the majority of Housing First options have up-front costs. 
These costs dissipate over time. I calculated housing options for four frequent flyers because police officers and city officials told me this was the average number of frequent flyers in Marinville at any given time.

\begin{tabular}{|c|c|c|c|c|}
\hline Project Costs & $\begin{array}{l}\text { Frequently } \\
\text { Flyer } \\
\text { Remain } \\
\text { Unsheltered } \\
\text { (Status } \\
\text { Quo) }\end{array}$ & $\begin{array}{c}\text { Tiny House } \\
\text { Project: Lower- } \\
\text { Upper } \\
\text { Estimates }\end{array}$ & $\begin{array}{c}\text { Work with } \\
\text { Property } \\
\text { Owners to Rent } \\
\text { Affordable Units }\end{array}$ & $\begin{array}{l}\text { Purchase and } \\
\text { Renovate Four- } \\
\text { Bedroom to House } \\
\text { Unsheltered }\end{array}$ \\
\hline Raw Materials & N/A & $\$ 8,800-192,000$ & N/A & $\begin{array}{l}\text { N/A see } \\
\text { "renovations" }\end{array}$ \\
\hline $\begin{array}{l}\text { Land/Property } \\
\text { Sale Price }\end{array}$ & N/A & $\$ 50,000-200,000$ & N/A & $\$ 150,000$ \\
\hline Utilities & N/A & $\$ 24,000-42,000$ & $\$ 42,000$ & $\$ 44,000$ \\
\hline Insurance & N/A & $\$ 3,690$ & N/A & $\$ 3,690$ \\
\hline $\begin{array}{l}\text { Routine } \\
\text { Maintenance }\end{array}$ & N/A & $\$ 2,430$ & N/A & $\$ 2,430$ \\
\hline $\begin{array}{l}\text { Renovation } \\
\text { (includes the } \\
\text { cost of } \\
\text { contractor } \\
\text { staff) }\end{array}$ & N/A & N/A & N/A & $\$ 31,857$ \\
\hline Rent & N/A & N/A & $\$ 108,000$ & N/A \\
\hline $\begin{array}{l}\text { Administrative } \\
\text { Staff Hours }\end{array}$ & N/A & $\$ 31,045-\$ 64,090$ & $\$ 31,045$ & $\$ 31,045$ \\
\hline $\begin{array}{l}\text { Homeless } \\
\text { Services, Law } \\
\text { Enforcement, } \\
\text { Hospital } \\
\text { Interactions } \\
\end{array}$ & $\$ 258,160$ & Unknown & Unknown & Unknown \\
\hline Gain Equity & No & Yes & No & Yes \\
\hline Ability to Sell & No & Yes & No & Yes \\
\hline Totals & $\$ 258,160$ & $\begin{array}{l}\$ 119,965- \\
504,210\end{array}$ & $\$ 181,045$ & $\$ 263,022$ \\
\hline
\end{tabular}


I sourced multiple available datasets to estimate the cost of Housing First strategies. To estimate tiny house project costs, I reviewed news articles about similar projects in Denver, CO, Seattle, WA, Austin, TX, Portland, OR, and New York City, NY. I used a range for this column since costs proved highly variable. I reviewed available parcel and property-level city data to determine averages for land costs in Marinville (vacant lots for sale). I used the website Zillow to determine the median housing price for a four-bedroom house in Marinville. I used 2018 countylevel data from the Internal Revenue Service to estimate the cost of utilities. I used data from HUD's 2011 American Housing Survey (AHS) to determine utilities and homeowners' insurance estimates. The AHS reports, in 2011, the average housing occupant spent thirty-three dollars on routine maintenance per month and fifty dollars on homeowners' insurance per month. Adjusting for a three percent inflation rate, in 2018, routine maintenance would be about forty dollars and fifty cents per month and homeowner's insurance, sixty-one dollars and fifty cents per month. In addition, I averaged the projected cost of housing renovation for a four-bedroom house in Central Illinois from several well-known websites (Home Advisor, Home Guides, and Houzz). To calculate the cost of staffing the project, I turned to the City of Marinville compensation report. In 2018, the City of Marinville paid a housing inspection and development employee $\$ 51,278$ or about twenty-four dollars and sixty-five cents per hour (assuming a forty-hour workweek). I estimate a Housing First project employee would be on a similar pay-grade and would devote five hours per week over five years, however, since the tiny house project option would be more labor intensive, it could be up to ten hours per week. I reviewed rental market data, rental unit postings in Marinville, as well as the cost of rent for an affordable housing apartment complex near a prominent HSO to determine the cost of affordable rent $(\$ 450$ per 
month). For the status quo, one frequent flyer costs $\$ 12,908$ per year. Therefore, four frequent flyers in Marinville cost $\$ 51,624$ per year. Over five years, this would cost $\$ 258,160$.

The data I collected provides evidence that Housing First would be cost-effective in Marinville if implemented strategically. The above cost-benefit analysis shows preventative housing costs are comparable to criminal justice, homeless services, and medical costs for frequent flyers. However, the ideal housing strategy is complex and dependent on many factors. Since the tiny house project has such a large cost range and little available data, it is difficult to determine whether this strategy makes sense for Marinville. If implemented with all cost-saving mechanisms, a tiny house project could be the cheapest option, but it would likely cost somewhere in-between the high and low estimate $(\$ 119,965-504,210)$. It may be more realistic to work with property owners or renovate an existing four-bedroom home to house frequent flyers because there is more cost certainty. I believe the City of Marinville should consider the option of working with property owners because it may cost is less than the status quo $(\$ 181,045)$. In addition, working with property owners would require less maintenance than renovation efforts, but the project manager would not gain equity on the property. Renovating a four-bedroom house is seemingly a more expensive option, but the project manager would gain equity on the property and could sell, if necessary $(\$ 263,022)$. If the City of Marinville owns viable properties for these housing options, city officials should adjust the above cost-benefit analysis.

Besides the monetary benefit, I believe a focus on housing would improve quality of life for Marinville frequent flyers and the public-at-large. Regardless of how Housing First is implemented, it should be implemented. Even if the City of Marinville could not execute Housing First frugally, I argue the expense of housing individuals is worth it. There are negative 
externalities like social, emotional, environmental, and health costs, not included in my calculations, that are associated with unsheltered homelessness. This is especially true for frequent flyers. These externalities are difficult to value in cost-benefit analysis but are imperative to decision-making. It is in the City of Marinville's best interest to avoid these negative externalities and Housing First would reduce them to some extent. For example, Housing First would reduce socioemotional stress and compromised immune systems caused by exposure to extreme weather for frequent flyers as well as litter generated by homeless encampments. The reduction of these externalities would be mutually beneficial.

Realistically, not all people are employable or can be self-sufficient. Whether due to disability, serve mental illness, and/or extenuating life circumstances, some frequent flyers cannot pay for housing. Further, some frequent flyers have an extensive criminal record or credit history that prevent them from obtaining employment. Marinville needs a strong social safety net to "catch" frequent flyers trapped in the homeless encampment eviction cycle. Housing First is a humane, cost-effective option for the City of Marinville to reduce criminalization of frequent flyers. 


\section{CHAPTER V: CONCLUSION \& RECOMMENDATIONS}

\section{Conclusion}

The City of Marinville is a case study of a how public servants enforced and were subjected to powerful ideologies and systems. In Marinville, the regulatory systems I observed were not unique. Across all Western cities, socioeconomic stratification, classism, privatization, neoliberal ideology, and NIMBYism afflict the unsheltered population. This thesis details the dilemmas and pressures that spurned powerful people to participate in the homeless encampment eviction cycle.

Marinville city officials, police officers, and homeless services workers all stigmatized the unsheltered population although it was displayed distinctly. In Marinville, police officers interacted with unsheltered individuals often due to order maintenance training and orientation. The structure of the policing occupation made it so the police never heard success stories, especially about frequent flyers. The frequency of interaction with a small, unruly segment of the population accelerated Marinville police officer burnout. Therefore, police officers were more likely to speak reductively and bluntly about unsheltered individuals. Although police officers retained the power of discretion in how to address the unsheltered population, lack of resources and time, pressured them to resort to easier options such as taking frequent flyers to jail.

HSO occupational culture, in Marinville, varied because it was hierarchical. Entry-level HSWs acted cultural similar to the police, while upper managers utilized diplomatic language and political framing (like city officials). Survey suggest HSWs were perceived by their coworkers as more compassionate and likely to view unsheltered individuals as good people and productive member of society. Yet, they too exhibited nuanced forms of stigmatization. HSWs 
were more likely to medicalize unsheltered individuals and describe them as anti-authoritative and mentally ill. Like the police, the high level of contact caused them to become burnt out. Further, since prioritization for shelters was decided by the Continuum of Care, shelters excluded some groups. This exclusion extended further. I observed HSOs often found ways to segregate volunteers and staff from their clients.

City officials retained a high degree of geographic and social distance from the unsheltered population, and are thus, may feel discomforted by their presence. However, they were most skillful at speaking diplomatically about this population. Due to the Open Meetings Act, city officials could not discuss the unsheltered population freely. Few city councilmembers took the time to read city code due to the part-time, low pay nature of their positions. On top of that, city officials spent a lot of their time fulfilling FOIA requests. In short, city officials were not aware of issues facing the unsheltered population or the legacy ordinances that target them. City official's lack of engagement with these issues compounded the problem for other occupational groups.

Regardless of occupation, residents of the United States have been socialized to stigmatize the unsheltered population. Like all Western cities, Marinville is influenced by capitalist ideology and thus privatization and stigma are so entrenched, it is inescapable. All members of capitalist society, including Marinville residents, have been exposed to stereotypical representations of the unsheltered population. Whether in Hollywood films, "bum bashing" videos, or posts on social media, all have been repetitively shown a narrow version of unsheltered experiences. In Marinville, research participants recanted many of the dominant stereotypes about the unsheltered population: lazy, mentally ill, violent, criminal, anti- 
authoritative, and/or substance abusers. Only research participants who took extensive time to unlearn the anti-homeless bias made progress.

Although problematic, pervasive stigmatization, I determined, was not as crucial a finding as to how the structure of occupations, city complaint system, the obligation of public servanthood, and the policing protocol enable stigmatization. Powerful occupations are setup to serve other powerful groups, not groups that are marginalized. Furthermore, in Marinville, the city complaint system enabled public complaints in alignment with neoliberal ideology. Then, regulatory actions against individuals who deviated from hegemonic norms were justified by privatization and legacy ordinances. The notion of public servanthood held decision makers and regulatory entities accountable to the public, but not all members of the public had the resources and the political power to participate. The obligation of public servanthood was so strong, that unmarked members of the public used public servants as puppets to carry out their discriminatory requests. Specifically, discriminatory vocal complainers such as FOIA-filers, bloggers, serial commenters, repeat callers, and regular meeting attendees retained the power to pressure public servants into pushing unsheltered individuals from public space. For these reasons, I believe that the structure and constraints of public servant occupations are dissatisfactory and the conventional ways to address the unsheltered population, inhumane.

The City of Marinville and other cities should adjust the protocols and processes that enable the discriminatory public because they are within the realm of feasible change. It is imperative Marinville restructures public servant duties and protocols to cultivate equitable and just treatments for the city's most vulnerable residents. With changes, Marinville could be an example of a city that adapted to bolster processes of compassion for its employees and residents, including the unsheltered population. 


\section{Recommendations}

The City of Marinville should take measures to improve the protocols and structure of public servant occupations as well as increase available services. Simple adjustments can improve conditions for the unsheltered population.

In order to counter societally infused stereotypes, all must actively work to unlearn perceptions. Specifically, it is essential that occupations that influence the unsheltered population's quality of life, unlearn what society has taught them. I believe training and strategic exposure can effectively reduce stigma.

Public servants need training. In one department, Marinville police officers took a weeklong Crisis Training, but no department offered a training specific to the unsheltered population. Since Marinville only had about four frequent flyers at one time, this training had not been deemed a priority. Similarly, city officials did not have homeless-specific training, and rarely consider their policies' implications for this population. City official and police officers could benefit from this training if only to bring the topic to the forefront of conversation. All mid-sized cities should consider offering training to equip employees with accurate information and resources to navigate the unsheltered population in the public right-of-way.

Public servants need forms of exposure to individuals experiencing homelessness that does not reinforce stereotypes. Since police officers only address a small, unruly segment of the population, they hardly ever witness successes and progress. Police officers should be encouraged to interact with individuals experiencing homelessness in a non-confrontational setting. It is essential that police officers see that not all unsheltered individuals remain in the cycle of poverty. Police officers need to see that there are success stories and that unsheltered individuals can thrive with the right treatment and conditions. Ultimately, police officers need to 
be exposed to a different side of homelessness. This can bolster rejuvenation, consideration, and compassion for this population. If police officers see the unsheltered population as residents with potential, they may take the time and effort to offer resources. Similarly, city officials need exposure but because of their extreme geographic and social distance from the unsheltered population. Since city officials interact with unsheltered individuals less frequently, they are more likely to base their judgment on hearsay, rather than their own observations. Just like with the police, exposure to homelessness can re-humanize this population. Exposure can be obtained through volunteering with HSOs or through organized events. While interacting with the unsheltered population, city officials and police officers should be cognizant that they do not use new experiences to reinforce their old mental model, but rather build new perceptions from the ground-up.

Public servants should listen to the public but question their bias. People like Marijuana Guy, The Guardian, and Idealist, are passionate, but they are not always compassionate. Societally ingrained stigma guides complaints from the Marinville public. Therefore, city officials and police officers should always ask themselves the question, "safe for who?" In times when the public calls City Hall or a police department requests action upon an unsheltered individual, this question is essential. When considering punitive action, public servants should consider whether the result will make sheltered or unsheltered residents feel safe. If a public servant must choose a population to feel safe, they should prioritize serving individuals who are most vulnerable. Public servants should center "marked" groups, such as the unsheltered population, in their decision-making, rather than using utilitarian decision-making. Public servants should base decisions on equity, not perceived desires of the "larger community." 
Departments need structures of success. The structure of public servant occupations should not enable discrimination from the public but counter it. However, public servants should institute mechanisms to ignore or invalidate public request carefully. Public servants should only do so when there are formal, mandatory guidelines in-place. These guidelines and protocols can reduce discretion and the opportunity of the public servant's bias to influence the outcome. Public servants, like other groups, have implicit biases, so they should not have the ultimate authority to make this decision. Clear guidelines would reduce the likelihood of discretion becoming authoritarianism. Protocols and guidelines should be used to help public servants decide whether public complaints are discriminatory and should be nullified. A formalized process can help police officers and city officials dispute requests from the public in order to avoid harassing certain groups. An example of a guideline Marinville police could use is: If an unsheltered person has already been contacted by police officers earlier that day AND already given a resource guide AND the public complaint does not involve observed or threatened violence.

Additionally, a best practice flow-chart should be used when police officers encounter the unsheltered population in the public-right-of-way (see Appendix D). The best practices flowchart I created can help police officers make virtuous decision amongst the noise of their exhausting, time-constrained occupation. The direction of the flowchart reduces discretion. Ultimately, the outcome of each trajectory on the flow-chart is an informed suggestion on how to handle each situation. The flow-chart avoids incarceration and penal action (unless necessary) and instead recommends resources and services as a course of action. Each trajectory ends in the police officer providing the unsheltered individual a resource guide. I argue all Marinville police 
should carry an updated resource guide in their vehicles. The Marinville police departments' mission should be to break the homeless encampment eviction cycle, not perpetuate it.

Another recommendation is utilizing third party social workers in situations when the police have been called to approach an unsheltered individual. As Hartmann, McNamara, and Burns (2012) recommend, the police should be a separate occupation from social workers. Police are expected to be a "catch-all" occupation and handle any situation that arises, but this is an unrealistic expectation. Although police officers are not social workers, they can utilize them. As Thomas (1986) advocated, police use of social workers can create a stronger collaborative network. Unfortunately, when an officer enters a situation, the unsheltered population may become mistrustful, defensive, and unwilling to accept resources and services. Instead of police officers spending their time approaching non-violent, unsheltered individuals, they can call upon trained social workers to handle the situation. This will reduce the number of interactions perceived as harassment. Then, when police officers and unsheltered individuals interact, it will be less frustrating and intentional. Further, if the public inquires, police officers can report they acted to address the situation by calling upon experts. For social workers to be effective there should be a referral protocol constructed. The use of social workers should not be an excuse neglect training police officers on how to handle interactions with the unsheltered population.

To be sustainable, employees in demanding occupations need a break. Originally, I had not considered mandatory sabbatical until a city interviewee proposed this suggestion. When brainstorming solutions, councilmember Jaster said,

One thing I've talked about is...take some time off! Could we not have someone to say, "three months on the street, two months on the desk"? So, [police] are dealing with people who have more minor situations- [like a] lost 
dog. [Over time] more serious stuff gets to you... They [see] stuff over and over again. [Some] cops who've been on the force ten or fifteen years have never had a break.

Public servants and homeless services workers would rejuvenate if given the proper time and resources. This is, especially, necessary for police officers who retain the power of the justifiable use of force and discretion. Paid time off could be offered for police officers to reflect, relax, volunteer, engage in their hobbies, travel, and spend time with family or friends.

Ultimately, this could be a time for self-care and goal setting. This sabbatical should be no shorter than two months. During this time, they can reconnect with a side of Marinville they rarely see on the clock. Sabbaticals could be extended to other occupations, like HSWs, with a tendency for burnout. If not sabbaticals, as Miller, Birkholt, and Scott (2006) recommended, HSO upper management can vary entry-level HSW job involvement, roles, and duties. Jonathan Carl told me, he thinks HSO should engage staff in new initiatives that re-energizes them and/or rotate positions.

The City of Marinville and HSOs should work together to build structures that encourage political participation from unsheltered individuals and homeless advocates. As Feldman (2004) argued, Marinville should move away from the false dichotomy between providing resources to the unsheltered population and recognizing their political voice in city operations. Marinville entities that interact with residents experiencing homelessness should encourage voter registration and day-of voting. This may include distributing hard-copy voter registration to clients (HSO mail, kitchens, dormitories). HSWs may need to travel to locations where unsheltered individuals congregate to provide voter information. Further, public servants and HSWs should encourage residents experiencing homelessness to attend city meetings and voice 
their opinions. Marinville public servants should work to afford unsheltered citizens the same political power as other members of the public. If unsheltered individuals do not have the time or resources for politician participation, there needs to be a voice to counter vocal complainers. Homeless advocates should make an effort to balance perspectives in city affairs. If homeless advocates are not in city meetings, city officials should make an effort to invite them. Especially when city officials are discussing issues pertaining to homelessness. It should be noted that although homeless advocates may be employed by HSOs, HSWs are not necessarily homeless advocates.

For the City of Marinville, civil or human rights lawyers should work closely with city officials. As seen in Papachristou vs. City of Jacksonville, anti-homeless ordinances have been overturned due to violations of the United States Constitution; they unfairly target certain populations and impede on their rights as citizens. It should be mandatory for human/civil rights lawyers to assess amendments before archiving them in city code. Additionally, human/civil rights lawyer should review the entirety of city code and assess whether legacy ordinances are constitutional. As city official Saral told me, many legacy ordinances exist simply because no one has taken the time to overturn them.

Similar to what Hartmann, McNamara, and Burns (2012) recommended, shelters should be expanded to serve all Marinville residents. There should be emergency shelter option for all people, even sex offenders. It is potentially more dangerous to have sex offenders roaming the streets than enrolled in a shelter and social services program. The lack of shelter options for sex offenders does not contribute to public safety, and in fact, hinders it. Sex-offender-specific emergency shelters could tailor resources to the population, and reduce the fear associated with mixing sex offenders into communal, dormitories. Additionally, there need to be options for 
people unwilling to relinquish pets. Shelters should have a pet wing could provide residents comfort of visiting their animal regularly.

As Hartmann, McNamara, and Burns (2012) recommended, day centers should be available in Marinville, or at the least, space where anti-homeless ordinances are not enforced. Undoubtedly, the lack of day shelters contributes to arrest and incarceration for ordinance violations. I argue it is worth city resources to re-open a similar facility. The reduction of penal costs may offset the property and maintenance costs. Opening a shelter for this population would reduce the costs associated with frequent flyers.

Finally, the City of Marinville should implement Housing First. This model will save money, especially if implemented strategically; with volunteer labor, grant funding, existing cityowned land. Marinville could create a tiny house project, renovate an old building, or work with property owners to reduce the cost of frequent flyer interactions and repetitive incarceration. Most importantly, the City should implement Housing First to increase the stability of frequent flyers and improve quality of life all parties involved:

Although police officers, city officials, and homeless service workers can take strides to be more cognizant, inclusive, and human-rights-oriented, I discovered that, usually, the public is the initiator of the homeless encampment eviction cycle. Therefore, there needs to be greater public self-awareness, accountability, and education. The most important recommendation is this: engage in self-reflection. If you have complained about the presence of an unsheltered individual — loitering at your business, exuding body odor, showing signs of mental illness, asking for money - it is possible YOU triggered the regulatory system and trapped a human being in the cycle of justice-involvement and homelessness 


\section{REFERENCES}

9 News. 2016. "Denver Planning to Evict Homeless from Camps" 9 News. Accessed on October $6^{\text {th }}, 2016$ at: http://www.9news.com/news/local/denver-planning-to-evicthomeless-from-camps/71083455

Abelson, Elaine S. 2003. "Women Who Have No Men to Work for Them: Gender and Homelessness in the Great Depression, 1930-1934”. Feminist Studies. 29(1): 104127. Accessed on September 29 ${ }^{\text {th }}, 2016$ at: http://www.jstor.org/stable/3178478?seq=3\#page_scan_tab_contents

Adams, Gary \& Bill Buck. 2010. "Social Stressors and Strain Among Police Officers" Criminal Justice and Behavior. 37(9). Accessed online on March 1st, 2018 at: http://journals.sagepub.com/doi/abs/10.1177/0093854810374282

Adichie, Chimanmanda. 2009. "The Danger of a Single Story” TEDGlobal 2009. Video. Accessed online on May 30 ${ }^{\text {th }}, 2018$ at: https://www.ted.com/talks/chimamanda_adichie_the_danger_of_a_single_story/upnext

Agnew, Robert. 1992. "Foundation for a General Strain Theory of Crime and Delinquency" Criminology. 30(1): 47-88 Accessed online on January 19 , 2018 at: http://onlinelibrary.wiley.com/doi/10.1111/j.1745-9125.1992.tb01093.x/full

Amster, Randall. 2008. Lost in space: The Criminalization, Globalization, and Urban Ecology of Homelessness. New York City, New York: LFB Scholarly Publishing. 
Anderson, Colin L. 2015. "Median Bans, Anti-homeless ordinances and the Urban Growth Machine” Journal for Social Justice. 8(2): 405-454 Accessed on October $9^{\text {th }}, 2016$ at: http://eds.a.ebscohost.com.libproxy.lib.ilstu.edu/eds/detail/detail?vid=1\&sid=44972ee 7-c801-4ae3-b30f-

f9a4973e1315\%40sessionmgr4008\&hid=4210\&bdata=JnNpdGU9ZWRzLWxpdmU mc2NvcGU9c210ZQ\%3d\%3d\#db=a9h\&AN=114854748

Balch, Robert L. 1972. “The Police Personality: Fact of Fiction?” The Journal of Criminal Law, Criminology, and Police Science. 63(1):106-119 Chicago, Illinois: Northwestern University of Law. Accessed on November $2^{\text {nd }}, 2016$ : http://scholarlycommons.law.northwestern.edu/

Basset, Ellen M, Andree Tremoulet, \& Allison Moe. 2012. "Homeless Encampments on the Public Right-of-Way: A Planning and Best Practices Guide” Portland State University Urban Studies and Planning. Portland, Oregon. Accessed on November $9^{\text {th }}, 2016$ at: http://www.academia.edu/27798870/Homeless_Encampments_on_Public_Right-ofWay_A_Planning_and_Best_Practices_Guide

Becker, Gray S. 1993. "An Economic Way of Looking at Life” Coase-Sandor Institute for Law and Economics. University of Chicago Law School. Chicago, Illinois. Accessed online on April 7th, 2018 at:

https://chicagounbound.uchicago.edu/cgi/viewcontent.cgi?referer=https://scholar.goo gle.com/\&httpsredir=1\&article=1509\&context=law_and_economics 
Beekman, Daniel. 2016. "Seattle City Council gets an Earful as it Weighs Protections for Homeless in Camp Evictions" Seattle, Washington: Seattle Times. Accessed on October $18^{\text {th }}$, 2016: http://www.seattletimes.com/seattle-news/politics/seattle-citycouncil-gets-an-earful-as-it-weighs-protections-for-homeless-in-camp-evictions/

Berk, Richard \& John MacDonald. 2010. "Policing the Homeless: An Evaluation of Efforts to Reduce Homeless-related Crime" Criminology \& Public Policy. 9(4): 813-840 Accessed online on March 20th, 2017:

http://onlinelibrary.wiley.com/doi/10.1111/j.1745-

9133.2010.00673.x/abstract;jsessionid=E40ACD6552D20032612C771B2DA3A8C8. f02t04? systemMessage $=$ Wiley+Online+Library+will+be+unavailable+on+Saturday+ 25 th + March + from $+07 \% 3 \mathrm{~A} 00+\mathrm{GMT}+\% 2 \mathrm{~F}+03 \% 3 \mathrm{~A} 00+\mathrm{EDT}+\% 2 \mathrm{~F}+15 \% 3 \mathrm{~A} 00+\mathrm{SGT}$ +for+4+hours+for+essential+maintenance.++Apologies+for+the+inconvenience.

Bill of Rights Institute. 2018. "Bill of Rights of the United States of America (1791)" Bill of Rights Institute. Arlington, Virginia. Accessed online on April 28 $8^{\text {th }}, 2018$ at: http://www.billofrightsinstitute.org/founding-documents/bill-of-rights/ Bourgois, Philippe I. \& Jeffery Schonberg. 2009. Righteous Dopefiend. Berkley, California: University of California Press. Accessed online on March 27th, 2018 at: https://books.google.com/books?hl=en\&lr=\&id=U4CGXvLnwEC\&oi=fnd\&pg=PA1\&dq=righteous+dopefiend\&ots=1HX3J1_zZj\&sig=RD7Z4YLD STQdCpeSH0GRq9Qivfg\#v=onepage $\& q=$ righteous\%20dopefiend $\& \mathrm{f}=$ false 
Brekhus, Wayne. 1998. “A Sociology of the Unmarked: Redirecting our Focus” Sociological Theory. 16(1): 34-51 American Sociological Association. Accessed online on April 7 th, 2019 at: http://www.soc.ucsb.edu/faculty/mohr/classes/soc4/summer_08/pages/Resources/Rea dings/SociologyofUnmarked.pdf

Brown, Mark. 2016. “Brown: Homeless Get 'Cleaned' out of South Loop” Chicago, Illinois: Chicago Sun Times. Accessed on October $6^{\text {th }}, 2016$ at: http://chicago.suntimes.com/news/brown-homeless-south-loop-tent-city-fearseviction/

Buck, Phillip O, Paul A. Toro \& Melanie A. Ramos. 2004. "Media and Professional Interest in Homelessness over 30 Years (1974-2003)" Analysis of Social Issues and Public Policy. http://onlinelibrary.wiley.com/doi/10.1111/j.1530-2415.2004.00039.x/full

Burt R., Martha. 1999. Homelessness: Programs and the People They Serve. Interagency Council on the Homeless. Accessed online on October $5^{\text {th }}, 2016$ at: https://books.google.com/books?hl=en\&lr=\&id=DJh0xIqo2oYC\&oi=fnd\&pg=PR13 $\& d q=$ urban+institute $+44 \% 25+$ of + homeless+worked+in+last $+30+$ days $+\& o t s=$ poAyuj F1E8\&sig=YPqumUr7Vnv7fVEnCLow7zMAfs\#v=onepage \&q=urban\%20institute $\% 2044 \% 25 \% 20$ of $\% 20$ homeless $\% 20$ worke $\mathrm{d} \% 20$ in $\% 20$ last $\% 2030 \% 20$ days $\& \mathrm{f}=$ false

Casino, Vincent Del \& Christine L. Jocoy. 2008. "Neoliberal Subjectivities, the "New" Homelessness, and Struggles Over Spaces of/in the City" Antipode. Accessed online on May $31^{\text {st }} 2018$ at: https://onlinelibrary.wiley.com/doi/full/10.1111/j.14678330.2008.00583.x 
Chamard, Sharon. 2015. "Factors Associated with Homeless Encampment Locations in Anchorage, Alaska" The Criminal Act. Accessed on November 1, 2016 at: http://link.springer.com/chapter/10.1057/9781137391322_11

Charmaz, Kathy. 1996. "A Search for Meaning - Grounded Theory” Rethinking Methods in Psychology. 27-49. London, England: Sage Publications. Accessed online on April 1st, 2018 at: http://www.sxf.uevora.pt/wpcontent/uploads/2013/03/Charmaz_1996.pdf

City of Albuequrque. 2018. "There's a Better Way" City of Albuequrque. Albuequrque, New Mexico. Accessed online on April 7th, 2018 at: http://www.cabq.gov/family/services/homeless-services/theres-a-better-way Cresswell, Tim. 2001. The Tramp in America. London, United Kingdom: Reaktion Books Ltd. Accessed on September 29 ${ }^{\text {th }}, 2016$ at: https://books.google.com/books?id=2sE_JYzkF0EC\&printsec=frontcover\#v=onepag $\mathrm{e} \& \mathrm{q} \& \mathrm{f}=$ false

Crouse, Joan M. 1948. The Homeless Transient in the Great Depression. New York State, 1929-1941. Albany, New York: State University of New York Press. Accessed on September 25th, 2016 at:

https://books.google.com/books?hl=en\&lr=\&id=NpHXi3Uea5IC\&oi=fnd\&pg=PR9\&d $\mathrm{q}=$ homelessness+and+the+great+depression\&ots=gfJtgXn0x\&sig=2CQJNa5qH31rYoSTWWz0pXN9os\#v=onepage $\& \mathrm{q}=$ homelessness $\% 20$ and $\% 20$ the $\% 20$ great $\% 20 \mathrm{depression} \& \mathrm{f}=$ false 
Dahl, Robert Alan. 1974. Who Governs? Democracy and Power in an American City. New Haven, Connecticut: Yale University Press. Accessed online on March 9 ${ }^{\text {th }}, 2019$ at: https://books.google.com/books?hl=en\&lr=\&id=L99RHLc3WoC\&oi=fnd\&pg=PR7\&dq=city+employees $+\& o t s=y \_c W X v S 3 C v \& s i g=$

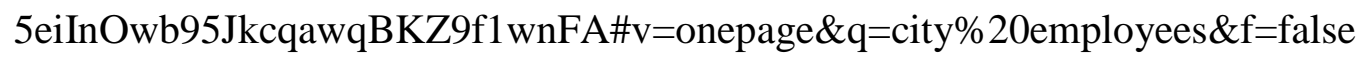
Davies, Peter. 2013. "Norms and Values in Defining a Sense of Place". Journal of Student Research. Lampeter, Wales: University of Wales Trinity Saint David. 2(2): 49-58

Dear, Michael \& Jennifer Wolch. 1987. Landscapes of Despair: From Deinstitutionalization to Homelessness. Princeton, New Jersey: Princeton University Press. Accessed online on February 11th, 2018:

https://books.google.com/books?hl=en\&lr=\&id=GPz_AwAAQBAJ\&oi=fnd\&pg=PP $1 \& \mathrm{dq}=$ deinstitutionalization + and + homelessness\&ots=GXt0P9Dgzx \&sig=HDeK8k5 HYVEC0UEwsFU6nRnVr1M\#v=onepage\&q=deinstitutionalization\%20and\%20hom elessness\&f=false

Dear, Michael. 2007. "Understanding and Overcoming the NIMBY Syndrome" Journal of the American Planning Association. 58(3):288-300. Accessed online on April 1, 2018 at: https://www.tandfonline.com/doi/abs/10.1080/01944369208975808 
Desjarlais, Robert R. 1997. Shelter Blues: Sanity and Selfhood Among the Homeless.Philadelphia, Pennsylvannia: University of Pennsyvania Press. Accessed online on March 27th, 2018 at:

https://books.google.com/books?id=ipieJpjYA0oC\&printsec=frontcover\&dq=shelter +blues \&hl=en\&sa=X\&ved=0ahUKEwiCpL-

flY3aAhWQAHwKHbcoCmgQ6AEIKDAA\#v=onepage \&q=shelter\%20blues\&f=fals e

Dhanani, Lindsay. 2001. "How Religiosity Affects Perceptions of the Homeless" The University of Central Florida Undergraduate Research Journal. 4(2):52-61. Accessed online on April $7^{\text {th }}, 2018$ at: https://www.urj.ucf.edu/docs/Dhanani.pdf Downtown Streets Team. 2018. “Downtown Streets Teams” Downtown Streets Team. San Jose, California. Accessed online on April 7th, 2018 at: http://streetsteam.org/index Duneier, Mitchell. 1999. Sidewalk New York City, New York: Farrar, Straus, and Giroux. Accessed online on May $3^{\text {rd }}, 2018$ at https://books.google.com/books?hl=en\&lr=\&id=CCN-

17p_eUC\&oi=fnd\&pg=PP3\&dq=mitchell+duneier+sidewalk\&ots=Jze98b1el7\&sig $=4 J U 1 U T f k K s K z J N N J Y 3 G v H p 55 t 9 w \# v=$ =nepage $\& q=$ mitchell\%20duneier\%20side walk \&f=false

Falcone, David \& L. Edward Wells. 1995. "The County Sheriff as a Distinctive Policing Modality" American Journal of Police. XIV(3/4):123-149. Accessed on March 22nd at: https://reggienet.illinoisstate.edu/access/content/group/bddf7e86-dd6d-403a-b414f7086f151222/Falcone.\%20The\%20County\%20Sheriff.pdf 
Feldman, Leonard. 2004. Citizens Without Shelter: Homelessness, Democracy, and Political Exclusion Ithaca, New York \& London, England: Cornell University Press. Accessed online on April 12th, 2018 at: https://books.google.com/books?id=1duRLZ4VsoC\&pg=PA147\&lpg=PA147\&dq=mitchell+duneier+the+sidewalk+selfsustaining+habitat\&source=bl\&ots=kbWIDewLbx\&sig=YnjHOh2ie7tO9ypxpV1sXa59XM\&hl=en\&sa=X\&ved=0ahUKEwi5i9Dp97TaAhURzFMKHfC0C9UQ6AE IVTAH\#v=onepage \&q\&f=false

Ferolito, Phil. 2016. "Yakimo Homeless Camp Given 72 Hours to Move" Yakima, Washington: YakimaHerald. Accessed on November 1" 2016 at: http://www.yakimaherald.com/news/local/yakima-homeless-camp-given-hours-tomove/article_eea8b764-43d5-11e6-8e2f-771c6dc0f414.html

Foucault, Michel. 1977 (1979). Discipline and Punish. Vintage. New York, New York. Foucault, Michel. 1990. "A History of Sexuality: Introduction, Volume I". The History of Sexuality. Translated by Robert Hurley. Outline by Philip Turetzky. New York City, New York: Vintage. Accessed online on February 11, 2018 at: https://s3.amazonaws.com/academia.edu.documents/31558216/Foucault_Sexuality_V ol_1.pdf?AWSAccessKeyId=AKIAIWOWYYGZ2Y53UL3A\&Expires=1518373342 $\&$ Signature $=$ X6mt5w72SFGhSwHHCyll8u0ILos\%3D\&response-contentdisposition=inline\%3B\%20filename\%3DOutline_of_Michel_Foucault_The_History_ o.pdf 
Frazzini, Kevin. 2015. “This Land is Whose Land?” State Legislatures. 41(7): 30-33 Accessed online:

http://eds.a.ebscohost.com.libproxy.lib.ilstu.edu/eds/detail/detail?vid=1\&sid=b76d4faa -dbb7-499e-8f28-

35586901 $\mathrm{ad30 \% 40sessionmgr4009 \& hid=4210 \& bdata=JnNpdGU9ZWRzLWxpdmUm}$ c2NvcGU9c210ZQ\%3d\%3d\#db=f5h\&AN=108589969

Hartmann, Robert, Charles McNamara, and Crawford Ronald Burns. 2013 "Policing the Homeless: Policy Practice, and Perceptions.” Policing: An International Journal of Police Strategies \& Management. 36(2): 357-374 Accessed on February 14 ${ }^{\text {th }}, 2017$ at: http://s3.amazonaws.com/academia.edu.documents/33329226/17088826.pdf?AWSAc cessKeyId=AKIAIWOWYYGZ2Y53UL3A\&Expires $=1487218979 \&$ Signature $=1 \% 2$ Fh3mylWXh8B\%2FrPWHehq\%2FJ7UMpY\%3D\&response-contentdisposition=inline\%3B\%20filename\%3D17088826.pdf

Henig, Jeffery R. 1989-1990. "Privatization in the United States: Theory and Practice" Political Science Quarterly. 104(4): 649-670. Accessed online on May 31, 2018 at: http://www.jstor.org/stable/2151103?seq=1\#page_scan_tab_contents

Herbert, Steve. 1998. "Police Subculture Reconsidered” Criminology. 36(2) Bloomington, Indiana: Indiana State University. Accessed on November 1st, 2016 at: http://heinonline.org/HOL/LandingPage?handle=hein.journals/crim36\&div=23\&id= \&page $=$

Herring, Chris \& Manuel Lutz. 2015. "The Roots and Implications of the United Sattes Homeless Tent Cities.” Conference Papers- American Sociological Assocation. 1(22) Accessed on September 10 ${ }^{\text {th }}, 2016$. 
Herring, Chris. 2010. "Punitive Containment and Contesting Neoliberalism: The Roots and Implications of Homeless Camps in America" Budapest, Hungary: Central European University Department of Sociology \& Social Anthropology. Accessed on October 10th, 2016 at: http://www.etd.ceu.hu/2010/herring_christopher.pdf

Hertzberg, Edwina L. 1992. "The Homeless in The United States: Conditions, Typology, and Interventions" International Social Work. 35:149-161. Accessed online on May 20 ${ }^{\text {th }}$ 2018 at: http://journals.sagepub.com/doi/abs/10.1177/002087289203500205

Homeless Advocacy Policy Project. 2016 “Too High a Price: What Homelessness Costs Colorado" Denver, Colorado: University of Denver Sturm College of Law. Accessed on November 1, 2016 at: http://www.law.du.edu/documents/homeless-advocacypolicy-project/2-16-16-Final-Report.pdf

Howard, Ella. 2013. Homeless: Poverty and Place in Urban America. Philadelphia, Pennsylvania: University of Pennsylvania Press. (Requested at library) HUD (Department of Housing and Urban Development). 2009. "The 2008 Homeless Assessment Status Report to Congress: Summary of Findings" Department of Housing and Urban Affairs. Washington D.C.: Office of Community Planning and Development. Accessed on November $9^{\text {th }}, 2016$ at: https://www.hudexchange.info/resources/documents/2008AHARSummary.pdf 
HUD (Department of Housing and Urban Development). 2011. “American Housing Survey for the United States" Office of Policy and Research Development. U.S. Department of Commerce- Economics and Statistics Administration. U.S. Census Bureau. Accessed online on May $29^{\text {th }} 2018$ at: https://www.census.gov/content/dam/Census/programs-surveys/ahs/data/2011/h15011.pdf

HUD (Department of Housing and Urban Development). 2012. "2012 Homelessness Pointin-time Count Estimates of Homelessness" Departments of Housing and Urban Affairs. Washington D.C.: Office of Community Planning and Development. Accessed on November $9^{\text {th }}, 2016$ at: https://www.hudexchange.info/resources/documents/2012AHAR_PITEstimates.pdf HUD (Department of Housing and Urban Development). 2015. “2015 AHAR: Part 1 - PIT Estimates of Homelessness" Departments of Housing and Urban Development Office of Community Planning and Development. Washington D.C. Accessed on September 24th, 2016 at: https://www.hudexchange.info/resources/documents/2015-AHAR-Part1.pdf

HUD (Department of Housing and Urban Development). 2016. "HUD 2016 Continuum of Care Homeless Assistance Programs Homeless Populations and Subpopulations" Department of Housing and Urban Development. Accessed on December 13th 2016.

HUD (Department of Housing and Urban Development). 2017. "The 2017 Annual Homeless Assessment Report (AHAR) to Congress" Department of Housing and Urban Development. Washington, DC. Accessed online on February 11, 2018 at: https://www.hudexchange.info/resources/documents/2017-AHAR-Part-1.pdf 
IRS. 2018. "Illinois - Local Standards: Housing and Utilities" Internal Revenue Service.

United States Government. Accessed online on April $7^{\text {th }}, 2018$ at:

https://www.irs.gov/businesses/small-businesses-self-employed/illinois-localstandards-housing-and-utilities

Jackson, John L. 2005. Real Black: Adventures in Racial Sincerity. Chicago, Illinois:

University of Chicago Press. Accessed online on February 21st, 2017:

https://books.google.com/books?id=FpIGAyGvZiUC\&pg=PA219\&lpg=PA219\&dq= anthroman+anthropologist \&source=bl\&ots=Finu3OYCmn\&sig=NTSbwRwVtXDJK Tp_mT-ELBIeJO0\&hl=en\&sa=X\&ved=0ahUKEwj7JORybfZAhUH2mMKHR8fChIQ6AEIOTAD\#v=onepage\&q=anthroman\%20anthro pologist\&f=false

Kelling, George L. \& Mark H. Moore. 1988. "The Evolving Strategy of the Police” The Police and Society. Edited by Victor E. Kappeler. Waveland Press: Long Grove, Illinois.

KING 5. 2016. "Proposal Gives Homeless 30 Days to Evict". Seattle, Washington: KING 5 Seattle. Accessed on October 18th 2016 at: http://www.king5.com/news/local/seattle/proposal-give-homeless-30-days-toevict $/ 323897237$

Knecht T, Martinez LM. 2009. Humanizing the homeless: does contact erode stereotypes? Social Science Research. 2009; 38: 521-34. 
Koegel, Paul, Audrey Burnam, \& Rodger Farr. 1988. “The Prevalence of Specific Psychiatric Disorders Among Homeless Individuals in Inner City of Los Angeles" Arch Gen Psychiatry. 45(12): 1085-1092. Accessed online on June $2^{\text {nd }} 2018$ : https://jamanetwork.com/journals/jamapsychiatry/article-abstract/494439

Kohn, Margaret. 2004. Brave New Neighborhoods: The Privatization of Public Space. New York, New York: Routledge. Accessed on October 9th, 2016 at: https://books.google.com/books?hl=en\&lr=\&id=evydnqLR6DcC\&oi=fnd\&pg=PA1\& $\mathrm{dq}=$ privatization + of + space + definition $\& \mathrm{ots}=\mathrm{xOH} 5 \mathrm{vAzpC} 8 \& \mathrm{sig}=\mathrm{uxma} 8 \mathrm{fs} 2 \mathrm{YwN} 11 \mathrm{r} 94$ NmHG2f08RU8\#v=onepage \&q=privatization $\% 20 \mathrm{of} \% 20$ space $\% 20$ definition $\& \mathrm{f}=$ false

Krauss, Michael W. 2015. "The Inequality of Politics: Social Class Rank and Political Participation". IRLE Working Paper No. 120-15. Berkley, California. Accessed online on February 26th, 2018 at: http://irle.berkeley.edu/workingpapers/120-15.pdf

Kusmer, Kenneth L. 2002. "Down and Out, on the Road: History of Homelessness in American History." Oxford, New York: Oxford Press. Accessed on September 29th 2016 at:

https://books.google.com/books?hl=en\&lr=\&id=xpJ3ME7vHuEC\&oi=fnd\&pg=PA3 $\& \mathrm{dq}=$ colonial+america + homelessness $\&$ ots $=$ GCbn1u91x\&sig=11b0j3JU7t_uwDZWdhGkobv7jNc\#v=onepage \&q=colonial\%20america\% 20homelessness \&f=false 
Langegger, Sig \& Stephen Koester. 2017. "Moving On, Finding Shelter: The Spatiotemporal Camp" International Sociology. 32(4):454-473. Accessed online on April 1st, 2018 at: https://www.researchgate.net/publication/315986404_Moving_on_finding_shelter_T he_spatiotemporal_camp

Lee, Barrett A. 1990. "Public Beliefs About the Causes of Homelessness" Oxford Journal. 69(1):253-265 Accessed online on October $2^{\text {nd }}, 2016$ at: http://sf.oxfordjournals.org/content/69/1/253.short'

Law, Robin. 2001. "Not in My City: Local Governments and Homelessness Policies in the Los Angeles Metropolitan Region." Environmental and Planning C: Politics and Space. 19:791-815. Accessed online on April 1, 2018 at: http://citeseerx.ist.psu.edu/viewdoc/download?doi=10.1.1.462.1948\&rep=rep1\&type $=\mathrm{pdf}$

Lester, David. 1983. "Why Do People Become Police Officers: A Study of Reasons and Their Predictions of Success". Journal of Police Science and Administration. 11(2):170-452. Accessed online on April 27 $7^{\text {th }}, 2018$ at: https://www.researchgate.net/profile/David_Lester/publication/290810192_Why_do_ people_become_police_officers_A_study_of_reasons_and_their_predictions_of_succ ess/links/593bfaeaa6fdcc17a9def45f/Why-do-people-become-police-officers-Astudy-of-reasons-and-their-predictions-of-success.pdf 
Lewis, Paul. 2017. "Outside in America: Tiny House Salvation for Homeless or Dead End?" The Guardian. Accessed online on February 11, 2018: https://www.theguardian.com/us-news/2017/mar/23/tiny-houses-solutionhomelessness-seattle

Lipsky, Michael. 1980 (2010) Street Level Bureaucracy: Dilemmas of Individuals in Public Service. Russell Sage Foundation. New York, New York. Accessed online on February 11, 2018 at: https://books.google.com/books?id=cs_djgS5vUC\&printsec $=$ frontcover $\& d q=$ street + level + bureaucracy\&hl=en $\& s a=X \& v e d=0 a h U K$ EwiV5faPzp7ZAhUpja0KHT8VA7UQ6AEIKDAA\#v=onepage\&q=street $\% 201$ evel\% 20bureaucracy \&f=false

Lotus-Farren, Zoe. 2011. "Tent Cities: An Interim Solution to Homelessness and Affordable Housing Shortage in United States” California Law Review. 99 (4): 1037-1081

Low, Setha \& Meil Smith. 2006. "The Politics of Public Space” Routledge Taylor \& Francis Group. New York City, New York. Accessed online on May 31, 2018 at: https://books.google.com/books?hl=en\&lr=\&id=65JhtDI7cYC\&oi=fnd\&pg=PA143\&dq=privatization + of + land + and + the + homeless $\&$ ots $=0$ ztxdYoqIx\&sig=uTAakzI5vr6pOMel7yJz3i21ZRc\#v=onepage\&q=privatization\%20o f\%20land $\% 20$ and $\% 20$ the $\% 20$ homeless $\& f=$ false

Lundahl, Erika. 2017. "Tiny Houses for the Homeless: An Affordable Solution Catches On". Charter for Compassion. Accessed online on February 11, 2018: https://charterforcompassion.org/problem-solving/tiny-houses-for-the-homeless-anaffordable-solution-catches-on 
Lutz, Manuel. 2015 "Uncommon Claims to the Commons: Homeless Tent Cities in the US." Urban Commons. Moving Beyond State and Market (2015): 101-116. Accessed on November 6th 2016 at: http://s3.amazonaws.com/academia.edu.documents/46359362/Manuel_Lutz_Uncom mon_Claims_to_the_Commons_Homeless_Tent_Cities_in_the_US.pdf?AWSAccessKeyId=AKIAJ56TQJRTWSMT

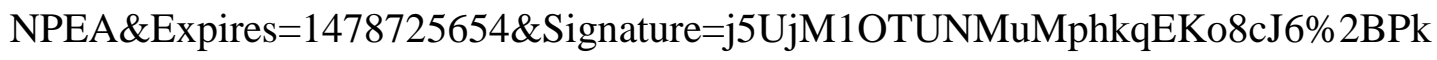
$\% 3 D \&$ response-contentdisposition=inline\%3B\%20filename\%3DUncommon_Claims_to_the_Commons_Ho meless.pdf

Lyon-Callo, Vincent. 2000. "Medicalizing Homelessness: The Production of Self-Blame and Self-Governance with Homeless Shelters" Medical Anthropology. 14(3): 382-345. Accessed online on March 9th, 2018 at: http://onlinelibrary.wiley.com/doi/10.1525/maq.2000.14.3.328/full Maanen, John Van. 1978. “Assholes” The Police and Society. Editor: Victor E. Kappeler. Waveland Press: Long Grove, Illinois.

Mann, Gregory A. 2006. “A Motive to Serve: Public Service Motivation in Human Resource Management and the Role of PSM in the Nonprofit Sector" Public Personnel Management. 35(11):38-48. Accessed online on April 27 $7^{\text {th }}, 2018$ at: http://journals.sagepub.com/doi/abs/10.1177/009102600603500103

Manning, Peter K. 1978. “The Police: Mandates, Strategies, and Appearances” The Police and Society. Edited by Victor E. Kappeler. Waveland Press: Long Grove, Illinois. 
Mauss, Marcel. 1954. The Gift: The Form and Reasons for Exchange in Archaic Societies. Cohen \& West. London, England and New York City, New York. Accessed online on April 8th, 2018 at: https://libcom.org/files/Mauss\%20-\%20The\%20Gift.pdf

McCoy, C. 1986. "Enforcement Workshop- Policing the Homeless" Criminal Law Bulletin. 22(3): 263-274. Accessed on March 22, 2017 at: https://www.ncjrs.gov/App/abstractdb/AbstractDBDetails.aspx?id=101501

McGhee, Tom. 2017. "Tiny-home community cleared to serve some of Denver's homeless" The Denver Post. Denver, Colorado. Accessed online on February 11, 2018: https://www.denverpost.com/2017/04/03/tiny-home-community-rino-denverhomeless/

McNulty, Bernadette R. 1992. "Homeless and Hopeless: Registration in News Media Construtions of Homelessness as a Social Problem" Annenberg School for Communication. Philadelphia, Pennsylvania: University of Pennsylvania. Accessed online on May $5^{\text {th }}, 2018$ at: https://repository.upenn.edu/dissertations_asc/7/

Meyer, Jon'a, Richard Paul, \& Diana Grant. 2009. "Peace Keepers Turned Peace Makers" Peacemaking Criminology: A Special Issue- Part II. 12(3) 331-344. Accessed online on February 11, 2018 at: http://www.tandfonline.com/doi/abs/10.1080/10282580903105897

Michel Foucault. 1977 (1982). "The Subject and Power". Critical Inquiry. 8(4):777-795. Accessed online on February 11, 2018: http://www.journals.uchicago.edu/doi/abs/10.1086/448181 ?journalCode=ci 
Miller, Katherine, Marty Birkholt, Craig Scott. 1995. "Empathy Burnout in Human Services: An Extension of the Communication Model" Communication Research. 22(2). Accessed online on March 9th, 2019 at: http://journals.sagepub.com/doi/abs/10.1177/009365095022002001

Miller, Lawerence. 2005. “The Police Officer Suicide: Causes, Prevention, and Practical Intervention Strategies" International Journal of Emergency Mental Health. 7(2):101-114. Accessed online on April 27, 2018 at: https://www.psychceu.com/miller/Miller_Pol_Ofcr_Suicide.pdf

Nader, Laura. 1972. "Up the Anthropologist: Perspectives Gained from Studying Up" Department of Health Education \& Welfare. Department of Anthropology. University of California- Berkeley. Accessed on January 2018 at: https://files.eric.ed.gov/fulltext/ED065375.pdf

NAEH (National Alliance to End Homelessness). 2009. "Organizational Change: Adopting a Housing First Approach" National Alliance to End Homelessness. Washington, DC. Accessed online on February 27th, 2018 at: http://endhomelessness.org/wpcontent/uploads/2009/08/adopting-a-housing-first-approach.pdf

NAEH (National Alliance to End Homelessness). 2010. "Fact Sheet: Point-in-Time Count" National Alliance to End Homelessness. Washington, DC. Accessed on November 7th, 2016 at: http://www.endhomelessness.org/library/entry/fact-sheet-point-in-timecounts

NAEH (National Alliance to End Homelessness). 2016. "Fact Sheet: Housing First". National Alliance to End Homelessness. Accessed online on February 27th, 2018 at: http://endhomelessness.org/wp-content/uploads/2016/04/housing-first-fact-sheet.pdf 
National Low-Income Housing Coalition. 2005. "The Crisis in America's Housing” Washington D.C.: National Low Income Housing Coalition.

NCFTH (National Coalition for the Homeless). 2008. "Hate, Violence, and Death on Main Street USA: A Report on Hate Crimes and Violence Against People Experiencing Homelessness 2008" National Coalition for the Homeless. Accessed on October 17th 2016 at: http://nationalhomeless.org/wpcontent/uploads/2014/06/hate_report_2008.pdf

NLCHP (National Law Center on Homelessness \& Poverty). 2014. "No Safe Place:

Criminalization of Homelessness in US Cities" Washington, D.C.: National Law Center for Homelessness \& Poverty. Accessed on September 25th, 2016 at: https://www.nlchp.org/documents/No_Safe_Place

NLCHP (National Law Center on Homelessness \& Poverty). 2014. "No Safe Place: Advocacy Manual" Washington, D.C.: National Law Center for Homelessness \& Poverty. Accessed on June $4^{\text {th }} 2018$ at: https://www.nlchp.org/documents/No_Safe_Place_Advocacy_Manual\#page=31 NLCHP (National Law Center on Homelessness and Poverty). 2010. "Myths and Facts About Homelessness" National Law Center on Homelessness and Poverty. Accessed online on February 26, 2018 at: http://www.nhchc.org/curriculum/module/module1D/h3MythsandFactsAboutHomele ssness.pdf/ 
Novac, Sylvia, Joe Hermer, Emily Paradis, \& Amber Kellen. 2009. "More Sinned Against that Sinning? Homeless People as Victims of Crime and Harrassment" Finding Home: Policy Options for Addressing Homelessness in Canada. University of Toronto Press: Toronto, Canada. Accessed online on March 21 ${ }^{\text {st }}, 2017$ at: http://www.homelesshub.ca/sites/default/files/7.2\%20Novac\%20et\%20al.\%20$\% 20$ Homeless\%20People\%20as\%20Victims\%20of\%20Crime.pdf

Noy, Darren. 2009. "When Framing Fails: Ideas Influence, and Resources in San Francisco's Homeless Policy Field" Social Problems. 56(2):223-242. Accessed online on April 1st, 2018 at: https://academic.oup.com/socpro/article/56/2/223/1616195

Paoline, Eugene A. 2003. "Taking Stock: Toward a Richer Understanding of Police Culture" Journal of Criminal Justice. 31(3): 199-214. Accessed online on March 1st, 2018 at: https://www.sciencedirect.com/science/article/pii/S0047235203000023

Pershan, Caleb. 2016. "City to Clear 'Tent City' Homeless Encampment within 72 Hours" Sfist. San Francisco, Californa. Accessed on November 2, 2016 at: http://sfist.com/2016/02/23/division_street_tent_city_to_be_cle.php

Petersilia, Joan \& Kevon R. Reitz. 2012. "History and Development of the American Jail" The Oxford Handbook of Sentencing and Corrections. New York, New York:University of Oxford Press. Accessed online on March 3rd, 2017 at: https://books.google.com/books?hl=en\&lr=\&id=uUUSDAAAQBAJ\&oi=fnd\&pg=P A389\&dq=shire+reeve+and+homeless\&ots=MH38nyZ3YD\&sig=BYmKKJDUpgc6 9QGzG6IBv7BFCr0\#v=onepage \&q=shire\%20reeve $\% 20$ and $\% 20$ homeless $\& \mathrm{f}=$ false 
Phelan J, Link BG, Stueve A, Moore RE. 1995. "Education, social liberalism, and economic conservatism: attitudes toward homeless people." American Sociological Review. $60: 323-37$.

Rabe-Hemp, Cara. 2017. "Innovations in Policing” Policing and Society. Lecture Handout. Illinois State University. Normal, Illinois.

Reichel, Phillip L. 1988. "Southern Slave Patrols as a Transitional Police Type” American Journal of Police. Greeley, Colorado: University of Northern Colorado Press. Accessed online at: https://reggienet.illinoisstate.edu/access/content/group/bddf7e86dd6d-403a-b414-f7086f151222/Reichel.pdf

Runyan, Robin. 2016. "This Tiny House Could Be a Game Changer for the Low-Income Population in Detroit" Curbed Detroit. Detroit, Michigan. Accessed online on February 11, 2018 at: https://detroit.curbed.com/2016/9/9/12860756/tiny-housedetroit-neighborhood-low-income

Saelinger, Donald. 2006. "Nowhere to Go: The Impacts of City Ordinances Criminalizing Homelessness" Georgetown Journal on Poverty Law \& Policy. XIII(3) Washington, D.C. Accessed on November 1st, 2016 at: http://heinonline.org/HOL/LandingPage?handle=hein.journals/geojpovlp13\&div=31 \&id=\&page $=$

Schultz, Elizabeth. 1992. "The Fourth Amendment Rights of the Homeless" Fordham Law Review. 60(5)1003-1033. Accessed online on April 28 ${ }^{\text {th }}, 2018$ at: https://ir.lawnet.fordham.edu/cgi/viewcontent.cgi?referer=https://www.ecosia.org/\&h ttpsredir=1\&article=2971\&context=flr 
Simon, Harry. 1992. "Towns Without Pity: A Constitutional and Historical Analysis of Official Efforts to Drive Homeless from American Cities" Tulane Law Review. 66(631) Accessed on October $9^{\text {th }}, 2016$ at: https://litigationessentials.lexisnexis.com/webcd/app?action=DocumentDisplay\&crawlid=1\&doctype $=$ cite $\&$ docid $=66+$ Tul. + L. + Rev. $+631 \&$ srctype $=$ smi $\&$ srcid $=3$ B $15 \&$ key $=018 \mathrm{~d} 259 \mathrm{fb} 797$ c5b3cfadc8c3fddcb141

Smith, Abbott Emerson. 1947. Colonists in Bondage: White Servitude and Convict Labor in America. Chapel Hill, North Carolina: University of North Carolina Press. Accessed on September 24th at: https://books.google.com/books?id=HN_qCQAAQBAJ\&pg=PA138\&dq=vagabonds +sent+to+british+colonies\&hl=en\&sa=X\&ved=0ahUKEwiFnL7Pp6nPAhXM7yYK HdvKAIkQ6AEINDAE\#v=onepage \&q=vagabonds $\% 20$ sent $\% 20$ to $\% 20 \mathrm{british} \% 20 \mathrm{col}$ onies $\& \mathrm{f}=$ false

Smith, Roger. 1997. Civic Idea: Conflicting Visions of Citizenship in US History. New Haven and London: Yale University Press. Accessed online on May $5^{\text {th }} 2018$ at: https://books.google.com/books?hl=en\&lr=\&id=e1cJJu9W9DcC\&oi=fnd\&pg=PA1\& dq=history+of+citizenship+us+\&ots=UUt0WmQBqj\&sig=H73FLATdO4RwUM505 BwkIxjeKBA\# $=$ onepage $\& q=$ property $\& f=$ false

Snow, David A. \& Michael Mulcachy. 2001. "Space, Politics, and the Survival Strategies of the Homeless" American Behavior Scientist. Accessed on November 1st, 2016 at: http://abs.sagepub.com/content/45/1/149.short 
Snyder, Kaitlyn. 2015. "Ending Homelessness Today" National Alliance to End Homelessness Official Blog. Accessed online on March 3rd, 2018: https://endhomelessness.org/study-data-show-that-housing-chronically-homelesspeople-saves-money-lives/

Speer, Jessie. 2016. “'It's Not Like Your Home': Homeless Encampments, Housing Projects, and the Struggle over Domestic Space" Antipode: A Radical Journal of Geography. Accessed on October $18^{\text {th }}, 2016$ at: http://onlinelibrary.wiley.com/doi/10.1111/anti.12275/full

Stover-Wright, Ehren. 2018. "Housing First Policy Video" Institute for Community Alliance. Midwestern Sociological Society 2018 Annual Meeting. Minneapolis, Minnestota. Tepeci, Mustafa and A. L. Bart Bartlett. 2002. "The Hospitality Industry Culture Profile: A Measure of Individual Values, Organizational Culture, and Person-organization fit as Predictor of Job Satisfaction and Behavioral Intention" International Journal of Hospitality Management. 21(2): 151-170 Accessed online on October 5th 2016 at: http://www.sciencedirect.com/science/article/pii/S0278431901000354

Thomas, T. 1986. Police and Social Workers. Averbury Publishing Co. Brookfield, Vermont. Accessed online on March 1st, 2018 at: https://www.ncjrs.gov/App/abstractdb/AbstractDBDetails.aspx?id=102314

Thompsom, Sanna J, Holly McManus, Janet Lantry, Liliane Windsor, \& Patrick Flynn. 2006. "Insights from the Street: Perceptions of Services and Providers by Homeless Young Adults" Evaluation and Program Planning. 29(1):34-43. Accessed online on March $9^{\text {th }}, 2018$ at: https://www.sciencedirect.com/science/article/pii/S0149718905000844 
Tompsett, Corolyn J., Paul A Toro, Melissa Guzicki, Manuel Manrique, \& Jigna Zatakia. 2006. "Homelessness in the United States: Assessing Change in Prevalence and Public Opinion, 1993-2001. American Journal of Community Psychology. 37(12):29-46 Accessed on October $2^{\text {nd }}, 2016$ at: http://onlinelibrary.wiley.com/doi/10.1007/s10464-005-9007-2/full

Trubetzkoy, Nikolai. 1939 (1969). Grundzu“ge der Phonologie. Prague, Vandenhoeck and Ruprecht Translation: C. A. M. Baltaxe. Principles of Phonology. Berkeley, California: University of California Press. Berkley, California.

Turner, Susan Marie. 2006. "Mapping Institutions as Work and Texts" Institutional Ethnography as Practice. Ed. Dorthy E. Smith. Lanham, Maryland: Rowman \& Littlefield Inc. Accessed online on February 22, 2018 at: https://books.google.com/books?hl=en\&lr=\&id=BGSP8Y1Q3IC\&oi=fnd\&pg=PA139\&dq=city+council+ethnography+\&ots=U5detXAqGw \&sig=E53pWIPouS8bJkJi5rq0vFFZbgM\#v=onepage\&q=city\%20council\%20ethnogr aphy\&f=false

US Constitution. 1964. “Civil Rights Act” Public Act 88-352. United States Senate and House of Representatives. Accessed online on April 3rd at: http://library.clerk.house.gov/reference-files/PPL_CivilRightsAct_1964.pdf Wacquant, Loic. 2009. Punishing the Poor: The Neoliberal Government of Social Insecurity. Durham and London: Duke University Press. Accessed online on May 31, 2018: https://books.google.com/books?hl=en\&lr=\&id=NkyFsGi2erEC\&oi=fnd\&pg=PT7\& $\mathrm{dq}=$ neoliberalism+and+homelessness+united+states\&ots=KRXLrgTbSM\&sig=na6tq zSr6zzRcuCSzyniHAkygCM\#v=onepage \&q=homelessness \&f=false 
Watkins, T.H. 1999. The Hungry Years: A Narrative History of the Great Depression in America. New York, New York: Henry Holt and Company. Accessed on October 2nd, 2016 at:

https://books.google.com/books?hl=en\&lr=\&id=4d8m3602eRcC\&oi=fnd\&pg=PR11 $\& \mathrm{dq}=$ the+stranger+homeless+and+the+great+depression\&ots=UBiNcF-Muz\&sig=d1775kb3Q894PkUOq5RWtki_QY\#v=onepage\&q\&f=false

Weber, Max. 2012 [1905]: "The Protestant Ethic and the Spirit of Capitalism" Digiread.com Publishing.

Williams, Joan C. 1986. "The Constitutional Vulnerability of American Local Government: The Politics of City Status in American Law" Wisconsin Law Review. Accessed on November $1^{\text {st }}, 2016$ at:

http://heinonline.org/HOL/Page?handle=hein.journals/wlr1986\&div=12\&g_sent=1\& collection=journals

Wilson, James Q. \& George L. Kelling. 1982. "Broken Windows" The Police and Society. Edited by Victor E. Kappeler. Long Grove, Illinois: Waveland Press.

Woods, Robert H. 1989. "More Alike than Different: The Culture of the Restaurant Industry." The Cornell Hotel and Restaurant Administration Quarterly. Ithaca, New York: Cornell University Press. 30(2) Accessed online on October $5^{\text {th }}, 2016$ at: http://www.sciencedirect.com/science/article/pii/S0010880489801120 


\begin{tabular}{|l|l|l|}
\hline \multicolumn{1}{|c|}{ Pseudonym } & \multicolumn{1}{c|}{ Occupation/Role } & \multicolumn{1}{|l|}{ Interaction } \\
\hline Eugena Palups & $\begin{array}{l}\text { Homeless Services Worker; } \\
\text { Formerly Homeless }\end{array}$ & Volunteering \\
\hline Marie Jameson & $\begin{array}{l}\text { Homeless Services Worker; } \\
\text { Formerly Homeless }\end{array}$ & Volunteering \\
\hline Ed Redders & $\begin{array}{l}\text { Homeless Services Worker; } \\
\text { Formerly Homeless }\end{array}$ & Volunteering \\
\hline Rosalie Almora & $\begin{array}{l}\text { Homeless Services Worker; } \\
\text { Formerly Homeless }\end{array}$ & Volunteering \\
\hline Carry Jenkins & Homeless Services Worker & Volunteering \\
\hline Kara Jag & Homeless Services Worker & Volunteering \\
\hline Officer Damien & Police Officer & Ride-Along \\
\hline Officer Larkens & Police Officer & Ride-Along \\
\hline Officer Peterson & Police Officer & Ride-Along \\
\hline Officer Libold & Police Officer & Ride-Along \\
\hline Officer Mayweather & Police Officer & Ride-Along \\
\hline Officer Marrich & Police Officer & Ride-Along \\
\hline Officer Smith & Police Officer & Observation \\
\hline Officer Rodriguez & Police Officer & Observation \\
\hline Officer Mendez & Police Officer & Email \\
\hline Officer Turk & Police Officer & Email \\
\hline Officer Seigh & Police Officer & Email \\
\hline Chief Watson & Police Officer & City Meetings; Phone \\
\hline Jacob Cookson & Unsheltered Individual & Observation \\
\hline Sandy Cheney & Unsheltered Individual & Observation \\
\hline The Guardian & Involved Public & Internet \\
\hline Marijuana Guy & Involved Public & City Meetings \\
\hline Roads Joe & Formerly Involved Public; City & City Meetings \\
\hline Official & Internet \\
\hline VG90 & Involved Public; Internet Troll & Internet \\
\hline Mayor & Involved Public; Internet Troll & City Meetings \\
\hline & City Official & \\
\hline & & \\
\hline
\end{tabular}




\section{APPENDIX B: INTERVIEWEES}

\begin{tabular}{|l|l|}
\hline \multicolumn{1}{|c|}{ Pseudonym } & \multicolumn{1}{c|}{ Occupation } \\
\hline Kristin Promise & \\
\hline Erin Jones & Homeless Services Worker \\
\hline Milton Wells & Homeless Services Worker \\
\hline Patricia Pale & Homeless Services Worker \\
\hline Jonathan Carl & Homeless Services Worker \\
\hline Mary Palser & Homeless Services Worker \\
\hline Julia Jaster & City Official \\
\hline Willy Foster & City Official \\
\hline Palli Johanesburg & City Official \\
\hline Justin Saral & City Official \\
\hline Officer Mayweather & City Official \\
\hline Fe Wilponi & Police Officer \\
\hline & News Reporter \\
\hline & \\
\hline
\end{tabular}


Chart 1:

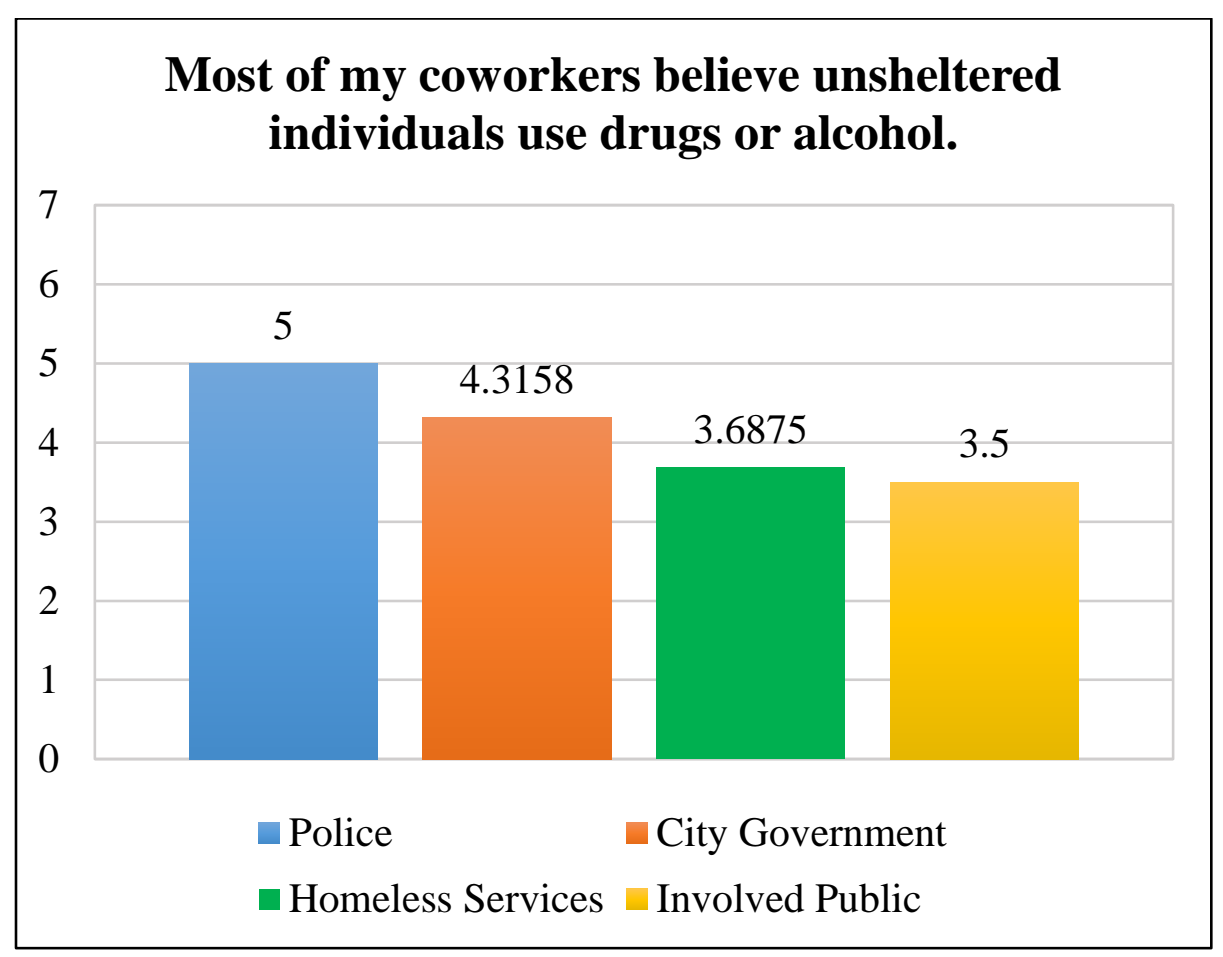

\begin{tabular}{|c|c|}
\hline 7 & Strongly Agree \\
\hline 6 & Agree \\
\hline 5 & $\begin{array}{l}\text { Somewhat } \\
\text { Agree }\end{array}$ \\
\hline 4 & $\begin{array}{l}\text { Neither Agree } \\
\text { nor Disagree }\end{array}$ \\
\hline 3 & $\begin{array}{l}\text { Somewhat } \\
\text { Disagree }\end{array}$ \\
\hline 2 & Disagree \\
\hline 1 & $\begin{array}{l}\text { Strongly } \\
\text { Disagree }\end{array}$ \\
\hline
\end{tabular}

\begin{tabular}{|c|c|c|c|c|c|c|}
\hline & & \multicolumn{4}{|c|}{ What type of organization/department do you work for? } & \multirow[b]{2}{*}{ Total } \\
\hline & & Police Department & City Government & Homeless Services & Involved Public & \\
\hline \multirow{7}{*}{ Most of my coworkers believe unsheltered homeless individuals use drugs/alcohol. } & Strongly Disagree & 0 & 0 & 1 & 1 & 2 \\
\hline & Disagree & 3 & 3 & 4 & 2 & 12 \\
\hline & Somewhat disagree & 2 & 2 & 2 & 2 & 8 \\
\hline & Neither agree nor disagree & 1 & 4 & 3 & 2 & 10 \\
\hline & Somewhat agree & 4 & 6 & 4 & 2 & 16 \\
\hline & Agree & 12 & 4 & 2 & 1 & 19 \\
\hline & Strongly agree & 1 & 0 & 0 & 0 & 1 \\
\hline & Mean & 5.00 & 4.32 & 3.69 & 3.50 & - \\
\hline & Total & 23 & 19 & 16 & 10 & 68 \\
\hline
\end{tabular}


Chart 2:

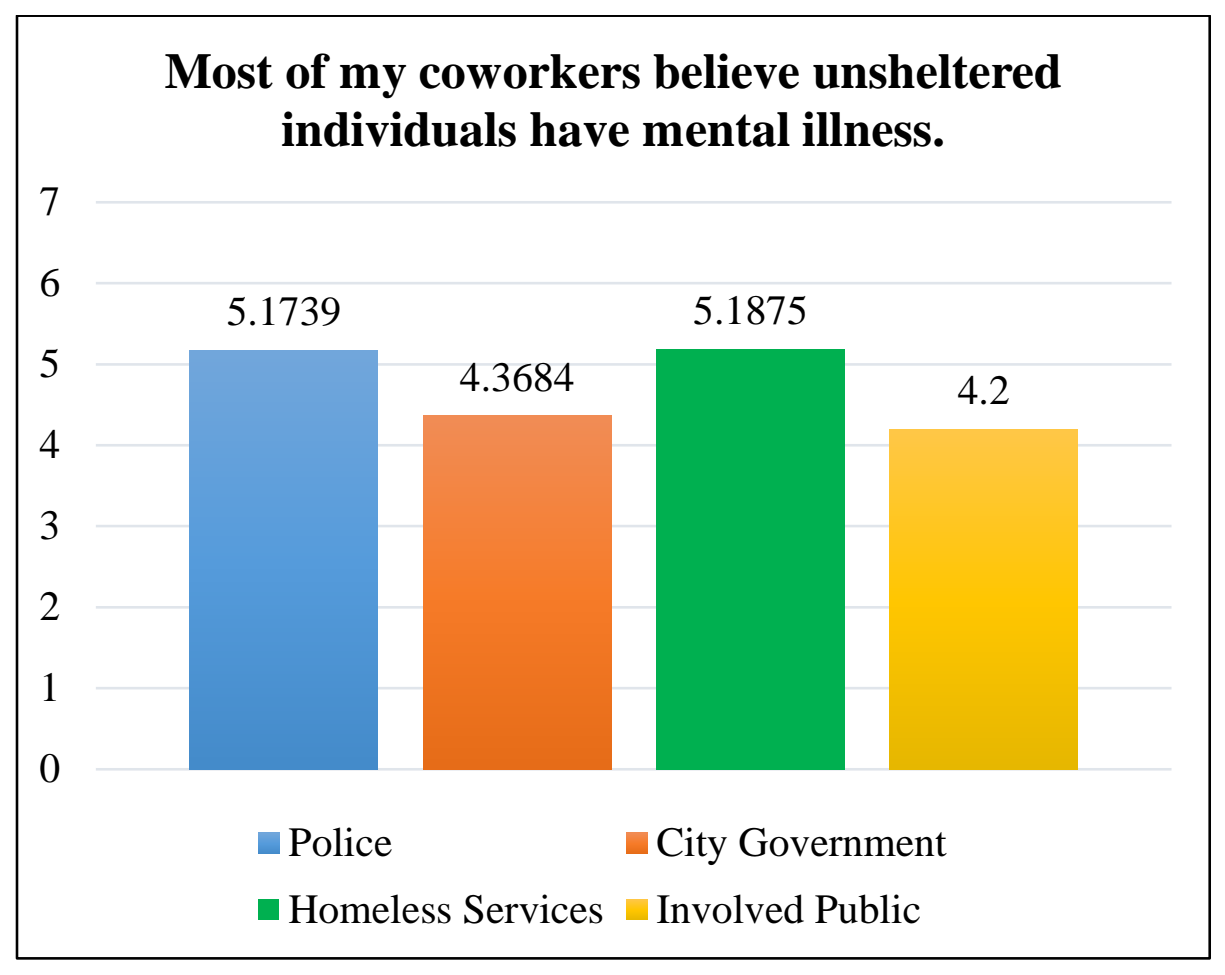

\begin{tabular}{|l|l|}
\hline 7 & Strongly Agree \\
\hline 6 & Agree \\
\hline 5 & $\begin{array}{l}\text { Somewhat } \\
\text { Agree }\end{array}$ \\
\hline 4 & $\begin{array}{l}\text { Neither Agree } \\
\text { nor Disagree }\end{array}$ \\
\hline 3 & $\begin{array}{l}\text { Somewhat } \\
\text { Disagree }\end{array}$ \\
\hline 2 & \begin{tabular}{l} 
Disagree \\
\hline 1
\end{tabular} \\
\hline
\end{tabular}

\begin{tabular}{|c|c|c|c|c|c|c|}
\hline & & \multicolumn{4}{|c|}{ What type of organization/department do you work for? } & \multirow[b]{2}{*}{ Total } \\
\hline & & Police Department & $\begin{array}{c}\text { City } \\
\text { Government }\end{array}$ & $\begin{array}{l}\text { Homeless } \\
\text { Services }\end{array}$ & $\begin{array}{l}\text { Involved } \\
\text { Public }\end{array}$ & \\
\hline \multirow{7}{*}{$\begin{array}{l}\begin{array}{l}\text { Most of my coworkers believe unsheltered homeless individuals have mental } \\
\text { illness. }\end{array}\end{array}$} & Strongly Disagree & 0 & 1 & 0 & 0 & 1 \\
\hline & Disagree & 1 & 1 & 0 & 1 & 3 \\
\hline & Somewhat disagree & 1 & 2 & 1 & 1 & 5 \\
\hline & $\begin{array}{l}\text { Neither agree nor } \\
\text { disagree }\end{array}$ & 2 & 7 & 3 & 4 & 16 \\
\hline & Somewhat agree & 9 & 4 & 6 & 3 & 22 \\
\hline & Agree & 9 & 2 & 4 & 1 & 16 \\
\hline & Strongly agree & 1 & 2 & 2 & 0 & 5 \\
\hline & Mean & 5.17 & 4.37 & 5.19 & 4.20 & - \\
\hline & Total & 23 & 19 & 16 & 10 & 68 \\
\hline
\end{tabular}


Chart 3:

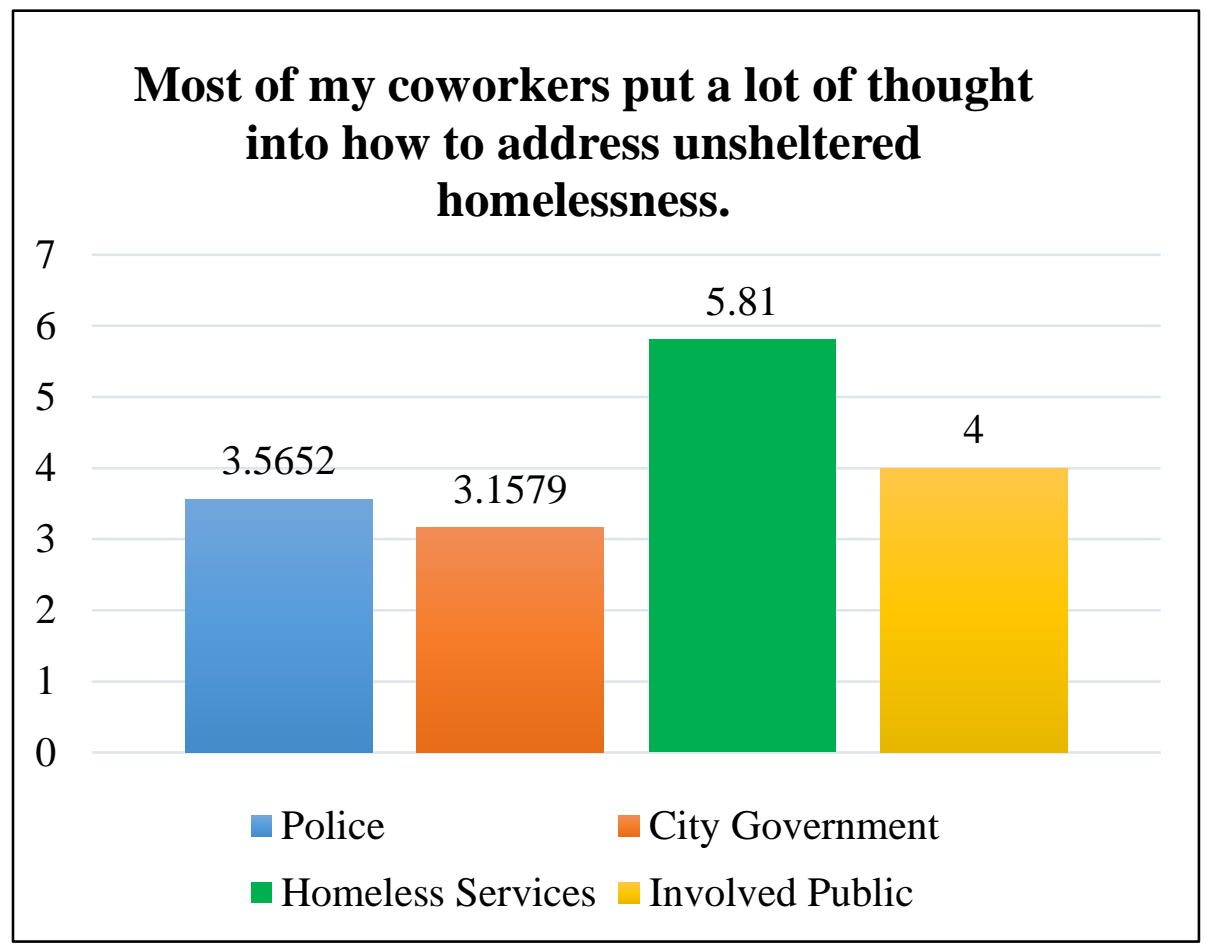

\begin{tabular}{|c|c|}
\hline 7 & Strongly Agree \\
\hline 6 & Agree \\
\hline 5 & Somewhat Agree \\
\hline 4 & $\begin{array}{l}\text { Neither Agree } \\
\text { nor Disagree }\end{array}$ \\
\hline 3 & $\begin{array}{l}\text { Somewhat } \\
\text { Disagree }\end{array}$ \\
\hline 2 & Disagree \\
\hline 1 & $\begin{array}{l}\text { Strongly } \\
\text { Disagree }\end{array}$ \\
\hline
\end{tabular}

\begin{tabular}{|c|c|c|c|c|c|c|}
\hline & & \multicolumn{4}{|c|}{ What type of organization/department do you work for? } & \multirow[b]{2}{*}{ Total } \\
\hline & & Police Department & $\begin{array}{c}\text { City } \\
\text { Government }\end{array}$ & $\begin{array}{l}\text { Homeless } \\
\text { Services }\end{array}$ & $\begin{array}{c}\text { Involved } \\
\text { Public }\end{array}$ & \\
\hline \multirow{7}{*}{$\begin{array}{l}\text { Most of my coworkers have put a lot of thought into how to address unsheltered } \\
\text { homelessness. }\end{array}$} & Strongly Disagree & 1 & 2 & 0 & 0 & 3 \\
\hline & Disagree & 7 & 6 & 1 & 3 & 17 \\
\hline & Somewhat disagree & 2 & 3 & 0 & 1 & 6 \\
\hline & $\begin{array}{l}\text { Neither agree nor } \\
\text { disagree }\end{array}$ & 6 & 4 & 1 & 2 & 13 \\
\hline & Somewhat agree & 5 & 3 & 2 & 1 & 11 \\
\hline & Agree & 2 & 1 & 7 & 3 & 13 \\
\hline & Strongly agree & 0 & 0 & 5 & 0 & 5 \\
\hline & Mean & 3.57 & 3.16 & 5.81 & 4.00 & - \\
\hline & Total & 23 & 19 & 16 & 10 & 68 \\
\hline
\end{tabular}


Chart 4:

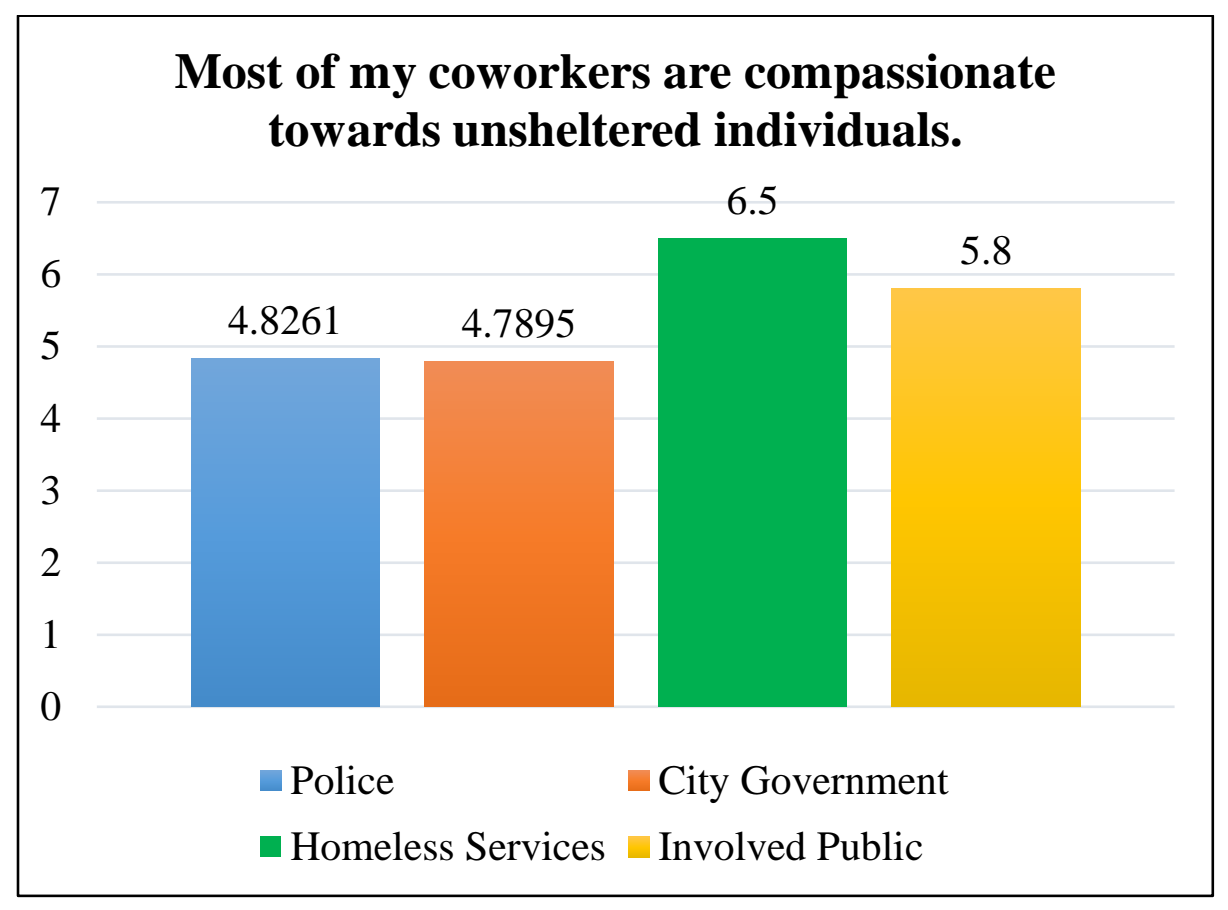

\begin{tabular}{|c|c|}
\hline 7 & Strongly Agree \\
\hline 6 & Agree \\
\hline 5 & $\begin{array}{l}\text { Somewhat } \\
\text { Agree }\end{array}$ \\
\hline 4 & $\begin{array}{l}\text { Neither Agree } \\
\text { nor Disagree }\end{array}$ \\
\hline 3 & $\begin{array}{l}\text { Somewhat } \\
\text { Disagree }\end{array}$ \\
\hline 2 & Disagree \\
\hline 1 & $\begin{array}{l}\text { Strongly } \\
\text { Disagree }\end{array}$ \\
\hline
\end{tabular}

\begin{tabular}{|c|c|c|c|c|c|c|}
\hline & & \multicolumn{4}{|c|}{ What type of organization/department do you work for? } & \multirow[b]{2}{*}{ Total } \\
\hline & & Police Department & City Government & Homeless Services & Other & \\
\hline \multirow{7}{*}{ Most of my coworkers are compassionate towards unsheltered homeless individuals. } & Strongly Disagree & 0 & 0 & 0 & 0 & 0 \\
\hline & Disagree & 2 & 0 & 0 & 0 & 2 \\
\hline & Somewhat disagree & 1 & 1 & 0 & 0 & 2 \\
\hline & Neither agree nor disagree & 2 & 3 & 1 & 1 & 7 \\
\hline & Somewhat agree & 6 & 4 & 0 & 2 & 12 \\
\hline & Agree & 11 & 7 & 5 & 5 & 28 \\
\hline & Strongly agree & 0 & 2 & 10 & 2 & 14 \\
\hline & Mean & 5.05 & 5.35 & 6.50 & 5.80 & - \\
\hline & Total & 22 & 17 & 16 & 10 & 65 \\
\hline
\end{tabular}


Chart 5:

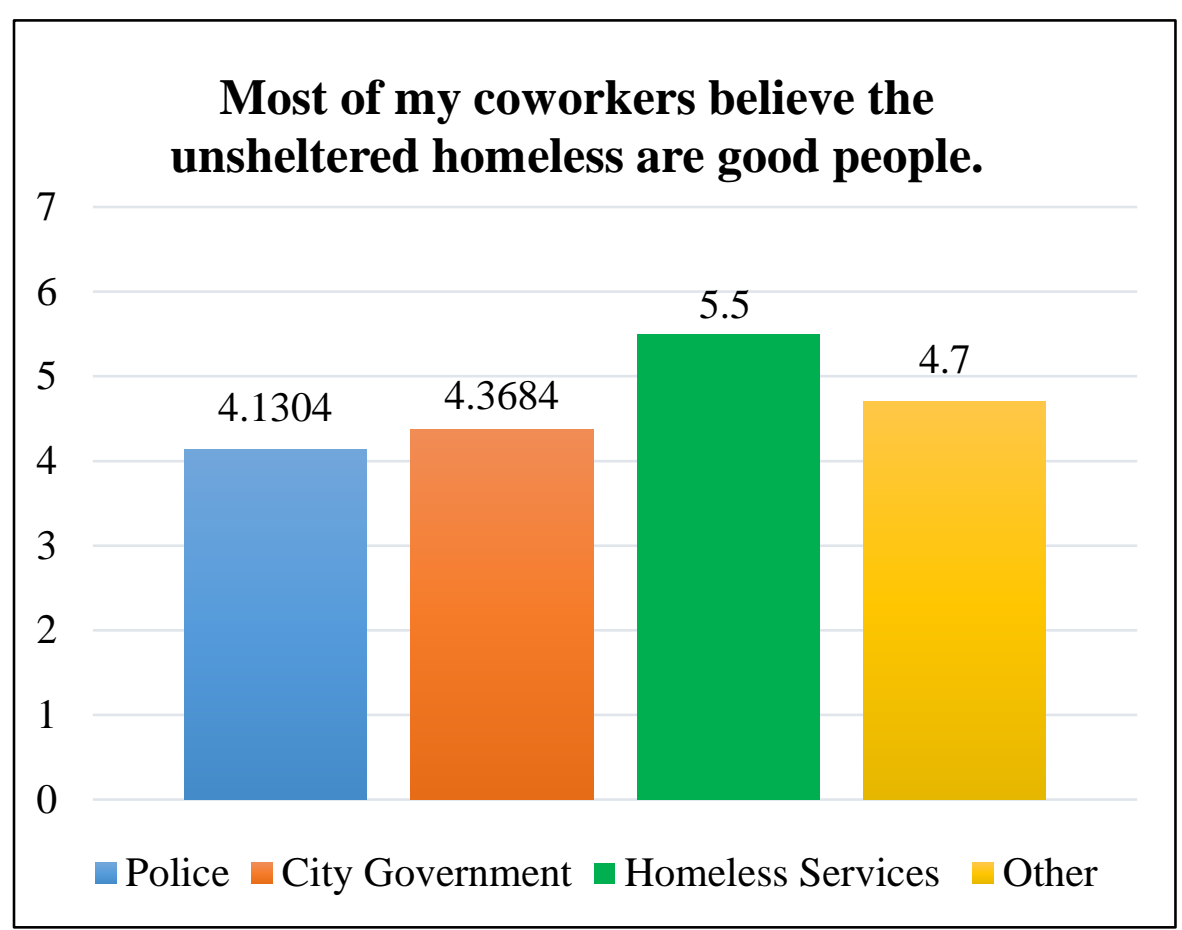

\begin{tabular}{|c|c|}
\hline 7 & Strongly Agree \\
\hline 6 & Agree \\
\hline 5 & Somewhat Agree \\
\hline 4 & $\begin{array}{l}\text { Neither Agree nor } \\
\text { Disagree }\end{array}$ \\
\hline 3 & $\begin{array}{l}\text { Somewhat } \\
\text { Disagree }\end{array}$ \\
\hline 2 & Disagree \\
\hline 1 & Strongly Disagree \\
\hline
\end{tabular}

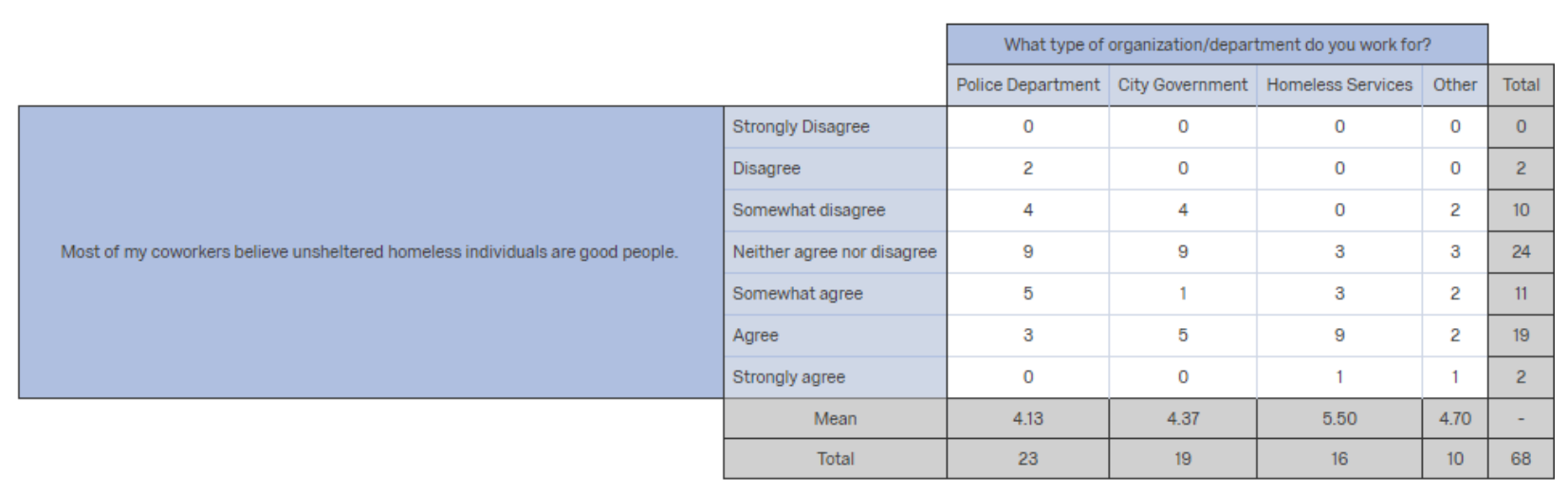


Chart 6:

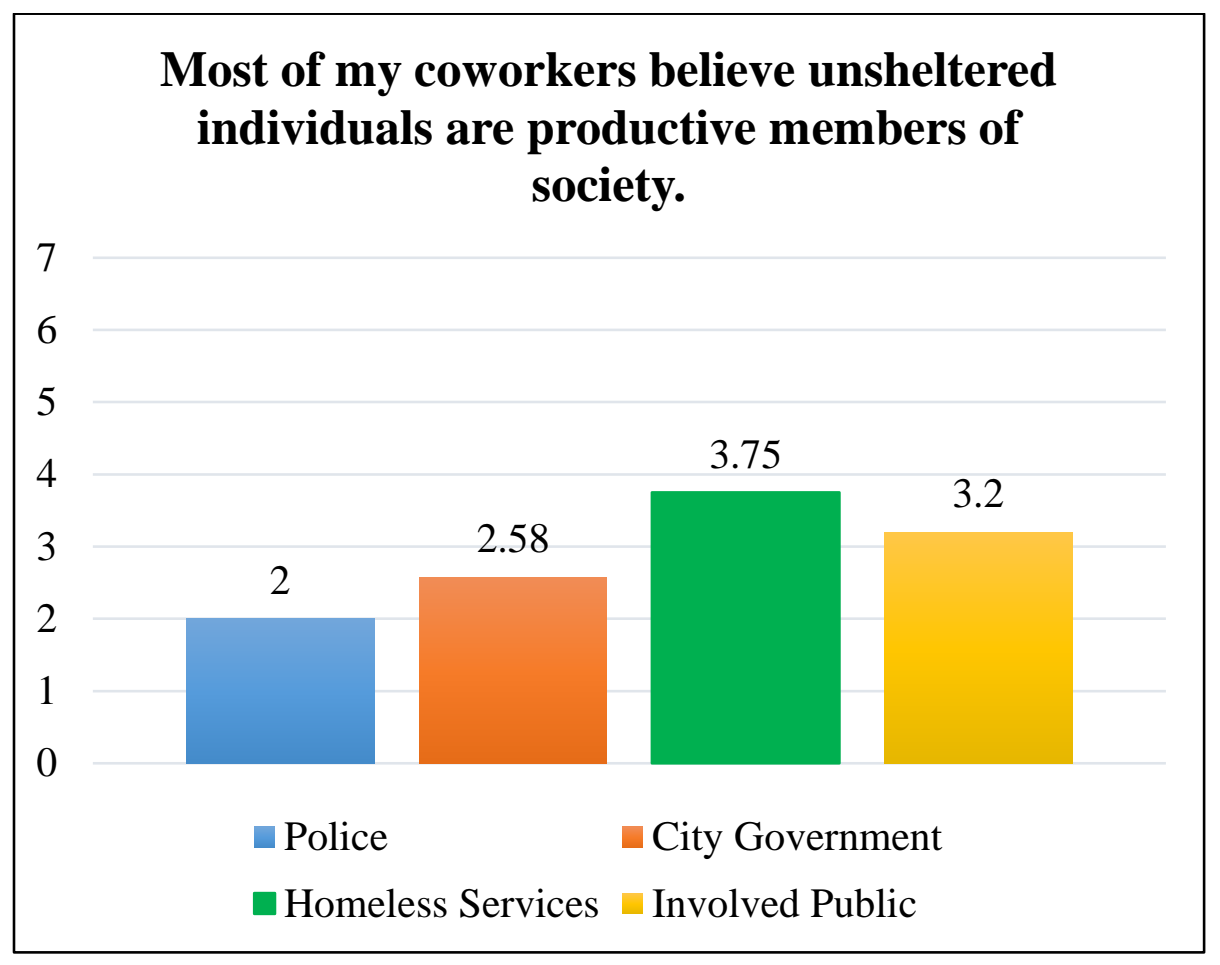

\begin{tabular}{|l|l|}
\hline 7 & Strongly Agree \\
\hline 6 & Agree \\
\hline 5 & $\begin{array}{l}\text { Somewhat } \\
\text { Agree }\end{array}$ \\
\hline 4 & $\begin{array}{l}\text { Neither Agree } \\
\text { nor Disagree }\end{array}$ \\
\hline 3 & $\begin{array}{l}\text { Somewhat } \\
\text { Disagree }\end{array}$ \\
\hline 2 & \begin{tabular}{l} 
Disagree \\
\hline 1
\end{tabular} \\
$\begin{array}{l}\text { Strongly } \\
\text { Disagree }\end{array}$ \\
\hline
\end{tabular}

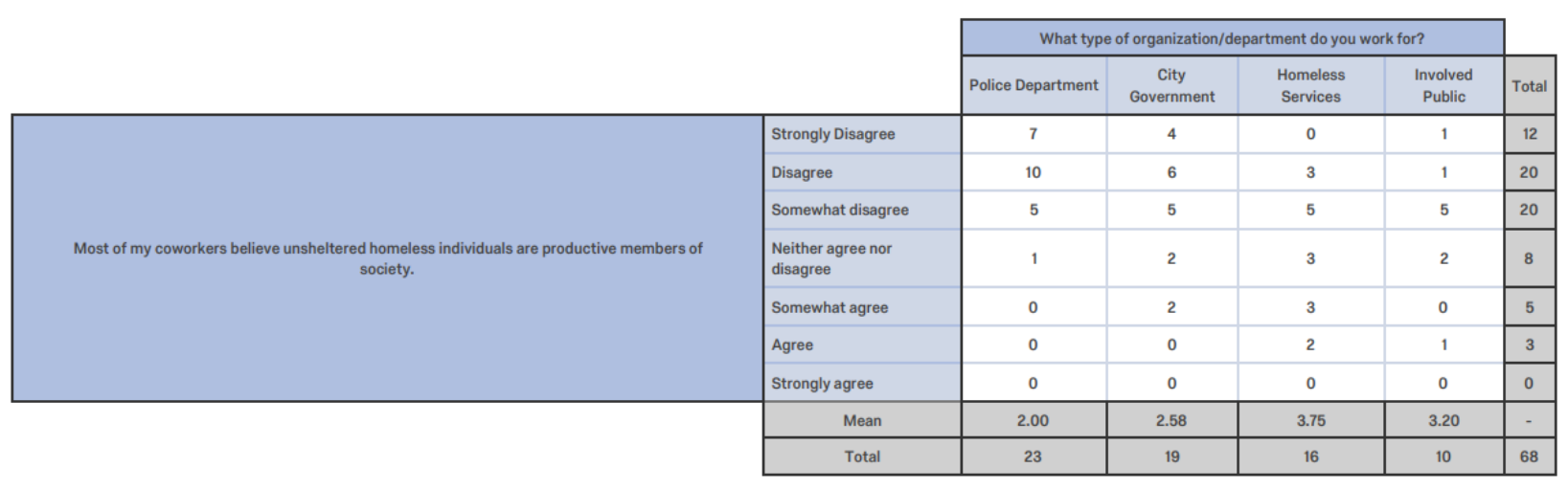


Chart 7:

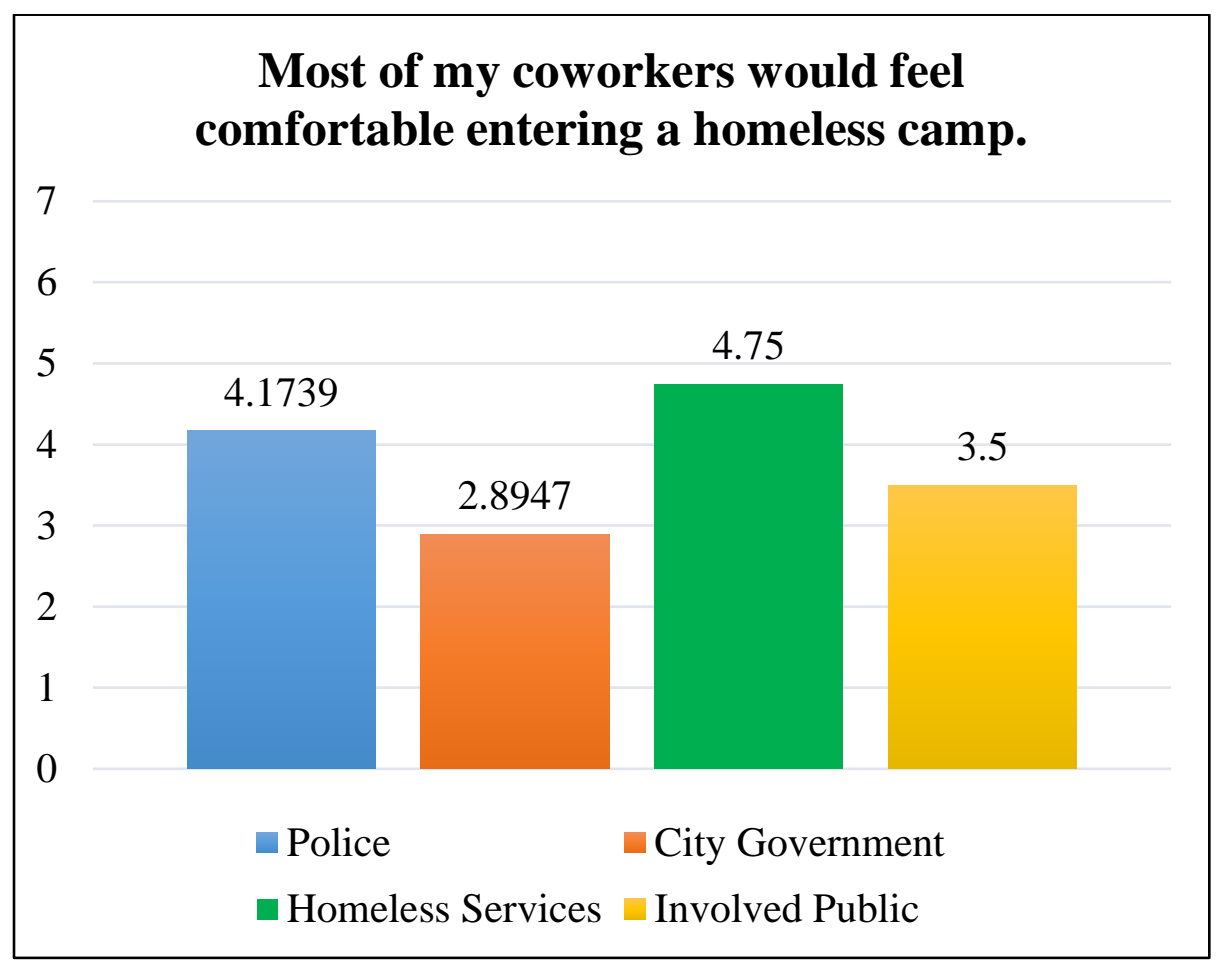

\begin{tabular}{|l|l|}
\hline 7 & $\begin{array}{l}\text { Extremely } \\
\text { Comfortable }\end{array}$ \\
\hline 6 & $\begin{array}{l}\text { Moderately } \\
\text { Comfortable }\end{array}$ \\
\hline 5 & $\begin{array}{l}\text { Slightly } \\
\text { Comfortable }\end{array}$ \\
\hline 4 & $\begin{array}{l}\text { Neither } \\
\text { Comfortable nor } \\
\text { Uncomfortable }\end{array}$ \\
\hline 3 & $\begin{array}{l}\text { Slightly } \\
\text { Uncomfortable }\end{array}$ \\
\hline 2 & $\begin{array}{l}\text { Moderately } \\
\text { Uncomfortable }\end{array}$ \\
\hline 1 & $\begin{array}{l}\text { Extremely } \\
\text { Uncomfortable }\end{array}$ \\
\hline
\end{tabular}

\begin{tabular}{|c|c|c|c|c|c|c|}
\hline & & \multicolumn{4}{|c|}{ What type of organization/department do you work for? } & \multirow[b]{2}{*}{ Tota } \\
\hline & & Police Department & $\begin{array}{l}\text { City } \\
\text { Government }\end{array}$ & $\begin{array}{c}\text { Homeless } \\
\text { Services }\end{array}$ & $\begin{array}{c}\text { Involved } \\
\text { Public }\end{array}$ & \\
\hline \multirow{7}{*}{$\begin{array}{l}\text { Most of my coworkers would feel comfortable entering a homeless } \\
\text { camp. }\end{array}$} & Extremely uncomfortable & 0 & 5 & 1 & 0 & 6 \\
\hline & Moderately uncomfortable & 2 & 5 & 2 & 3 & 12 \\
\hline & Slightly uncomfortable & 8 & 1 & 2 & 3 & 14 \\
\hline & $\begin{array}{l}\text { Neither comfortable nor } \\
\text { uncomfortable }\end{array}$ & 4 & 4 & 1 & 2 & 11 \\
\hline & Slightly comfortable & 3 & 3 & 3 & 0 & 9 \\
\hline & Moderately comfortable & 5 & 1 & 3 & 2 & 11 \\
\hline & Extremely comfortable & 1 & 0 & 4 & 0 & 5 \\
\hline & Mean & 4.17 & 2.89 & 4.75 & 3.50 & - \\
\hline & Total & 23 & 19 & 16 & 10 & 68 \\
\hline
\end{tabular}


Chart 8:

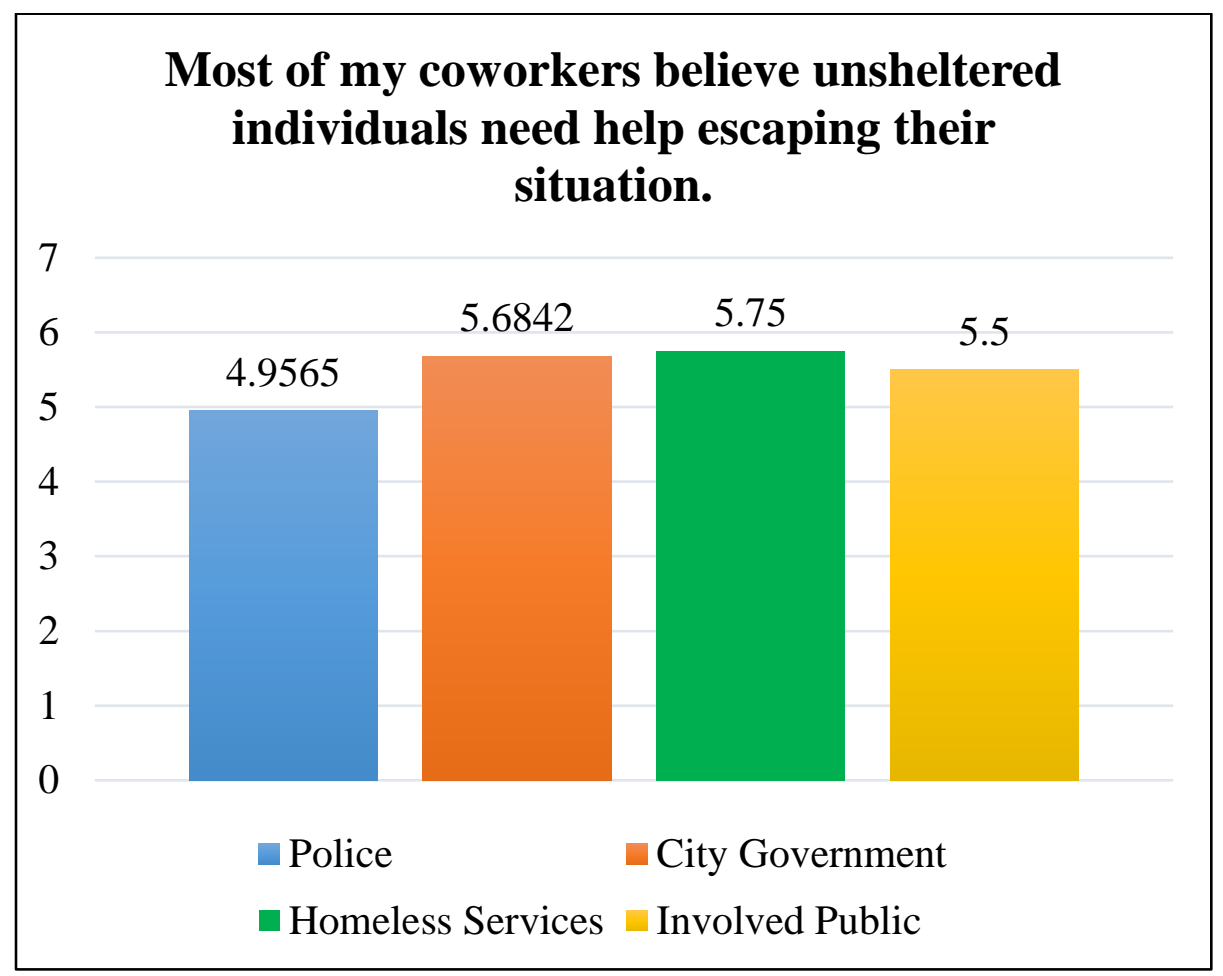

\begin{tabular}{|l|l|}
\hline 7 & Strongly Agree \\
\hline 6 & Agree \\
\hline 5 & $\begin{array}{l}\text { Somewhat } \\
\text { Agree }\end{array}$ \\
\hline 4 & $\begin{array}{l}\text { Neither Agree } \\
\text { nor Disagree }\end{array}$ \\
\hline 3 & $\begin{array}{l}\text { Somewhat } \\
\text { Disagree }\end{array}$ \\
\hline 2 & Disagree \\
\hline 1 & $\begin{array}{l}\text { Strongly } \\
\text { Disagree }\end{array}$ \\
\hline
\end{tabular}

\begin{tabular}{|c|c|c|c|c|c|c|}
\hline & & \multicolumn{4}{|c|}{ What type of organization/department do you work for? } & \multirow[b]{2}{*}{ Total } \\
\hline & & Police Department & $\begin{array}{c}\text { City } \\
\text { Government }\end{array}$ & $\begin{array}{l}\text { Homeless } \\
\text { Services }\end{array}$ & $\begin{array}{c}\text { Involved } \\
\text { Public }\end{array}$ & \\
\hline \multirow{9}{*}{$\begin{array}{l}\text { Most of my coworkers believe unsheltered homeless individuals need help escaping their } \\
\text { circumstance. }\end{array}$} & Strongly Disagree & 0 & 0 & 0 & 1 & 1 \\
\hline & Disagree & 2 & 1 & 0 & 0 & 3 \\
\hline & Somewhat disagree & 2 & 0 & 1 & 0 & 3 \\
\hline & $\begin{array}{l}\text { Neither agree nor } \\
\text { disagree }\end{array}$ & 3 & 0 & 1 & 1 & 5 \\
\hline & Somewhat agree & 7 & 4 & 4 & 2 & 17 \\
\hline & Agree & 6 & 12 & 5 & 2 & 25 \\
\hline & Strongly agree & 3 & 2 & 5 & 4 & 14 \\
\hline & Mean & 4.96 & 5.68 & 5.75 & 5.50 & - \\
\hline & Total & 23 & 19 & 16 & 10 & 68 \\
\hline
\end{tabular}


Chart 9:

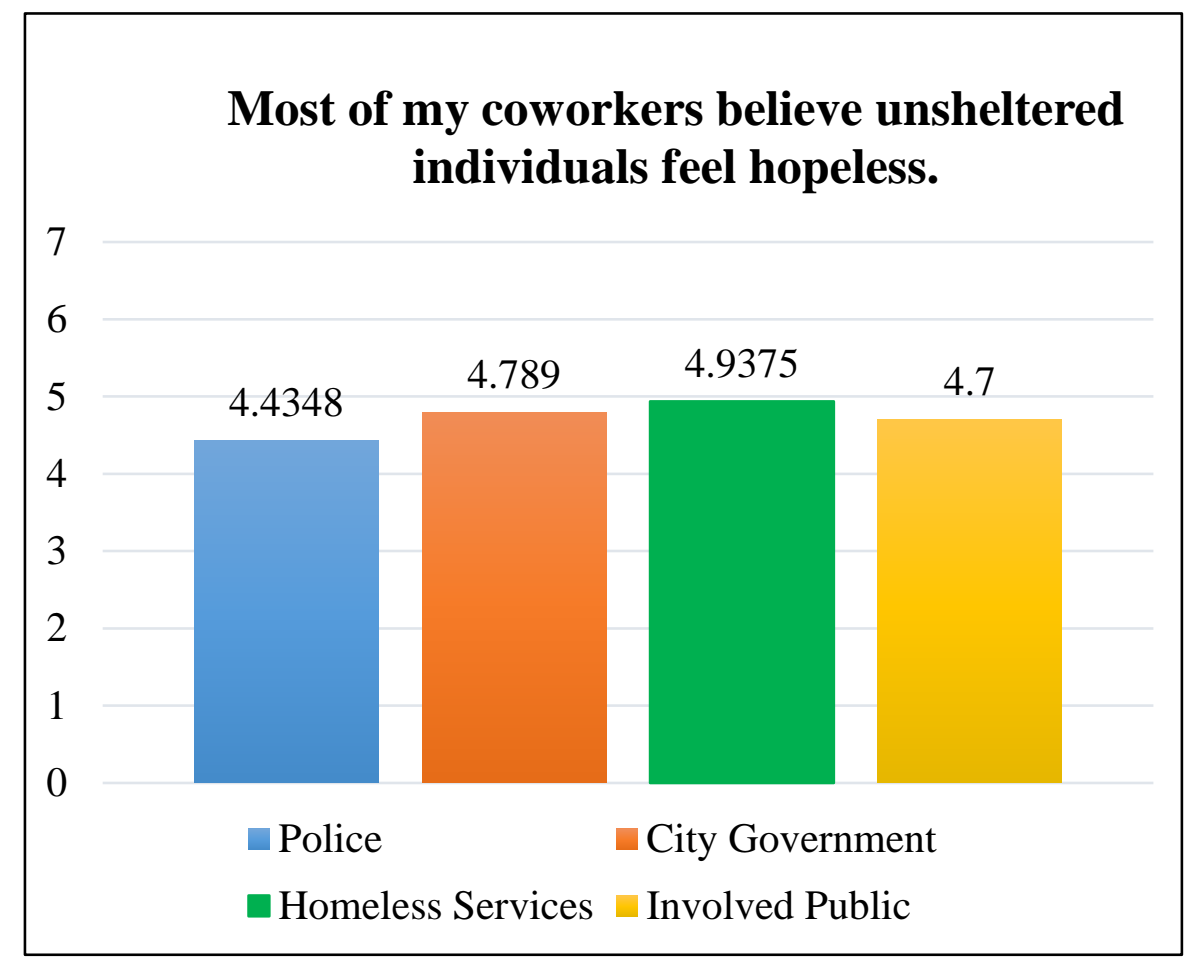

\begin{tabular}{|c|c|}
\hline 7 & Strongly Agree \\
\hline 6 & Agree \\
\hline 5 & $\begin{array}{l}\text { Somewhat } \\
\text { Agree }\end{array}$ \\
\hline 4 & $\begin{array}{l}\text { Neither Agree } \\
\text { nor Disagree }\end{array}$ \\
\hline 3 & $\begin{array}{l}\text { Somewhat } \\
\text { Disagree }\end{array}$ \\
\hline 2 & Disagree \\
\hline 1 & $\begin{array}{l}\text { Strongly } \\
\text { Disagree }\end{array}$ \\
\hline
\end{tabular}

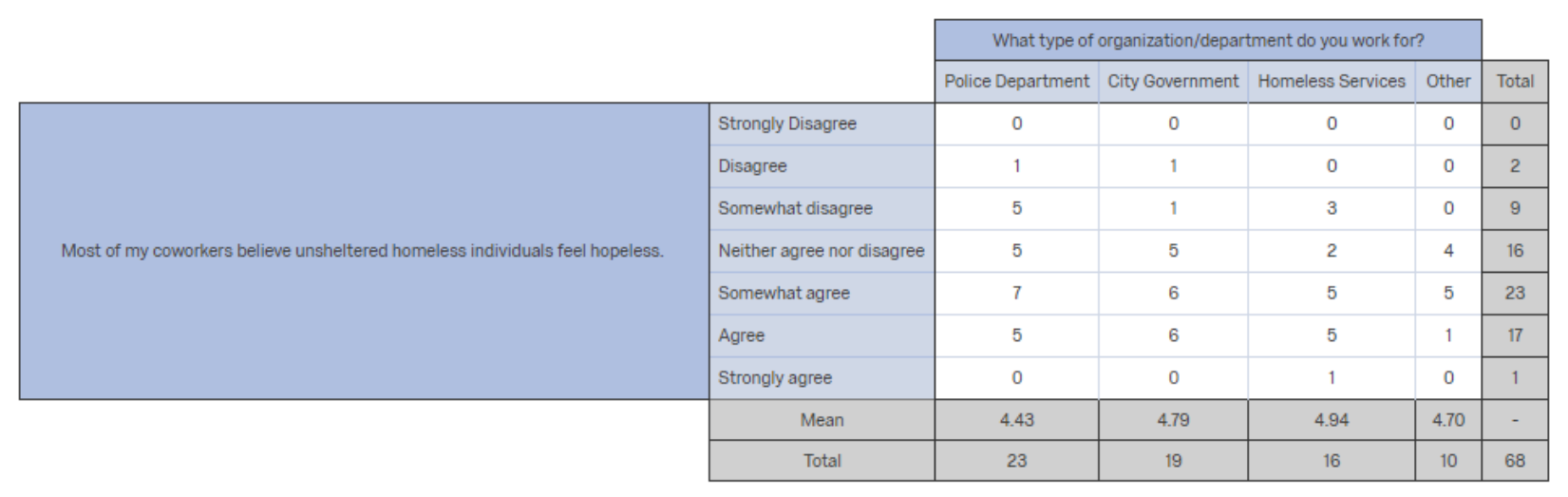


Chart 10:

\section{What is your level of contact with the unsheltered population?}

\section{5}

4

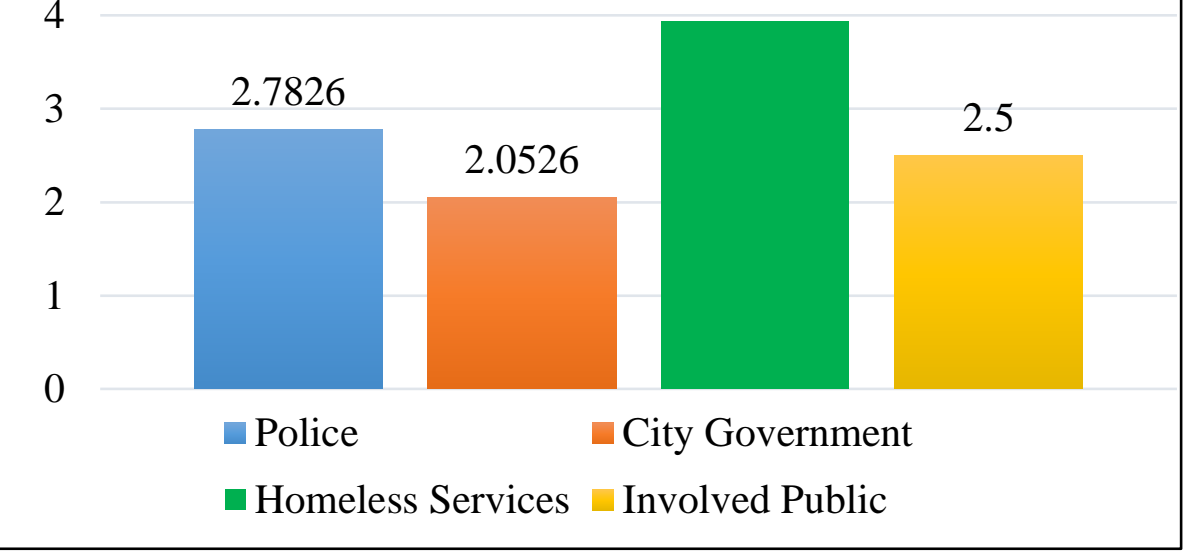

\begin{tabular}{|l|l|}
\hline 5 & Daily \\
\hline 4 & $\begin{array}{l}\text { Every Other } \\
\text { Day }\end{array}$ \\
\hline 3 & Once Per Week \\
\hline 2 & Once Per Month \\
\hline 1 & Almost Never \\
\hline
\end{tabular}

\begin{tabular}{|c|c|c|c|c|c|c|}
\hline & & \multicolumn{4}{|c|}{ What type of organization/department do you work for? } & \multirow[b]{2}{*}{ Tota } \\
\hline & & Police Department & $\begin{array}{c}\text { City } \\
\text { Government }\end{array}$ & $\begin{array}{l}\text { Homeless } \\
\text { Services }\end{array}$ & $\begin{array}{c}\text { Involved } \\
\text { Public }\end{array}$ & \\
\hline \multirow{5}{*}{$\begin{array}{l}\text { What is your level of contact with unsheltered homeless } \\
\text { individuals? }\end{array}$} & Almost never & 4 & 9 & 1 & 4 & 18 \\
\hline & Once a month & 9 & 4 & 1 & 1 & 15 \\
\hline & Once a week & 3 & 3 & 5 & 1 & 12 \\
\hline & $\begin{array}{l}\text { Every other } \\
\text { day }\end{array}$ & 2 & 2 & 0 & 4 & 8 \\
\hline & Daily & 5 & 1 & 9 & 0 & 15 \\
\hline & Mean & 2.78 & 2.05 & 3.94 & 2.50 & - \\
\hline & Total & 23 & 19 & 16 & 10 & 68 \\
\hline
\end{tabular}


Chart 11:

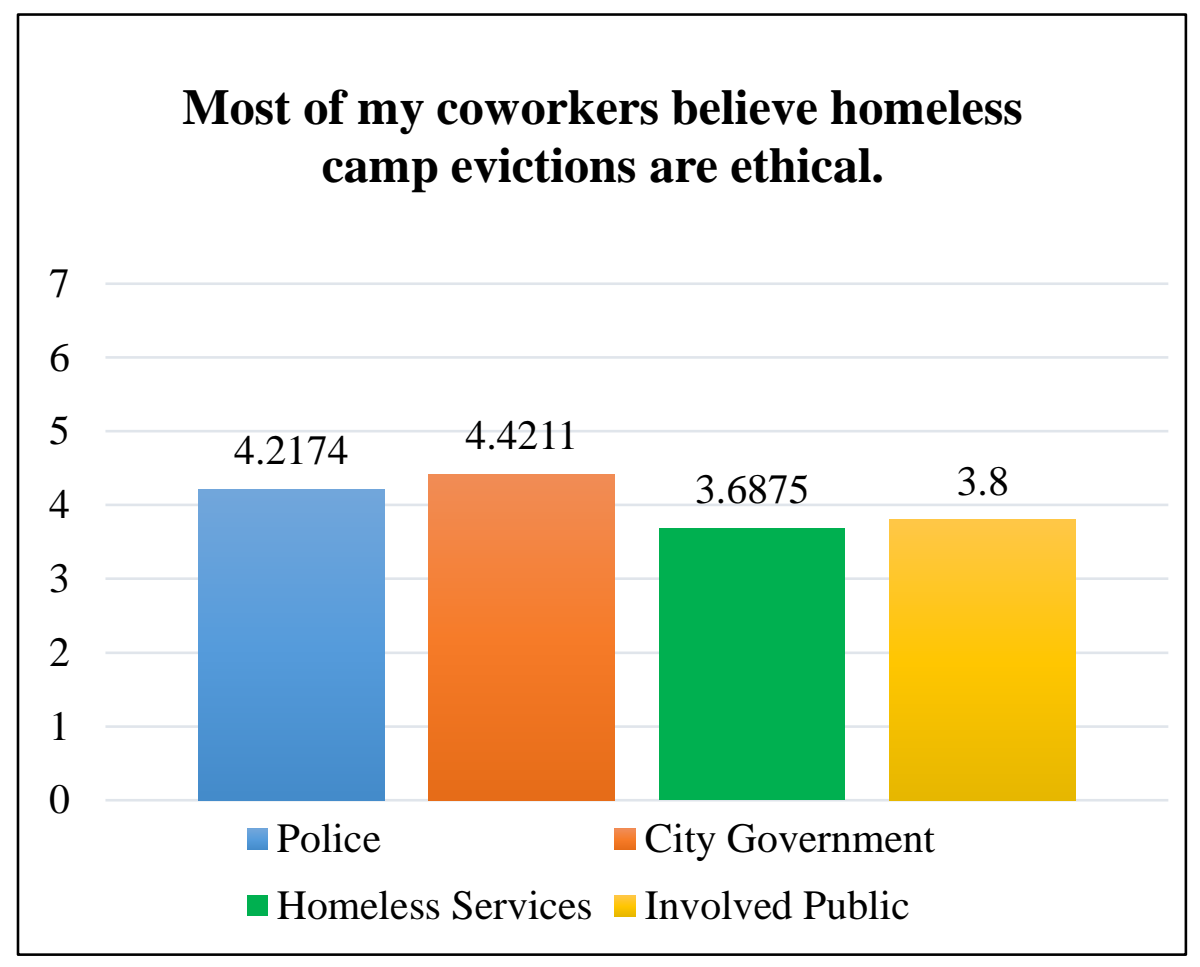

\begin{tabular}{|l|l|}
\hline 7 & Strongly Agree \\
\hline 6 & Agree \\
\hline 5 & Somewhat Agree \\
\hline 4 & $\begin{array}{l}\text { Neither Agree nor } \\
\text { Disagree }\end{array}$ \\
\hline 3 & $\begin{array}{l}\text { Somewhat } \\
\text { Disagree }\end{array}$ \\
\hline 2 & Disagree \\
\hline 1 & Strongly Disagree \\
\hline
\end{tabular}

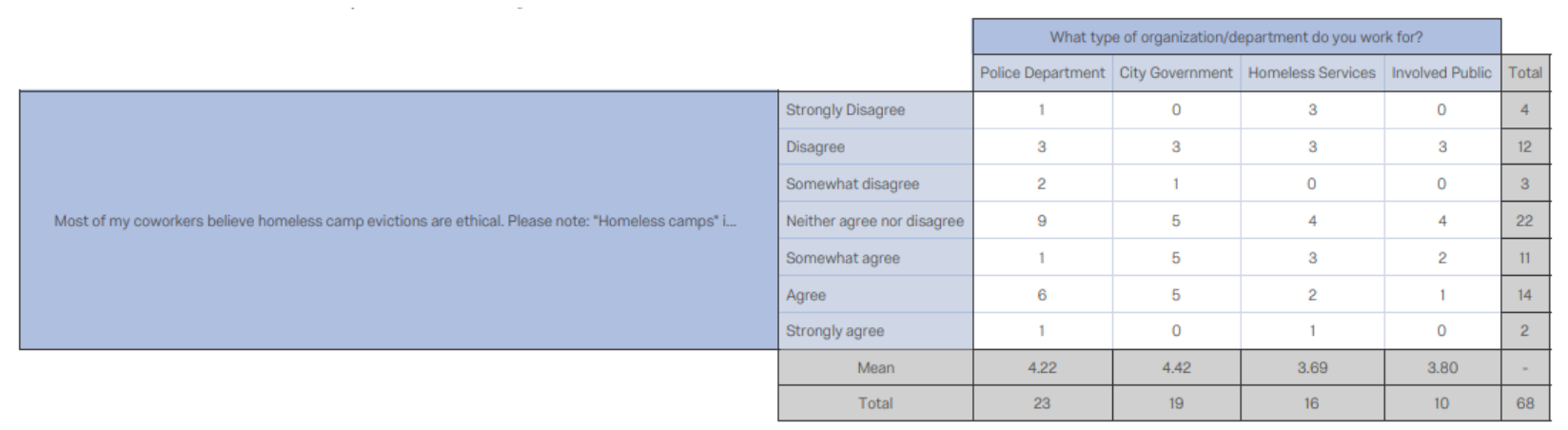


Chart 12:

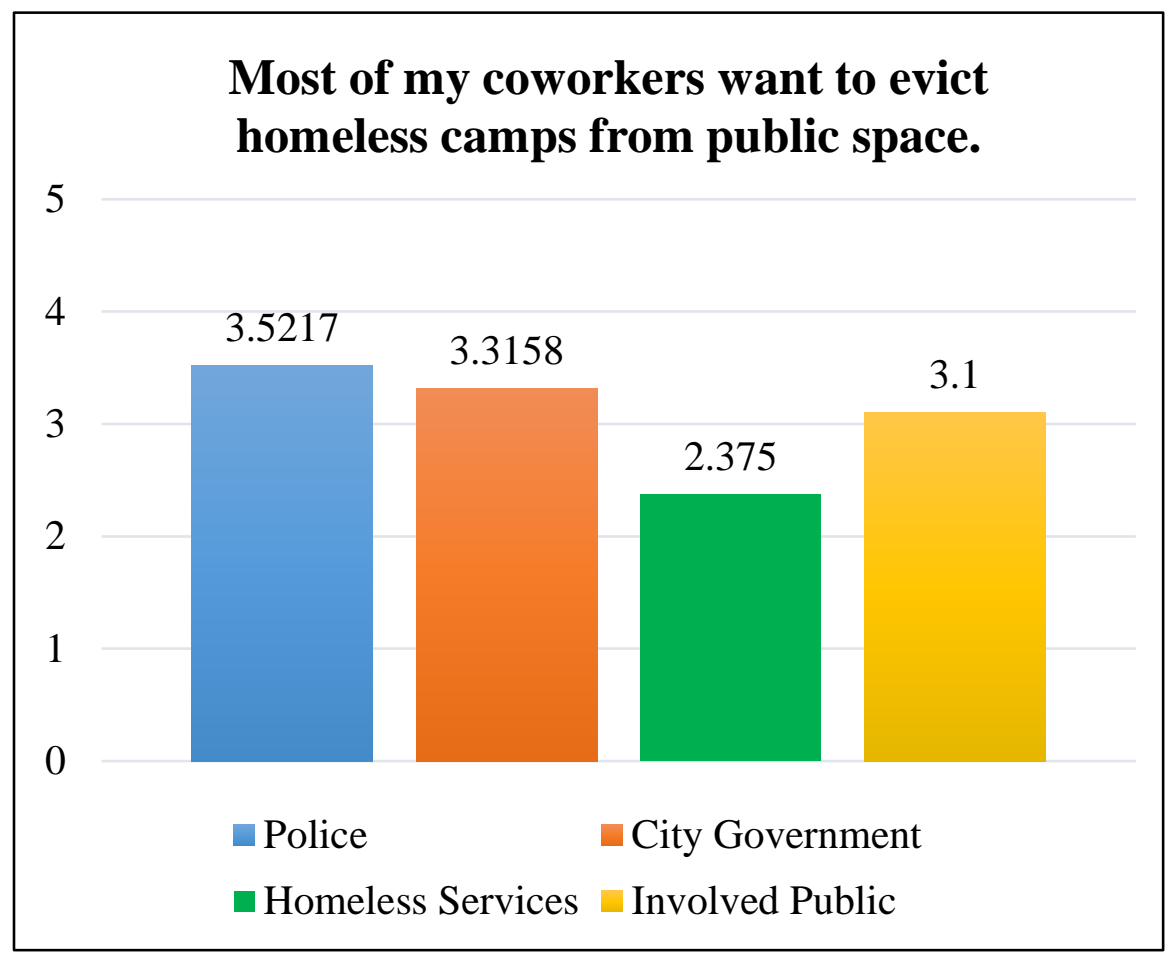

\begin{tabular}{|l|l|}
\hline 5 & Definitely Yes \\
\hline 4 & Probably Yes \\
\hline 3 & $\begin{array}{l}\text { Might or Might } \\
\text { Not }\end{array}$ \\
\hline 2 & Probably Not \\
\hline 1 & Definitely Not \\
\hline
\end{tabular}

\begin{tabular}{|c|c|c|c|c|c|c|}
\hline & & \multicolumn{4}{|c|}{ What type of organization/department do you work for? } & \multirow[b]{2}{*}{ Tota } \\
\hline & & Police Department & $\begin{array}{c}\text { City } \\
\text { Government }\end{array}$ & $\begin{array}{l}\text { Homeless } \\
\text { Services }\end{array}$ & $\begin{array}{l}\text { Involved } \\
\text { Public }\end{array}$ & \\
\hline \multirow{5}{*}{$\begin{array}{l}\text { Most of my coworkers want to evict homeless camps in public } \\
\qquad \text { space. }\end{array}$} & Definitely not & 0 & 1 & 5 & 1 & 7 \\
\hline & Probably not & 1 & 3 & 3 & 1 & 8 \\
\hline & $\begin{array}{l}\text { Might or might } \\
\text { not }\end{array}$ & 12 & 6 & 5 & 4 & 27 \\
\hline & Probably yes & 7 & 7 & 3 & 4 & 21 \\
\hline & Definitely yes & 3 & 2 & 0 & 0 & 5 \\
\hline & Mean & 3.52 & 3.32 & 2.38 & 3.10 & - \\
\hline & Total & 23 & 19 & 16 & 10 & 68 \\
\hline
\end{tabular}


Chart 13:
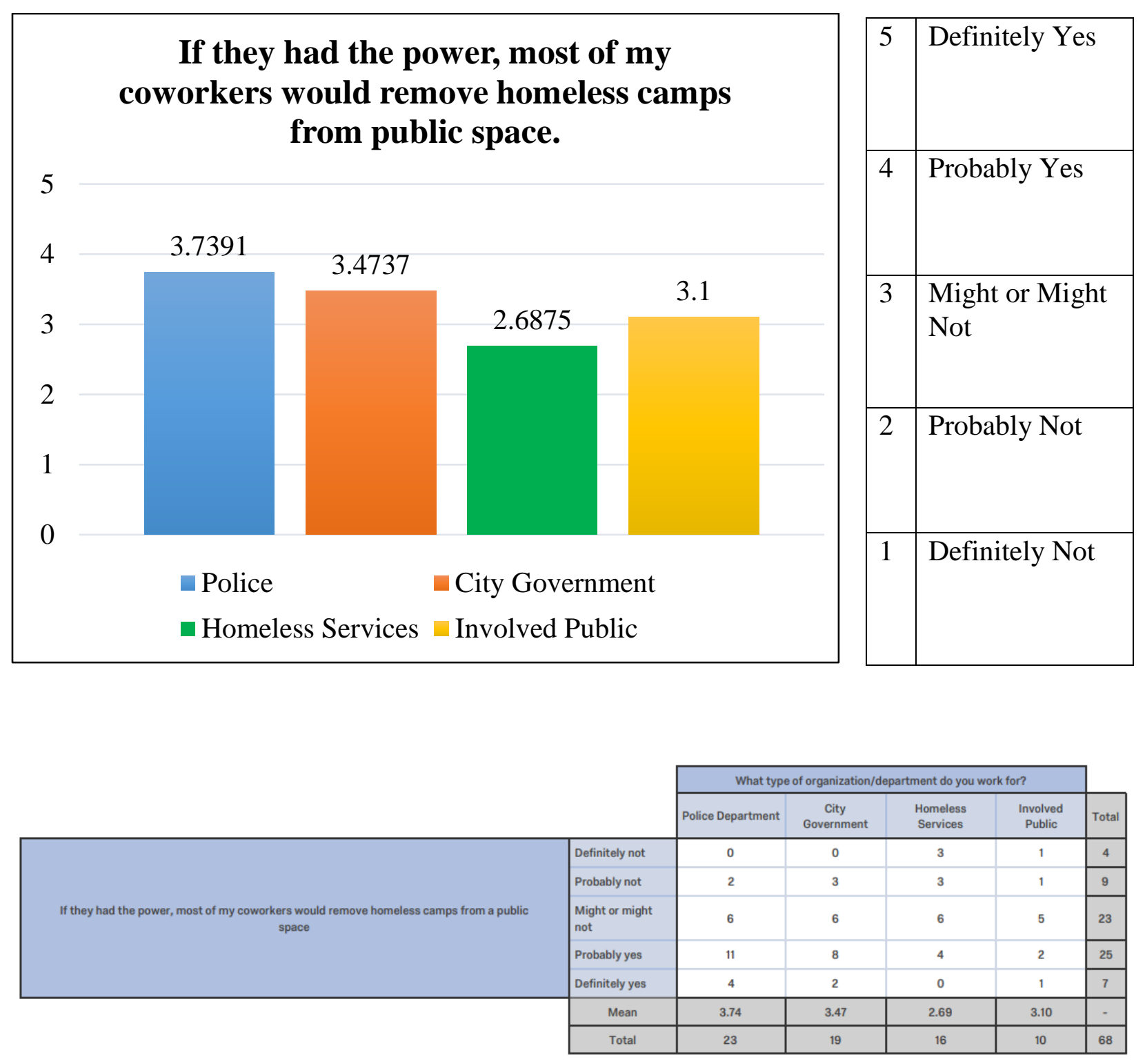


\section{APPENDIX D: BEST PRACTICES FLOW-CHART FOR POLICE DEPARTMENTS}

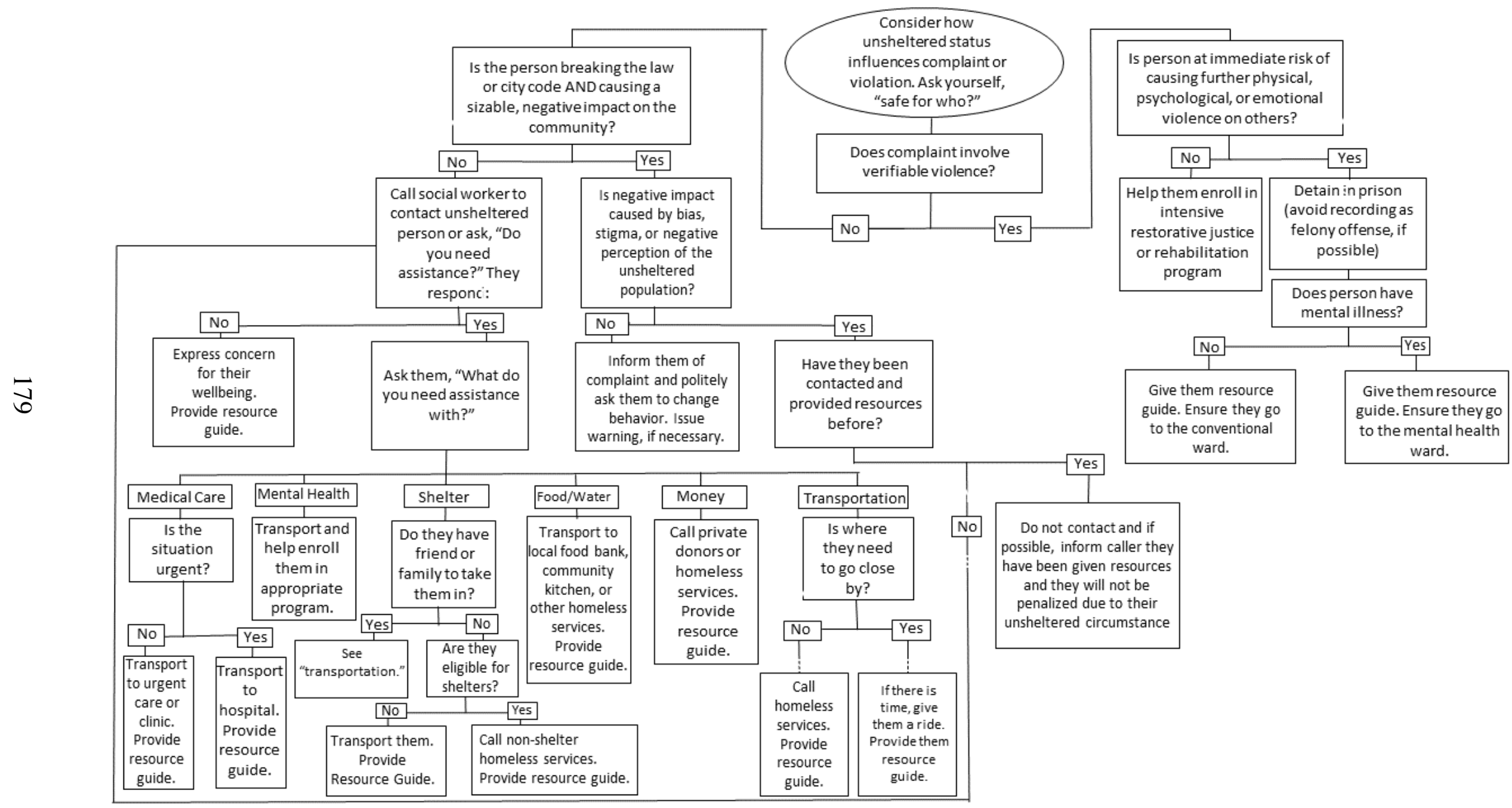




\section{APPENDIX E: EXECUTIVE SUMMARY FOR THE CITY OF MARINVILLE}

Purpose: It is imperative that alternatives to the homeless encampment eviction cycle are considered. The main goal of this research is to provide recommendations to the city, the police, and HSOs, so I propose protocol recommendations for addressing unsheltered individuals in the public right-of-way.

Findings: I determined that pervasive stigmatization of people experiencing homelessness was not as crucial to their criminalization as the structure of public servant occupations, the city complaint system, the obligation of public servanthood, and the policing protocol. In other words, the city complaint system enabled a few discriminatory "complainers" to have an exaggerated impact on the well-being of unsheltered individuals and their contact with law enforcement. The notion of public servanthood was so strong, that privileged members of the public used public servants as tools to carry out their discriminatory requests. Specifically, discriminatory complainers such as FOIA-filers, bloggers, serial commenters, repeat callers, and regular meeting attendees retained the power to pressure public servants into pushing unsheltered individuals from public space. These repeated interactions with law enforcement and public services are more expensive to taxpayers than some preventative housing options.

Recommendations: The City of Marinville and other cities should adjust the protocols and processes that enable the discriminatory public. This will cultivate equitable and just treatments for the city's most vulnerable residents. Recommendations are as follows:

1. The City of Marinville should fund/support a preventative Housing First program to house frequent flyers.

2. Emergency shelter capacity should be expanded, including day shelter and shelters that house sex offenders and people with pets.

3. Increase trainings on how to interact with unsheltered population for police officers and city officials and increase opportunities for exposure to individuals experiencing homelessness that do not reinforce stereotypes (increase self-awareness of contributions to the homeless encampment eviction cycle).

4. Listen to the public but question their bias. This should be accomplished through formal guidelines to nullify discriminatory requests from a member of the public.

5. Police should utilize third party social workers to address situations pertaining to unsheltered individuals.

6. Civil and human rights lawyers should read city code to ensure "legacy ordinances" are in alignment with constitutional rights.

7. Police should use the best practices flow-chart on page 175 to reduce discretion.

8. Build structures to increase political participation from unsheltered individuals and advocates.

9. Police should carry resource guides for the unsheltered population in their vehicles and distribute guides during every interaction.

Consider offering sabbaticals/breaks to employees like police officers in demanding positions. 